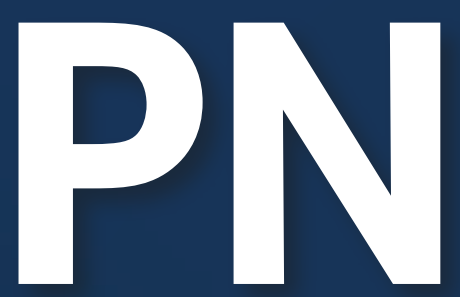

Physiology News

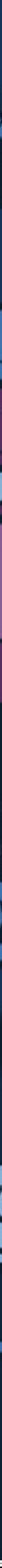

Issue 110 / Spring 2018
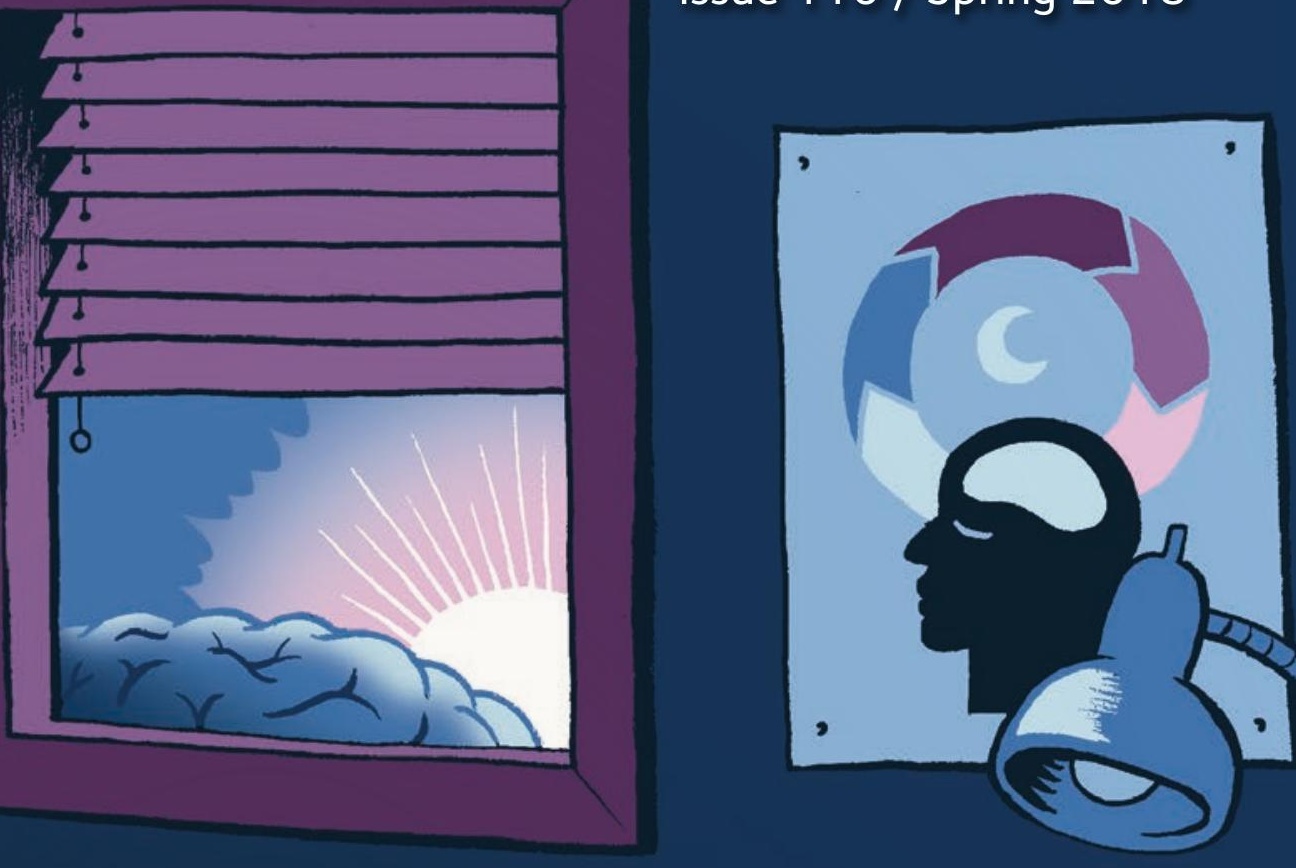

Makes a teen healthy, wealthy and wise?

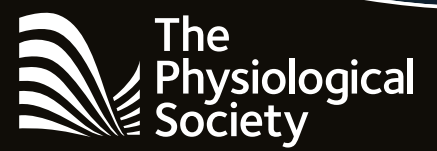




\section{Experimental models in physiology 27 - 29 June 2018 | University of Exeter, UK}

The Mighty Mouse and the might of other models

$\therefore$ Why is the mouse not so mighty?

$\because$ Complementary models

Pathophysiological models: Cells to complex systems

: Insights from animal models of human disease

$\because$ Towards human models

Future directions: Opportunities and challenges

\section{www.physoc.org/models}

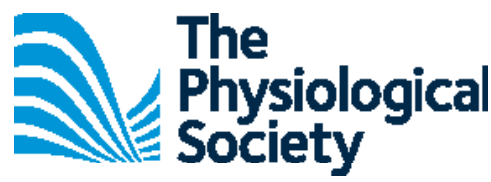

\section{Physiology News}

We welcome feedback on our membership magazine, or letters and suggestions for articles for publication, including book reviews, from our Members.

Please email Julia Turan at magazine@physoc.org

Physiology News is one of the benefits of membership, along with reduced registration rates for our high-profile events, free online access to our leading journals, The Journal of Physiology, Experimental Physiology and Physiological Reports, and travel grants to attend scientific meetings. Membership offers you access to the largest network of physiologists in Europe.

Join now to support your career in physiology:

Visit www.physoc.org/membership or call 02072695721

\begin{tabular}{lc}
\hline Membership Fees for 2017 & FEES \\
Fellow & $£ 120$ \\
Member & $£ 90$ \\
\hline Retired Member & - \\
\hline Affliate & $£ 40$ \\
Associate & $£ 30$ \\
\hline Undergraduate & - \\
\hline
\end{tabular}

Opinions expressed in articles and letters submitted by, or commissioned from, Members, Affiliates or outside bodies are not necessarily those of The Physiological Society.

(c) 2018 The Physiological Society ISSN 1476-7996 (Print) ISSN 2041-6512 (Online). The Physiological Society is registered in England as a company limited by guarantee: No. 323575. Registered office: Hodgkin Huxley House, 30 Farringdon Lane, London EC1R 3AW. Registered Charity: No. 211585.

Scientific Editor

Roger Thomas

(University of Cambridge)

Managing Editor

Julia Turan

Editorial Board

Karen Doyle

(NUI Galway)

Rachel McCormick

(University of Liverpool)

Keith Siew

(University of Cambridge)

Austin Elliott

(University of Manchester)

Mark Dallas

(University of Reading)

Fiona Hatch

(Cello Health Communications iScience,

Medical writer)

magazine@physoc.org

www.physoc.org

@ThePhySoc

1 /physoc

in /company/The-Physiological-Society

Youll /physoctv

Designed, produced and printed by Lavenham Press Ltd. 


\section{Welcome to the Spring 2018 edition of Physiology News}

\section{Introduction}

\section{Editorial}

06 President's view: Committing to inclusivity

07 Letters to the Editor

\section{News \& views}

08 Reports of recent Committee meetings

09 Physiology Feed

10 Book review: A Crack in Creation

11 A new video series about research in our journals Newly-elected Fellow Members

13 Policy Focus

\section{Events}

142018 Forthcoming events $\mathrm{H}^{3}$ symposium: Muscle Physiology and Metabolism

$15 \mathrm{H}^{3}$ symposium: Sensory Transduction in Insects

16 Future Physiology 2017: Early Career Conference

18 Thinking outside the box: Translational Research and Career Options beyond Academia $\mathrm{H}^{3}$ symposium: Purinergic Signalling in Obesity and Renal Pathophysiology

19 Europhysiology 2018: Bringing Together Physiologists From Around the World

21 From the Archives

\section{Features}

22 Early to bed and early to rise

26 Future directions in cardiac and respiratory physiology

28 Alveolar ventilation-perfusion ratios and pulmonary gas exchange: 100 years since recognition

32 Charles Bell's 'sixth sense'

36 Nanoscopy and cardiovascular physiology

\section{Membership}

40 The genesis of a new Sports and Exercise Science degree Bringing inspiring physiology to disadvantaged parts of the UK

41 The road to winning the Outstanding STEM Technician Award A problem shared is a problem halved: blogging my way through a PhD

42 Solidifying my career choice of research - a Rob Clarke Award winner's account

43 Publishing my first paper in The Journal of Physiology Learning a research career is within my reach: Vacation Studentship Scheme case study

44 Obituary: John H Coote

45 Obituary: Hans-Christoph Lüttgau

\section{Journal insights}

46 The latest from our Journals 


\section{Roger Thomas \\ Scientific Editor}

So. This is my last issue of Physiology News as Scientific Editor. I have thoroughly enjoyed my time in the editor's chair, ably helped by a sequence of managing editors, first Helen Burgess, then Helga Groll and currently Julia Turan. The current attractive format and appearance owes much to Alex Ford, the designer at the printers Lavenham Press. Andrew Mackenzie, the new Head of Policy and Communications, has already taken a very keen interest. One minor problem that has worried me is the overlap between the magazine and the more ephemeral Society outputs of Twitter feeds and email Newsletters. I think Facebook might be involved too. But Physiology News has the great advantage of being a printed magazine, often kept by members for many years. One of my first efforts as editor was to find a copy of the lost issue number one, which I finally tracked down, thanks to Bob Banks, as described in PN 100.

This issue has as usual many reports on Society activities as well as features on physiological topics. Charles Michel's feature on work a century ago by Haldane is particularly intriguing as it describes how he was removed from important work on gas masks during WW1 simply because his brother had been accused by the Daily Mail of having German sympathies. The accusation was based on his having praised German Universities several years before. But why the physiologist Haldane should be penalised for his brother's view is very strange, as indeed is the fact that that newspaper apparently had such power. Brexit makes me wonder if the situation has changed enough. I have a brother who is in favour of Brexit, but he does not read the Daily Mail.

There is also a fascinating feature on chronobiology, or why do teenagers sleep at different times from small children or mature adults. An article about Charles Bell and proprioception reveals him to be rather jealous of competitors. And the obituaries inevitably make me think about my own lifetime, which began a few months before Germany invaded Poland in 1939. I might add that the advertisements in Physiology News are not the Scientific Editor's responsibility.

My own involvement with The Society goes back to 1963, when I and Robert Walker demonstrated snail brain neurophysiology during a meeting at the University of Southampton. I gave my first oral communication to The Society 5 years later, at the Charing Cross meeting in January 1968, 50 years ago. This event was not mentioned in the meeting's minutes, reproduced in this issue. I remember being consoled afterwards by the late Alison Brading and Anne Warner. The Society dinner was held in the House of Lords, but I was not invited. I had already given two demonstrations so was then qualified to apply for membership, and was indeed elected in 1969. The same year I was appointed as a lecturer in the University of Bristol in the Department of Physiology. The department was chaired by Arthur Buller, who was very supportive in setting up my lab. I still use two Prior micromanipulators he gave me.

After my election in 1969, I began to take an interest in the politics of The Society. Each year before the AGM, then always held at UCL in March, members were sent a list of the committee members who were available for re-election, with suggested nominations for the upcoming vacancies. The numbers nominated were equal to the number of vacancies. A note stated that any five ordinary members could also nominate a candidate. No such nomination had occurred in living memory, so there was never a real election. In 1974, convinced that Ordinary Members ought to exercise a meaningful vote, I persuaded four colleagues to join me in nominating Tim Biscoe. This was in spite of considerable misgivings by Arthur Buller and Andrew Huxley. Tim was duly elected, and has had a distinguished career since. But I now wonder if my desire to make AGMs more interesting did not set in train a series of changes that led to The Society's slow decline in its support for members of The Society rather than the science. The committee stopped choosing nominees for its own vacancies, allowing more and more involvement of troublemakers who had little experience of administration or time to spend managing The Society's activities. In 1981, Arthur asked me to organise the next Physiological Society meeting in Bristol, and I enjoyed arranging the dinner in the ballroom of the Grand Hotel. At the next Bristol meeting in 1985, I hired a train to take members to a dinner in the pump rooms in Bath. I was the local organiser for several more meetings later.

As this is my last opportunity, I would like to thank four people who played crucial roles early in my career; my PhD supervisor Gerald Kerkut, the Pl's for my two postdoc posts Victor Wilson and EJ Harris, and the man who invited me to Bristol, Tony Ridge. Finally, I welcome the choice of my successor, Keith Siew. He has been a member of the editorial board for several years, so is much better prepared than I was three years ago. I am sure he will do a great job, and hope he enjoys the numerous discussions he will have to undertake. 


\section{Committing to inclusivity}

\section{David Eisner}

President, The Physiological Society

There is much discussion about issues relating to diversity in science, and many of these ideas are relevant to our subject and Society. One important area concerns gender and the extent to which our activities should consider this. The Physiological Society was founded in 1876 and, in keeping with the customs of the time when, for example, women could not vote, membership was restricted to men. Women were finally admitted as members in 1915 but it will have taken more than a century before, at this year's Annual General Meeting (AGM) in September, Bridget Lumb will become the first female President. As far as our journals are concerned, we had to wait until 2012 for our first female Editor-in-Chief when Sue Wray established Physiological Reports. The Journal of Physiology existed for 140 years before Kim Barrett became its first ever female Editor-in-Chief in 2016.

The Physiological Society is committed to taking account of Equality and Diversity issues and this area is championed by Sue Deuchars and Rachel Tribe.

Some issues are still, however, unresolved, and an important one is the extent to which female speakers participate in meetings. Today, many organisations, The Society included, require some kind of gender balance in scientific programmes. There are many arguments for this; not only on grounds of justice but also the need to provide role models for women at the start of their careers. A more difficult question is, in quantitative terms, what is meant by 'balance'? Should it reflect the gender balance of researchers in the field? This balance changes with age, with a female majority at PhD student level declining to a minority as people progress through the 'leaky pipeline'. Looking at The Society's membership, 50\% of the under 40 s are female whereas only $16 \%$ of the over 60 s are. Another indication of this comes from looking at those researchers awarded grants. Figures from the Medical Research Council from 2016/2017 show that women received $35 \%$ of grants. Again, the effect of career stage is obvious with women obtaining $46 \%$ of New Investigator Grants but only 18\% of programme grants. Depending on the sort of talk being considered, proportionality considerations would therefore lead to women comprising between 20 to 50\% of speakers. The Physiological Society currently requires at least $25 \%$ and sets a target of $33 \%$ female speakers. Perhaps The Society should lead the way by being even more ambitious than making the number of speakers proportional to the number of women. The fact that today only a minority of our most senior scientists are female reflects a number of influences during their careers including overt discrimination and problems of combining childcare with work, particularly when maternity leave was more restrictive than today. These senior women have also spent their careers in environments where harassment occurred at levels regarded as unacceptable today. Therefore, in order to provide role models to encourage younger women scientists, a more realistic $50 \%$ of speakers should be female. surprise in this but it does result in 'the same old people' giving talks at most meetings. Not only does it discriminate against female speakers but also against the large number of male speakers who are not on the conference circuit. Paying more attention to how speakers are selected, trying to avoid people who spoke at the last year's event, would therefore benefit men as well as women. The Society is dedicated to ensuring that its meetings encourage, support and provide opportunities for all researchers. In this context, the recent, successful Future Physiology meeting should be seen as providing opportunities for early career researchers.

So far, I have only discussed gender balance and paid no attention to other matters of diversity. What about ethnic diversity? Here it is much harder to obtain data to assess the issue as only 317 members of The Society

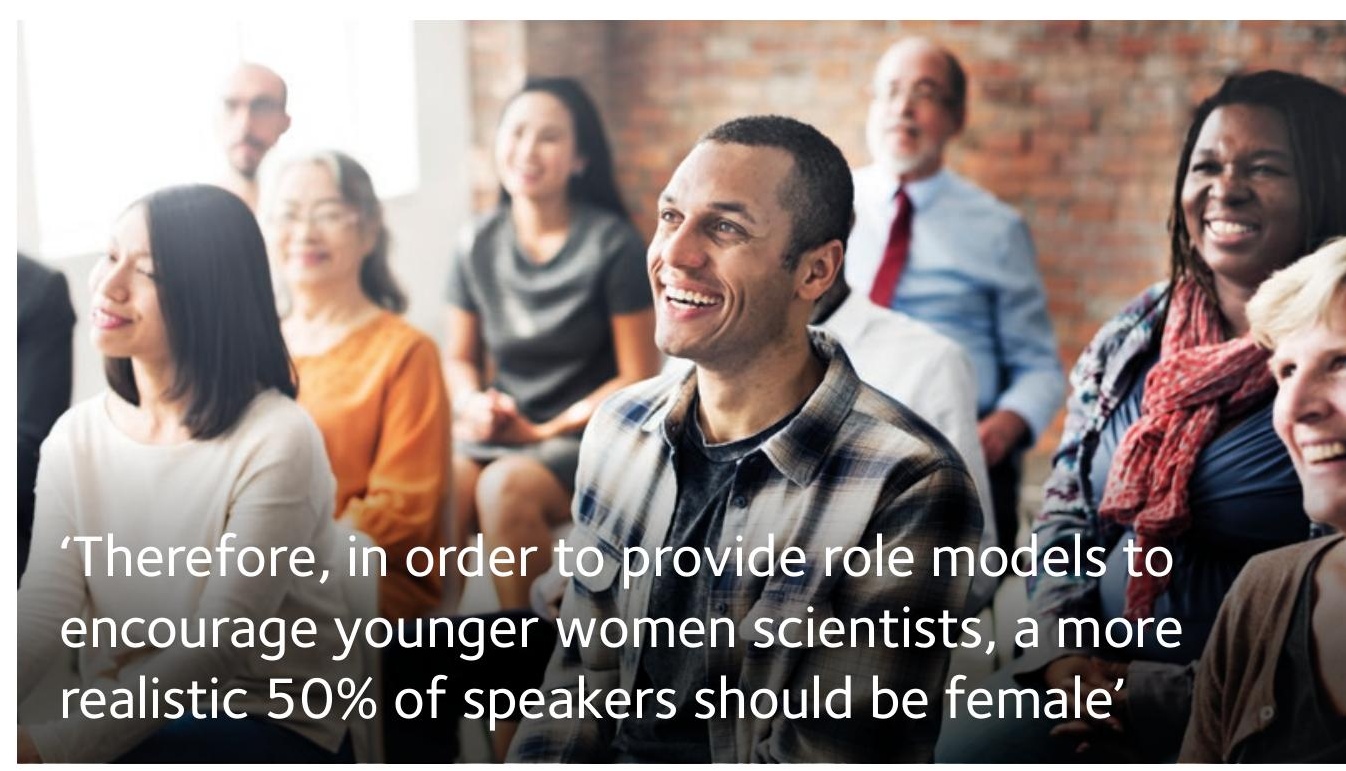

The difficulty of this issue was first brought home to me in my role as Chair of the International Scientific Programme Committee for the International Union of Physiological Sciences (IUPS) meeting held in Birmingham in 2013. We decided that there needed to be appropriate female representation and agreed that this would be about 30\%. A vocal minority objected to even this conservative figure on the grounds that fulfilling it would be positive discrimination and would risk diluting the quality of the science in the meeting. I still hear this argument today, phrased as, 'in my field there just aren't enough female leaders'. I would have more sympathy with it if I felt that people had considered all the people in the field. I have now been involved in organising enough symposia and meetings to realise that, when asked to suggest speakers, most of us (me included) think of people that we have heard speak recently. There is no have provided data on ethnic origins for the membership database. Of these, the largest group after White British/European is Asian British/European which makes up 10\% of membership. Here again, there are differences with age: $20 \%$ of the under 40 s but only $3 \%$ of the over 60 s are Asian. Given these figures, it is hard to suggest what appropriate representation as speakers means but I am sure that this will be an important issue for the future.

The Society is committed to ensuring that all its processes are fair and transparent. Members are encouraged to provide suggestions on how to improve inclusivity. Please, also, make sure that you have included your diversity data on the membership database - https://portal.physoc.org/ Equality-and-Diversity 


\section{The importance of attracting young people to physiology}

\author{
Brian Bush \\ University of Bristol, UK
}

Since a new Scientific Editor will be in place for the next issue of Physiology News, it might be timely to share a few thoughts on the magazine and The Society. Physiology is, I think, the most interesting, important and relevant to everyday life of the Natural Sciences, and an invaluable source of self-knowledge as well as a pathway to all sorts of interesting careers. Many skills learned in physiological research and teaching are widely transferable, not only within the sciences.

Physiology should therefore appeal to young people, so I believe it's important to try and attract new recruits at an early age, and also to encourage and empower a questioning mind-set and a real curiosity about 'how the body works'. To this end, The Society should offer to schools, particularly secondary schools lacking good science teaching, a variety of talks on bio-physiological topics, to be given by research-active physiologists, preferably enthusiastic, young Society members for whom this would be a valuable learning experience and to whom school students should more readily relate.

Nowadays, there seem to be fewer Society meetings than in my day, and most are in London and the south-east. More ordinary meetings at different universities throughout the UK would extend opportunities,

especially for geographically 'disadvantaged' physiologists, to communicate their research and interact with colleagues from elsewhere. Such meetings could, as in times past, include live or video-recorded demonstrations focusing on local research projects, as well as poster presentations and general sessions, thereby widening horizons and extending access for all. Communications describing a variety of methodological approaches, preparations from different phyla or species, novel techniques and original, imaginative ideas should be welcomed. Videoconferencing may also be worth trying, with advice and technical support in setting up cameras, etc.

A few personal landmarks may help to explain my take. Born in South Africa, I left for Cambridge in 1957, completing a PhD on Crustacean neurobiology in 1960. At Bristol University from 1966, my first Physiological Society 'Demonstration' (a requirement for Membership then) was a live experiment on a novel non-spiking muscle receptor organ in the shore crab: Andrew Huxley's questions were incisive and stimulating. In 1975, a sabbatical year at Monash University, Australia, gave me experience of 'proper' (neuro-) physiology experiments - on monkey and possum. And in my last research decade, I ran $\mathrm{PhD}$ and BSc projects utilising ideas developed from our work on crayfish and recording hand EMGs to study 'writer's cramp' in students (and myself)!

Now, despite recent reorganisation of the Biomedical sciences in Bristol (and elsewhere), I remain convinced that the continued pursuance of Physiology as an academic and research discipline is vitally important, and that everything should be done to encourage and support aspiring physiologists in their early careers and beyond. More frequent and varied opportunities to meet and exchange research results and ideas with physiologists at other institutions, and perchance to set up new collaborations on problems of mutual interest, could provide invaluable and motivating experience for future physiologists - and may help broaden the scope of British Physiology as Brexit looms!

\section{Minutes from the Meetings of 50 years ago}

Mordecai P Blaustein

School of Medicine, University of Maryland, USA

I recently was browsing through the Summer 2017 issue of Physiology News, and was delighted to see the transcription of the minutes of the Cambridge Meeting of The Physiological Society (May 20-21, 1967, I believe). It brought back many memories. It was my first Society meeting and oral presentation to The Society; I rehearsed my talk so much that I memorised it (was I nervous!). That was the public announcement of our discovery of $\mathrm{Na} / \mathrm{Ca}$ exchange. Also, I still remember helping Sir Henry Dale into his seat at the dinner in Pembroke, and later being admonished for passing the claret in the wrong direction (what did a provincial know about such things!). As I recall, the July 1967 meeting was in Oxford, and I was reprimanded by Sir Lindor Brown ('In England we stand when we speak!'). I was sitting in the very centre of the hall when I made a comment during a discussion, and had do to hold my tongue from responding, 'Yes, but in America we do not embarrass our guests.'

Thanks for helping me recall those memories.

By the way, my last piece in Physiology News, about my postdoctoral experience in the UK evoked several very nice responses e.g. from David Eisner, Bertil Hille, Otto Hutter \& Bill Van der Kloot. The one from Otto led to a wonderful exchange of correspondence and articles. Thanks again for inviting me to write the memoir.

Please send your correspondence to magazine@physoc.org

\section{Physiólogy Friday 12 October 2018
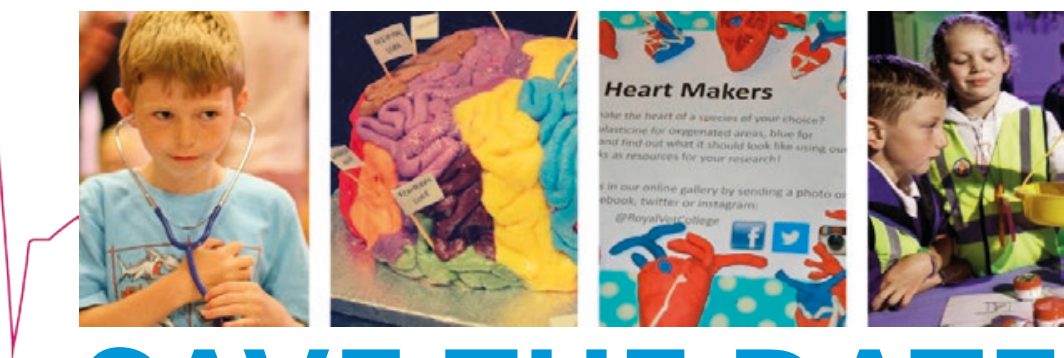


\section{Reports of recent Committee meetings}

The purpose of these short updates is to keep you informed about the work of our Committees. The following summaries detail the meetings of the past few months.

\section{Council}

Overseeing the development of a charity's strategy is one of the most important tasks a trustee must fulfil, and strategy update was on the agenda at the November Council. It was noted that considerable progress had been made in developing each strand of the 2018-2022 Strategy, and Committees will now develop their activities further:

- Meetings (scientific) - to advance physiology through our meetings and improve networking opportunities for physiologists including opportunities to present their work

- Publications - to ensure our journals continue to be international flagships for physiological research, across the subdisciplines of physiology, where any researcher is proud to publish.

- Engagement - through the overarching theme of 'Lifelong Health', The Society will engage our target audience as well as secondary audiences (such as policy-makers and press) required to influence them.

- Internal processes - to include more efficient working, better measures of outcomes and impact, improved governance, budgetary control and cross-departmental ways of working.

It was agreed the draft strategy would be submitted to Council on 7 March for approval.

Another important point of business included an update from the Property Strategy Working Group, chaired by President-elect Bridget Lumb. Following the closing date for the submissions to tender for the internal and external building work it was noted that two of the tenders were being explored in further detail by consultants Peter Fox (TP2MC) and Janie Price (Kennedy O'Callaghan Architects), who both have extensive technical knowledge. It was agreed that they would review the design and build techniques used for each tender and would make a recommendation to The Society regarding the best firm to engage. Members may be interested to note that Roxwells have been engaged to carry out the building work, which is now well underway.
The Society was invited to nominate candidates for REF2021. Nine candidates submitted completed forms for REF2021 and requested The Society endorse their nomination. The Trustees reviewed each candidate in turn and supported them all, noting the mix of areas of physiology and that several candidates could be submitted for more than one of the sub-panels, if required. The Society had previously supported the application of three individuals to be subpanel chairs. Council agreed that, should any of these not be appointed as a REF sub-panel Chair, The Society should support them as sub-panel members.

Membership trends were reviewed by Council, and the success of the Society Representatives event in November was also noted. One of the outcomes from this meeting was the development of a resources pack to support the Society Representatives when promoting The Society and benefits of membership at their institutions, for example, at university induction days.

It was also noted that the Fellowship scheme was being reviewed to explore how The Society could engage better with the Fellows and draw on their considerable experience. This would include exploring opportunities for Fellows to engage with early career physiologists and Affiliate Members.

\section{Education \& Outreach Committee}

At a busy meeting of the Education and Outreach Committee in October, the main points of business included updates on The Society's 2018-2022 Strategy review, our Physiology MOOC, a review of the Vacation Studentship Scheme (VSS), and discussion of proposals for developing Public Engagement (PE). The Committee put forward a number of suggestions for the theme and target audience of the Strategy, and discussion of these suggestions is ongoing. The Outreach Officer presented some recommendations on how future PE work might align with The Society's new Strategy, and the Committee discussed several ways that The Society could better encourage, support and recognise Members' PE activities. An undergraduate from Brunel University presented the outcomes of his studentship at The Society's London office in summer 2017 (building on the survey reported at the last meeting); highlights included the large proportion of awardees continuing to higher degrees or related work. One of the case studies gathered as part of this project is published on page 43 . The Committee also received a favourable report on The Society's MOOC, 'Physiology: The Science of Life', which ran for the first time this autumn. Over 7,000 people registered for the MOOC (exceeding the $6 \mathrm{k}$ target), and further analysis of learners' engagement with, and feedback on, the content is in progress. The results of this analysis will inform any modifications to the MOOC, before it is offered again in 2018; further details will be released as soon as the dates are agreed.

\section{Finance Committee}

The Finance Committee met with the haysmacintyre Audit Partner to agree the 2017 audit planning and confirm the statutory requirements and process for compiling the 2017 accounts. The Committee noted the inclusion of risk management in their Terms of Reference as of November 2017 and discussed the Charity Commission guidance on reporting key risks in the Trustees Annual Report.

The Committee also received the Q4 Management Accounts and noted key variances against forecasts. The updated financial delegations and anti-fraud policy was reviewed and approved for recommendation to Council. Finally, the Committee received a presentation from Cazenove Capital Management on The Society investment portfolio performance.

\section{Meetings Committee}

The recent Meetings Committee was held on 4 October and was chaired by Sue Deuchars, University of Leeds, UK.

The main steer of this meeting was to conduct a review of the current portfolio of Society events, taking into consideration the aims of the core strategy working group, 
together with the results of the membership survey. Society meetings give members the opportunity to present and share their research, and also provide networking. The format, structure and timing of the Main Meeting was appropriate, but may be enhanced by the addition of satellite meetings and workshops.

Topic Meetings provide breadth across a topic and an opportunity for attendees to meet with those that they would not ordinarily engage with. They can also explore the interfaces of physiology with other disciplines. The format of these will therefore not radically change but the planning of each Topic Meeting programme will involve a wider team of people.

The funding originally allocated to support three $\mathrm{H}^{3}$ symposia at Hodgkin Huxley House will now be allocated to support satellite meetings and workshops ahead of the annual Main Meeting.

Since the last meeting, we have confirmed that Physiology 2019, the Main Meeting, will take place in Aberdeen from Monday, 6 to Wednesday, 10 July, and funding will be available on a competitive basis for members to organise satellite meetings and workshops on Sunday, 5 July 2019.

\section{Publications Committee}

The Publications Committee met at the beginning of November 2017. This was the first Publications Committee to be led by Interim Chair Debbie Baines, who welcomed the other new members of the Committee: Sue Deuchars (Interim Chair of Meetings Committee), Frank Sengpiel (Honorary Treasurer) and Federico Formenti (Trustee).

\section{The Editors-in-Chief of The Journal of} Physiology and Experimental Physiology updated the Committee about their continuing strategic plans for the journals.

Kim Barrett, Editor-in-Chief of The Journal of Physiology, has been working to increase the number of non-traditional physiology papers submitted to The Journal of Physiology, particularly those that use non-mammalian animal models. She also outlined the steps The Journal has taken to encourage submissions from currently underrepresented areas of physiology. Also, the Editorial Board has been rationalised to ensure a more equal workload for the Reviewing Editors.

Mike Tipton, Editor-in-Chief of Experimental Physiology, reported strong growth, including increases in both submissions and full-text downloads in 2017 compared with 2016.

Tom Kleyman has been recruited as the new Editor-in-Chief of Physiological Reports, from the beginning of 2018

\section{Nominations Committee}

The Nominations Committee met to review the candidates for the three Honorary Officer positions (President-Elect, Chair of Meetings Committee, and Chair of Publications Committee) and the External Trustee position. Results will be ratified by Council and where required put to the member vote. The outcomes will be announced at the 2018 Annual General Meeting (AGM).

\section{Affiliate Working Group}

Following a very successful early career conference, Future Physiology, last December, the Affiliate Working Group (AWG) met in London to discuss their forthcoming plans.

The main agenda item was a revision to the groups' terms of reference, including how the Chair is appointed. All members were agreed that the new Chair should be selected from the current members of the group, and that the new Chair would also serve as the Affiliate representative to Council. Current members will be invited to express an interest in becoming the new AWG Chair, and in the event of more than one expression of interest it will be opened up to an online Affiliate Member vote.

The group also discussed the Early Career Physiologists' Symposium taking place ahead of Europhysiology in September. Planning is in progress, and the event is sure to be a great opportunity for members to present their research.

If you have any ideas or suggestions for ways the group should be supporting Affiliate Members and early career researchers, or would like to express an interest in joining the group, please get in touch. You can provide ideas by getting in touch with Jen Brammer, Membership Engagement Manager at jbrammer@physoc.org
Bringing you snippets of the latest intriguing research

\section{An internal 'bathroom scale' for regulating body weight and fat}

A newly discovered leptin-independent body weight homeostat, 'gravitostat', has been discovered in rodents. This new osteocyte-dependent sense detects changes in body weight via the weightbearing bones to regulate food intake and fat mass, providing a possible explanation for the anti-obesity effect of standing.

DOI: 10.1073/pnas.1715687114

\section{The answer to the ultimate question of life, the universe and everything, really is $\mathbf{4 2}$ (million)}

A new method has been devised to reliably and accurately pin down the number of protein molecules in a single cell to the nearest million. To achieve this, the team normalised and combined data from 21 analyses of protein abundance in the model organism Saccharomyces cerevisiae, and arrived at the bizarrely coincidental famous number 42.

DOI: 10.1016/j.cels.2017.12.004

\section{First attempt at gene editing inside the human body}

The first patient in a small clinical trial of in vivo gene editing has received treatment for a rare metabolic syndrome called Hunter syndrome. To increase safety, virusdelivered zinc finger nucleases under the control of a hepatocyte-specific promoter inserted the corrective gene into a 'safe harbour' under the albumin promotor, restricting the treatment to the liver.

DOI: 10.1126/science.aar5098

\section{Body clock problems may be an early warning of Alzheimer's disease}

Circadian rhythm disturbances occur in symptomatic Alzheimer disease and are hypothesized to contribute to its pathogenesis. However, new research shows that preclinical Alzheimer's disease is associated with rest-activity rhythm fragmentation, independent of age or sex, suggesting circadian dysfunction occurs very early before cognitive symptom onset. DOI: 10.1001/jamaneurol.2017.4719 


\section{A Crack in Creation: \\ Gene editing and the unthinkable power to control evolution}

\section{Fonathan Ashmore \\ University College London, London, UK}

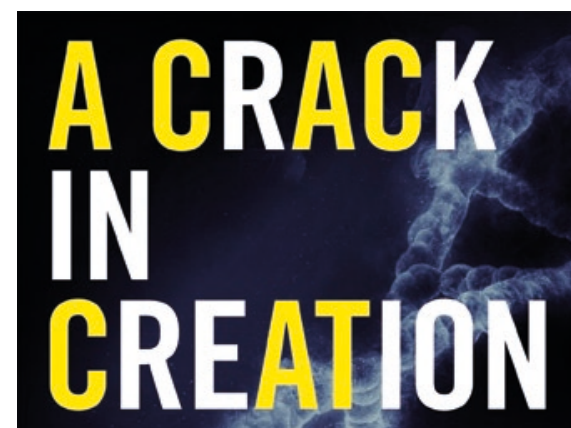

GENE EDITING AND THE UNTHINK BLE POWER TO CONTROL EVOLUTION

JENNIFER A. DOUDNA SAMUEL H. STERNBERG

Jennifer Doudna \& Sam Sternberg Houghton Mifflin Harcourt, 2017 ISBN: 978054476940

\section{'The subheading}

suggests 'unthinkable' but this is precisely why this book should be on every graduate's reading list'
You can hardly have missed the rise of CRISPR. It is not shorthand for a new app or for a Chinese dish, but for the gene-editing technology that makes precise, low-cost manipulation of DNA possible. Once a curiosity of bacterial DNA, it has now become a molecular biology tidal wave which many laboratories and companies are riding. Even the financial pages report on a patent rights fight to this potentially very lucrative technology. This fight, between MIT and UC Berkeley, is still running.

CRISPR (Clustered Regularly Interspaced Short Palindromic Repeats) describes sections of bacterial genomes which a bacterium uses to identify and target invading viruses. Although originally identified as a genomic quirk in 1987, it became clear about 10 years ago that this could be a sort of bacterial immune system as the repeating sections store a history, between the repeat sections, of previous viral attacks. These CRISPR regions activate, using the associated RNA, a family of Cas (CRISPR associated proteins) endonucleases which can then slice up the viral DNA. The key discovery, made by Jennifer Doudna and Emmanuelle Charpentier, was that one of these proteins, Cas9, also efficiently cuts eukaryotic DNA once targeted with the appropriate CRISPR-RNA. Once precisely cut, the rest of the cell's machinery can be hijacked to stitch up the cut strand or to insert a known sequence. And that is what makes it a very powerful technology.

The story of CRISPR-Cas9 technology, what it is, what it might do and how we should think ahead, is the topic of 'A Crack in Creation'. Even to the uninitiated - I include myself here - this is a gripping primer to the molecular biology. Doudna and Sam Sternberg, a research fellow in her Berkeley laboratory, have written a book with a to-diefor title and cut a wide swathe through a large raft of topics in contemporary science. These include how Doudna found herself running a laboratory studying RNA biochemistry, a slightly folksy account of how she met Charpentier (walking around San Juan in Porto Rico) and how in a brief collaboration this lead to the discovery of the CRISPR-Cas9 mechanism. And how, in an a-ha moment, she realised that this would allow precise genetic engineering of any living organism, bacterium, plant or animal. The separation between the laboratories which initially collaborated so effectively is slightly glossed over and although there are still some unresolved wrinkles (for example 'off-target' editing) the power and practical simplicity of the method is undeniable.

The second half of the book is about Doudna's response to opening Pandora's Box. Perhaps. Hers is the voice of a rational, liberal scientist who has organised conferences to discuss the ethics of her discovery. She admits to not knowing all the answers. But she spells out what can and maybe should not be done. The issues include that the technology is cheap to implement (just order the appropriate reagents) and that modification of the DNA of germline cells (read: 'designer babies') will propagate into the future with unforeseen consequences.

Science has been here before. When homologous recombination was discovered in the 1970s, a moratorium was proposed on such molecular biology engineering. The proposal was not implemented but it gave pause to think about consequences of unfettered technology. Similar issues faced the nuclear scientists - and gave rise to the Pugwash conferences, and may yet do so for the new developments in artificial intelligence and robotics where society's discussion is not keeping pace with the technology.

Has the horse already bolted before the stable door has closed? To date, PubMed shows over 7000 CRISPR-related publications since the Doudna-Charpentier paper in 2012 with no sign of the growth slowing down. Undoubtedly, there are companies promising correction of familial disease and removal of undesirable traits. A treatment for one form of muscular dystrophy using CRISPR was described by Eric Olsen in our 2017 Annual Prize Lecture. There have already been plant varieties engineered to increase shelf life. In the UK, the use of CRISPR on human eggs has been strongly regulated, but that does not extend everywhere. 'A Crack in Creation 'gives one pause for thought. The subheading suggests 'unthinkable', but this is precisely why this book should be on every life science graduate's reading list. For those who have lost the habit of reading books, Jennifer Doudna is the 2018 Croonian Lecturer at the Royal Society in May. It should be worth hearing what she has to say. 


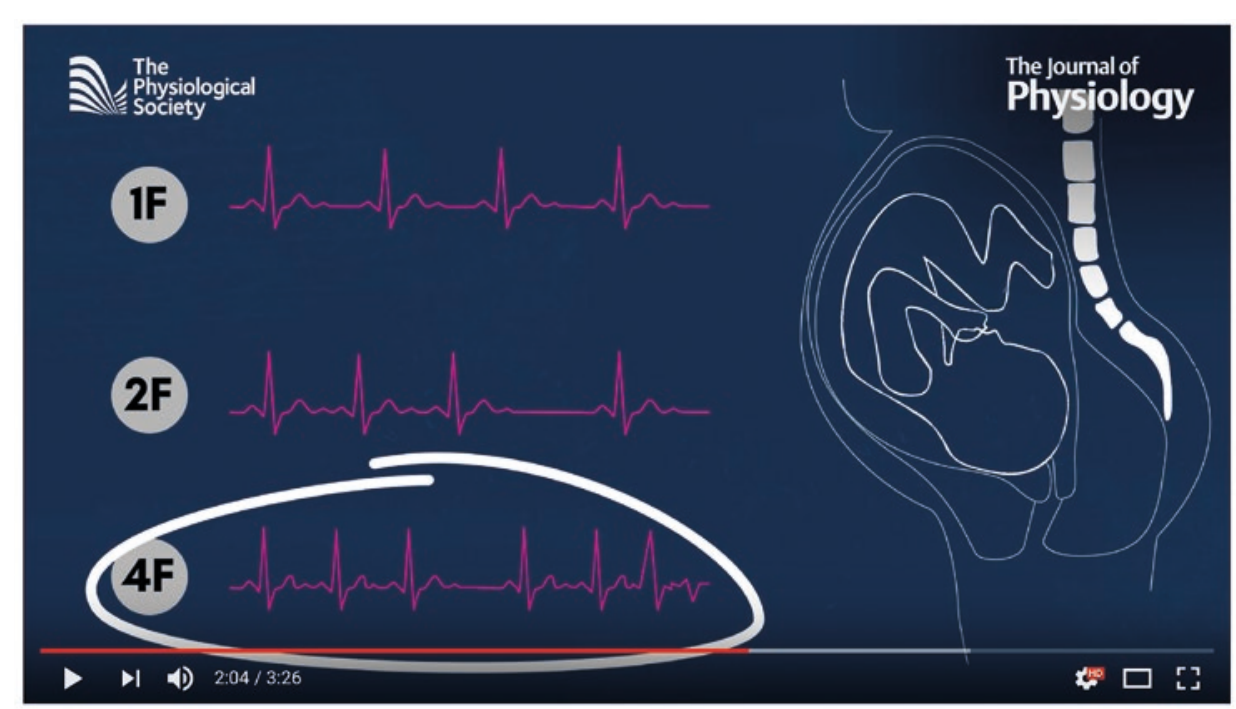

What is the best sleeping position for mums-to-be?

1,105 views

The Physiological Society

Published on Dec 12, 2017

In 5 q $0 \rightarrow$ SHARE $\equiv+\ldots$

SUBSCRIBE $3.9 \mathrm{~K}$

Researchers have monitored pregnant mothers and their babies to find out how sleeping position

affected the baby's activity. They explain why falling asleep on your side in late pregnancy is

\section{A new video series about research in our journals}

At a time when fake news, alternative facts and science deniers are hitting the headlines, strengthening the public understanding of science is as important as ever. While global climate change is most widely discussed, physiology is also vulnerable. With this in mind, we're working to widen the reach of the research published in our journals by continuing to harness the press, and reaching the public via videos and blogs. We've released four blogs and one video to date. Read and watch these, and stay tuned for more throughout the year.

Our first video can be watched at bit.ly/2FHQHOK.

\section{Newly-elected Fellow Members}

The Society's Members newly elected to Fellowship are as follows:

- Peying Fong, Kansas State University

- David Foster, University of Manchester

- Gwendoline Hughes, University of Nottingham

- Prem Kumar, University of Birmingham

- John Lockhart, University of the West of Scotland

- Frank Sengpiel, Cardiff University

- Lucia Sivilotti, University College London

- Anatoly Soloviev, Taras National Shevchenko University of Kyiv

\section{Non-aging mammals}

In addition to total immunity to cancer, naked mole rats also appear to defy Gompertzian laws, meaning that their age-specific hazard of mortality does not increase as they get older. Even at 25 times past their time to reproductive maturity, their risk of death does not increase.

DOI: 10.7554/eLife.31157

\section{Evidence for epigenetic 'muscle memory'}

New clusters of genes have been found to record periods of exercise-induced skeletal muscle growth as epigenetic modifications. Load-induced muscle hypertrophy causes gene hypomethylation that persists even after muscle mass returns to baseline, leading to larger increases in gene expression and muscle mass after re-loading.

DOI: 10.1038/s41598-018-20287-3

\section{Why young blood can rejuvenate old brains}

esearchers have discovered an enzyme in mice called Tet2 that when decreased in the young mouse hippocampus impairs neurogenesis and cognition. Loss of Tet 2 in aged mice is associated with regenerative decline, but young blood can restore levels to rescue neurogenesis and enhance cognition.

DOI: 10.1016/j.celrep.2018.02.001

\section{The type of alcohol you drink really DOES affect your mood when drunk}

Responses from 30,000 people in the Global Drug Survey, aged 18-34 across 21 countries who reported drinking all alcohol types, show that drinking spirits is associated with aggression but also confidence, energy and feeling sexy, whereas red wine and beer are associated with relaxation.

DOI: 10.1136/bmjopen-2017-016089

\section{Science search engine links papers to grants and patents}

A new database called Dimensions connects scientific publications to related grants, funding agencies, patents and clinical trials, and provides some of this data free of charge. Compared to other similar platforms, the company is more transparent about its data sources and wants to work with researchers to improve the software.

go.nature.com/2GudwqF 


\section{How can we better support your career?}

Our Members are at the heart of everything we do. We want to be the first-choice society for all those involved in physiology, be it in academia, industry or clinical.

Throughout 2018, we are carrying out a project to better understand our membership and how to support you in your career.

We want to know what influenced your decision to join The Society and how we can help you remain engaged with The Society as your career in physiology progresses.

There will be a number of opportunities for you to take part over the next few months through interviews, surveys and focus groups. We are really looking forward to listening to your thoughts and then using them to shape a Society that works better for you. We look forward to sharing our findings in the early part of next year.

Sign up to our member insight panel now at www.physoc.org/memberinsight-panel.

For any questions, please contact Jen Brammer, Membership Engagement Manager, jbrammer@physoc.org.
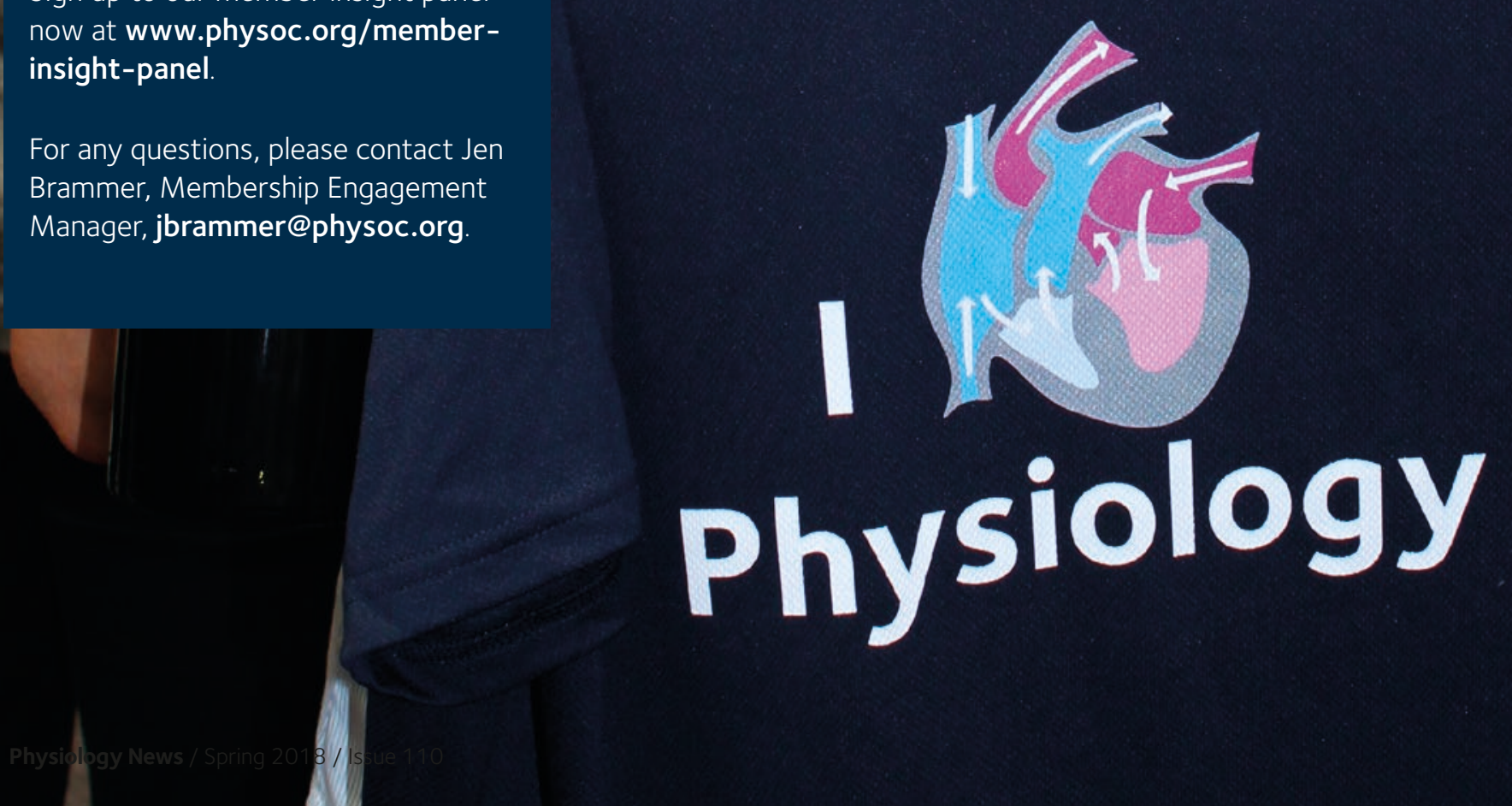


\author{
Henry Lovett \\ Policy and Public Affairs Officer, \\ The Physiological Society
}

\section{The Society informs government on the details of animal sentience and welfare concerns}

In a vote on an amendment to the European Union (Withdrawal) Bill at the end of last year, the government voted not to transfer the EU protocol on animal sentience into UK law. This led to some campaigners claiming that MPs had voted not to recognise animals as sentient, and in doing so reduced the protection they enjoy. However, the vote did not weaken existing UK law covering animal rights, and many MPs took to social media to defend this action and stress that no one in the House of Commons disagreed that animals display sentience.

Despite this rebuttal of the criticism, some members of the public continued to be concerned. The Secretary of State for the Environment, Food and Rural Affairs, Michael Gove MP, released a statement saying 'This government will ensure that any necessary changes required to UK law are made in a rigorous and comprehensive way to ensure animal sentience is recognised after we leave the EU. The Withdrawal Bill is not the right place to address this; however, we are considering the right legislative vehicle.'

A consultation has now been released on a draft Animal Welfare (Sentencing and Recognition of Sentience) Bill, and The
Physiological Society has made sure to put across the position of in vivo scientists. It is imperative that the new legislation is compatible with existing rules such as the Animals (Scientific Procedures) Act 1986, known as ASPA. This sets the constraints scientists work within over what animals can be used in research, what procedures can be performed and the levels of harm involved.

Among our priorities at the consultation phase are to tighten the definitions in the Bill of 'animal' and 'sentience' to take into account the true scientific understanding of these terms, and not use a very broad lay definition which could, for example, lead to research on insects counting as contravening animal welfare rules and becoming prohibited.

The EU undertook a long period of research before determining its own animal research laws, and used definitions the research community support. Unless the UK government wishes to duplicate and update this effort, the pragmatic approach would therefore be to adhere to the EU conclusion: that is, 'animal' includes nonhuman vertebrates and cephalopods. We also advocate that 'sentience' should be recognised as more than displaying an escape reflex, but rather that a sentient creature needs to be able to determine what is pleasurable or painful and consciously make learnt choices that reflect these perceptions. This demonstrates thought, emotion and learning.

The consultation closed at the end of January, but The Society has continued to work with the Department for the Environment, Food and Rural Affairs (Defra) on the new legislation, and the Home Office, which oversees ASPA, going forwards. We aim to ensure the development of the Bill reaches an effective and mutually agreeable conclusion.

\section{Ministerial changes affecting science and academia}

The January government reshuffle saw Sam Gyimah MP given the brief for universities and science, which continues to be split between the Departments for Education (DfE) and Business, Energy and Industrial Strategy (BEIS). At the time of writing, his official title is listed as 'Minister for Higher Education', but we have not heard of any change in the Minister's responsibilities, and Gyimah himself tweeted 'Off to my new role as Universities \& Science Minister and looking forward to the challenges ahead'. The previous incumbent, Jo Johnson MP, was moved to the position of Minister of State in the Department for Transport.

Gyimah has been identified as 'one to watch' in the Conservative Party for some time. He was first elected to Parliament in 2010 and was brought into the government in 2013. Previous Ministerial responsibilities have been as Parliamentary Under-Secretary of State for Childcare and Education (2014-2016) and Parliamentary Under-Secretary of State for Prisons and Probation (2016-2018), making his new role a promotion to Minister of State level.

The Secretary of State for Education has also been replaced, with Damien Hinds MP succeeding Justine Greening MP. These new personnel in charge of higher education could open the door to new changes affecting academics' teaching and research activities.

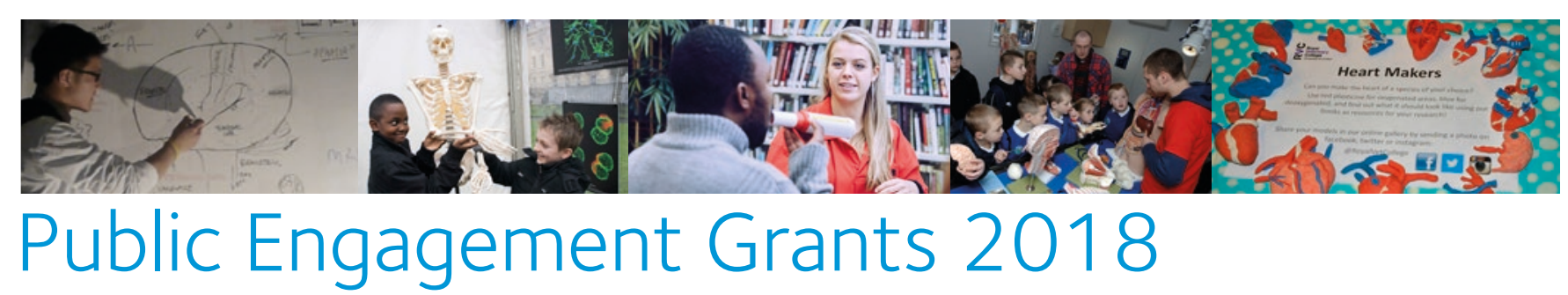

Funding of up to $£ \mathbf{5 0 0 0}$ is available for activities that promote the discussion of physiology with public audiences 


\section{Events}

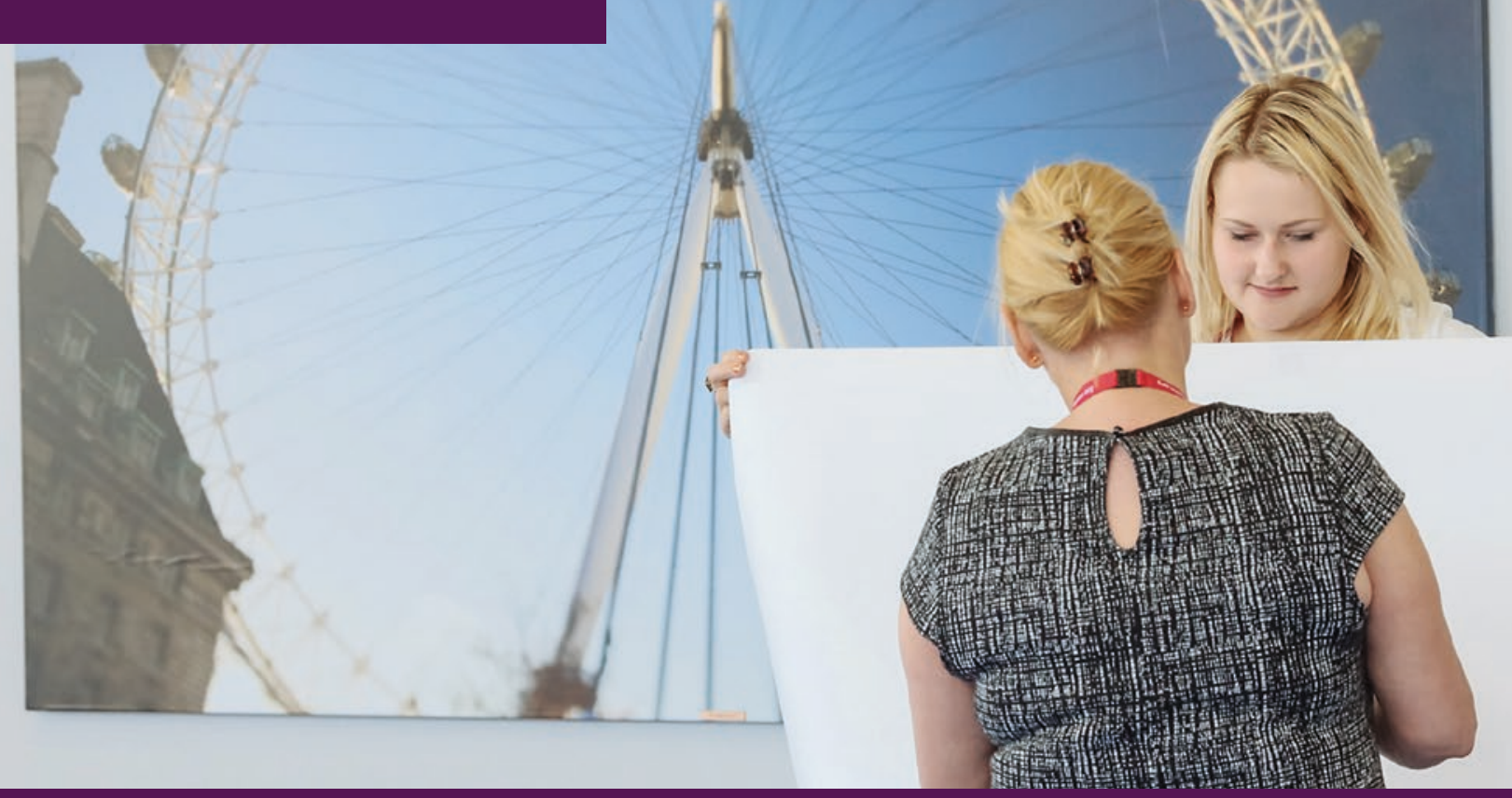

\section{Forthcoming events}

Experimental Models in Physiology University of Exeter, Exeter, UK

www.physoc.org/models
Early Career Physiologists' Symposium (ECPS 2018) QEII Centre, London, UK

www.europhysiology2018.org/ ECPS2016
Europhysiology 2018

- Main Meeting

The QEII Centre,

London, UK

www.europhysiology2018.org
Sleep and Circadian Rhythms from Mechanisms to Function Barbican, London, UK

www.physoc.org/sleep_ circadian/sleep-and-circadianrhythms-mechanisms-function
Meeting Notes

\section{$\mathrm{H}^{3}$ Symposium: Muscle Physiology and Metabolism}

30 November 2017 , Hogkin Huxley House, London, UK

\section{Nathan Hodson \\ University of Birmingham, UK}

On 30 November 2017 the $\mathrm{H}^{3}$ symposium: Muscle Physiology and Metabolism was held in the memory of Professor Michael Rennie. This event brought together numerous leaders in the fields of amino acid metabolism and transport, many of whom had been good friends with Prof. Rennie. As a final year PhD student, the opportunity to attend this symposium provided a unique chance to network with these academics from whom I gained invaluable knowledge not only about muscle physiology but also how they all managed to succeed in their respective careers. In particular, learning how young faculty members made the transition from postdoctoral fellows to faculty was fascinating and will definitely help with my future career in research.

This symposium, much like other Society events I have attended, was structured in such a way to permit these networking opportunities, and all attendees contributed to such a friendly atmosphere allowing stimulating discussions to flow. Having spoken to several other early career physiologists who attended this meeting, all agreed with this observation, commenting on how enlightening it was to have such an opportunity to converse with such highprofile researchers. Specifically, hearing experts present about lesser-publicised areas such as Hippo/Yap signalling and proton- assisted amino acid transport was of great relevance to my own research going forward.

At this symposium I was lucky enough to be awarded one of the inaugural Michael Rennie - Universities of Dundee and Nottingham Awards, an honour which I will treasure for the entirety of my research career. The chance to present before such an esteemed audience of muscle physiologists certainly improved my presentation skills, something which will no doubt aid any future presentations I may give.

I would certainly recommend the $\mathrm{H}^{3}$ symposia to all early career physiologists, as a chance to 'learn from the best' in your field and have the opportunity to network with the people you normally may only see as a final author on a paper. Finally, I would like to thank The Physiological Society for organising this event which, as I'm sure all who attended would agree, was a great success and a fitting tribute to one of the major contributors to our field. 
Meeting Notes

\section{$\mathrm{H}^{3}$ Symposium: Sensory Transduction in Insects}

8 December 2017, Hogkin Huxley House, London, UK

\section{Bob Banks}

University Of Durham, Durham, UK

In these days of 'impact', 'translation', 'outreach' and other political impositions, it can sometimes be difficult to hold on to the intrinsic importance of science as a way of understanding. I must not, of course, presume to know the motives of anyone but myself, but I'm sure I can't be alone in having been motivated primarily by a desire to understand how things are and how they work. Now, in my retirement from my academic post, I try to maintain an active involvement in research and my primary motivation remains the same. In this spirit, the one-day symposium organised by Ben Warren and Jörg Albert on sensory transduction in insects was for me a joy from start to finish. I attended purely as an observer, as my own work focuses on mammalian mechanoreceptors, but I am also a zoologist, so when the symposium was announced it was clearly one I should not miss.

The symposium was divided into three sessions of oral presentations and two of posters. The first oral session was on the physiology of sensory neurons, often with instances of the importance of the particular sensory system to the insect's behaviour. The second was on the electrophysiological basis of sensory transduction; with a strong emphasis on mechanotransduction, this was, perhaps, of particular relevance to me. The final oral session consisted of three plenary lectures on cross-sensory modalities in sensory neurons. Roger Hardie (Cambridge) spoke on the contribution of mechanical events in phototransduction. Martin Göpfert (Göttingen) showed us the complementary involvement of opsins in mechanotransduction, and presented a fascinating idea on the possible common evolutionary origin of photoreception and mechanoreception through the role of opsins in maintaining sensory dendrite structure. Andrew French (Dalhousie) concluded the session with his talk on the dynamics of insect olfaction, including the development of a system for rapid presentation of odorants such as $\mathrm{CO}_{2}$ while recording single units from antennal nerves - a technical tour-de-force. Of course, odorant molecules are in constant thermal motion with characteristic frequencies, so it should come as no surprise once more that mechanical involvement turns out to be critically important in olfaction too.

'I must not, of course, presume to know the motives of anyone else, but I'm sure I can't be alone in having been motivated primarily by a desire to understand how things are and how they work'

In this very brief account, although I could not do justice to all the individual oral and poster presenters, I must note that the standard was universally high and enlightening, including the discussions both formal and informal around posters and refreshments. And so my initial thought that this meeting was not to be missed was amply confirmed; I congratulate The Society on supporting the meeting and especially Ben and Jörg for organising it.

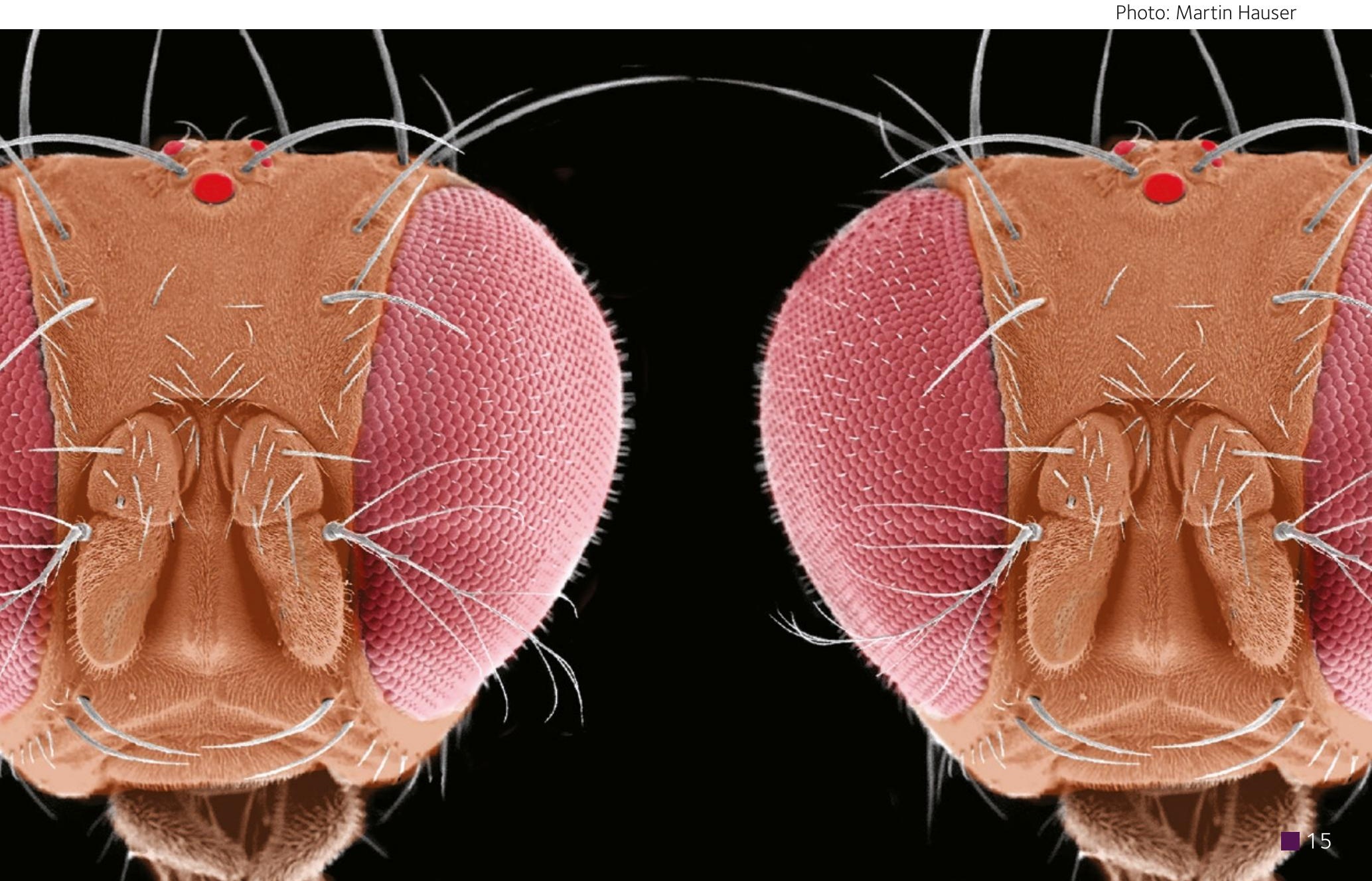


In conclusion, I think this conference was a good first step to put the uncertainties that ECRs face throughout their development as researchers in the spotlight, and provide them (us!) with tools and networks for better tackling these.

\section{Dan Brayson}

Kings College London,

London, UK

As a member of the Affiliate Working Group of The Society, I was privileged to have the opportunity to help with the planning and execution of the Future Physiology meeting, an early career researcher (ECR) focused meeting held at the University of Leeds recently. The meeting was 'by ECRs for ECRs'. This meant that the Affiliate Working Group was placed at the forefront of the brainstorming process to come up with a plan for a meeting which facilitated an engaging experience for early career scientists.

\section{What we hoped for was an opportunity} for ECR's to shed their inferiority complex baggage (we all have it) and to feel invigorated by the conference experience rather than being overwhelmed. To this end, 20 ECRs were selected for oral presentations

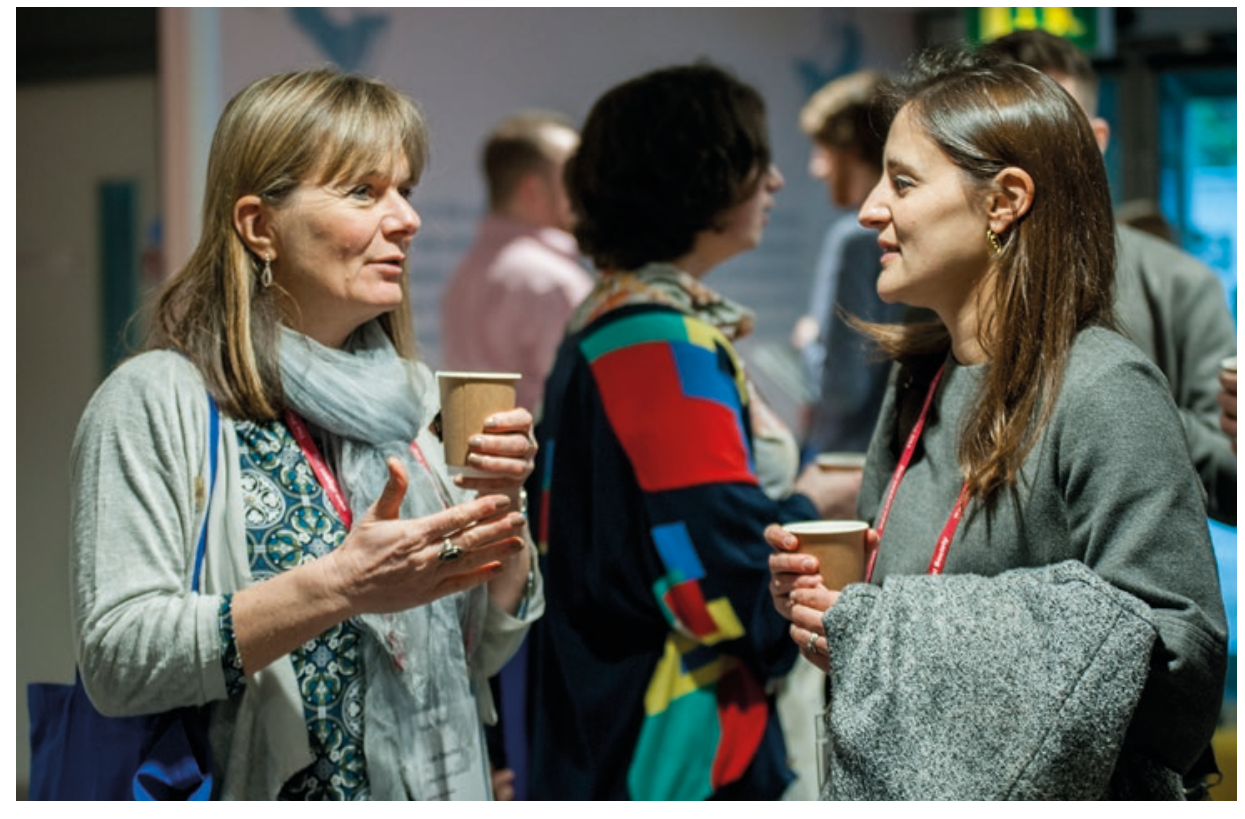

whilst five talks were given by senior scientists (for balance, of course). Of these, three were young principal investigators and shining examples that we don't have to wait around for professors to retire in order to make significant progress in our careers. We hoped that this would add a motivational slant for attendees. If they can do it, why can't we?

On a personal note, it was a red letter day. I was charged with sharing the chairing and presentation-marking duties with my fellow Affiliate Working Group members, a first for me, and with this, I got to experience the joy of facilitating meeting proceedings rather than merely taking part. At least this was my perception of it, and I would definitely do it again.

Reflecting now on the meeting, I feel that it was a good first crack at a meeting for ECRs. However, I also feel that there is further scope to create the most engaging and immersive experience for young scientists. One idea would be to have facilitated debate workshops on general topics (neuroscience, cardiovascular physiology, gastrointestinal physiology, etc.). This would engage people in a relaxed environment to talk more generally about the big issues/questions facing their chosen fields.

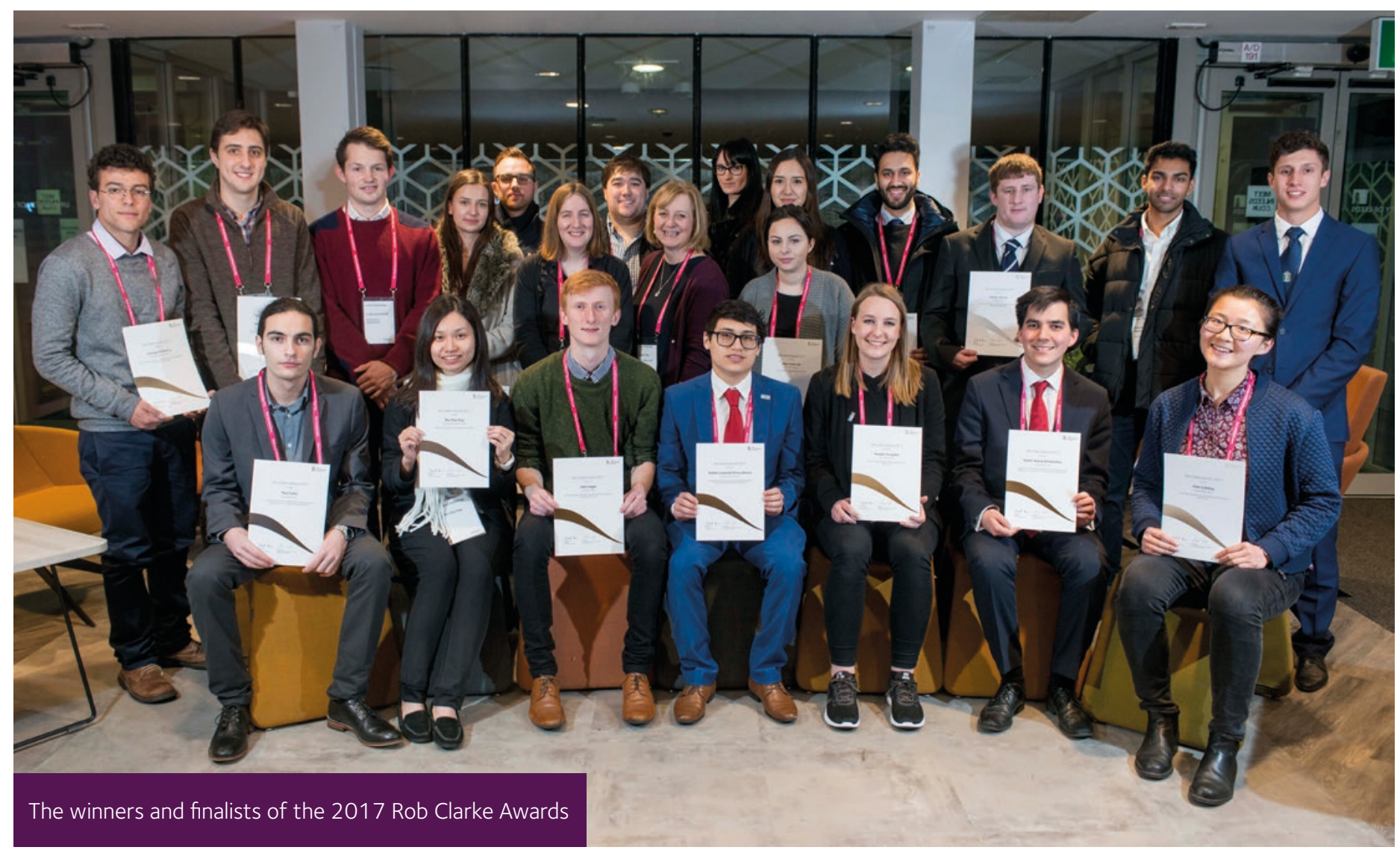


Thinking Outside the Box: Translational Research and Career Options beyond Academia

\author{
12 January 2018, \\ University of Leicester, \\ Leicester, UK
}

\section{Amelia Pollard \\ University of Nottingham, UK}

On Friday, 12 January, The Physiological Society hosted an outstanding conference titled 'Thinking outside the box: Translational Research and Career Options beyond Academia'. The conference was hosted at the University of Leicester, and around 60 postgraduate students and early career researchers were in attendance. The day kicked off with four keynote speakers, all of whom had previously undertaken PhDs and had since followed different career trajectories.
First, we heard from Kristen Clements, who is a senior translational scientist at the National Centre for Sport and Exercise Medicine.

Kristin gave an extremely interesting presentation on how the centre has implemented various research projects to the wider public. We were also given some useful tips to help disseminate our research along with tools to measure impact. Secondly, Damian Pattinson, vice president of Publishing Innovations at Research Square, spoke about the ways in which they aim to improve how scientists can disseminate research. Damian also has an editorial background, and so it was helpful to hear some of the 'dos and don'ts'

from an editor when writing a research paper.

The third speaker was Paul Greenhaff, who is a professor of muscle metabolism at the University of Nottingham. Paul introduced the newly formed Nottingham Biomedical Research Council and gave an insightful overview of the progression of his research. It was great to hear how his research has been applied, starting from the lab bench to the bed side in clinical practice. Finally, we heard from Victoria Cabera-Sharp, who is the Research Development Manager at the University of Oxford, who enlightened us about the field of para-academia. Victoria explained how the skills that we have developed as scientists can be transferred to other academic-related jobs. Following on from the talks, a panel Q\&A session took place which was joined by Richard Evans, a professor of molecular and cellular biology at the University of Leicester.

Whilst the presentations were extremely informative, the highlight for many of the delegates was the structured networking event, which gave us the chance to talk to the panel in small groups. This worked well as we were able to ask a variety of questions to each of the speakers in a comfortable and relaxed environment. It also gave the delegates an opportunity to get to know each other and offer advice to one another. It was good to hear from fellow scientists about their career aspirations and how they have started to implement their journey towards their chosen career path. Equally, for those that were unsure about their future career, it was very reassuring to find out about a range of excellent and stimulating jobs outside of academia that our skills are transferable to.

Overall, the conference was well thoughtout and was highly beneficial to both postgraduate students and early career researchers. The tools and tips provided to us on how to disseminate and track the impact of our research were extremely useful, and I'm sure many of those who attended will be implementing them in their own work. Furthermore, the event highlighted the many doors that are open to us upon completion of our PhD aside from the traditional academic route.

\section{Meeting Notes}

\section{$\mathrm{H}^{3}$ Symposium: Purinergic Signalling in Obesity and Renal Pathophysiology}

\author{
22 January 2018 \\ The Hatton, \\ London, UK
}

\section{Helle Praetorius}

Aarhus University, Denmark

\section{Bellamkonda K. Kishore}

University of Utah Health \& VA Medical Center, USA
To reverse the order and start with the conclusion, the $\mathrm{H}^{3}$ symposia sponsored by The Physiological Society are an outstanding tool for focused presentations and discussions with an emphasis on truly understanding the ongoing research and networking. As the organisers, we strongly recommend this format, particularly to facilitate new upcoming research areas and to join efforts regarding certain research challenges.

As the organisers, we used this informal symposium format to invite scientists with interesting stories in adjacent fields, and the result was an extremely constructive atmosphere and extensive networking on upcoming projects. Our symposium topic was deliberately interdisciplinary, joining obesity and renal research with purinergic signalling as a common denominator. We could, thus, have inputs to topics from local tissue regulation to overall cerebral regulation of body homeostasis. This allowed new insights in the complicated phenotypes of global transgenic models. For this to truly work, we used the symposium format to have longer talks with extensive time for discussion and just regular questions. This in turn allowed the time needed to understand the complexity of the various topics in depth which is the essence of physiology and pathophysiology. This format clearly has an appeal, and we found it very easy to lure engaged scientists to London in January from a large variety of places.

When organising a symposium, The Physiological Society offers excellent support with a genuine understanding of the busy schedule of scientists and the difficulty in planning an out-of-town symposium. The Society has clear policies that one has to comply to in the planning but the result was a very harmonious, balanced symposium with an extremely constructive atmosphere. We find that this type of symposium covers a completely different kind of need than larger international meetings, which cannot be supplied by smaller interest-group symposia as pre-meetings. The Physiological Society has to be commended for their effort, which really is an inspirational tribute to physiology by strengthening global scientific collaboration and project development. We would like to use this opportunity to again thank all speakers and contributors for their outstanding engagement for this event. 


\section{‘Discovering new}

advancements and

ideas in the different

fields of physiology will

be an opportunity to

strengthen already

existing friendships,

and to make new ones'

Indeed, early career researchers are also less aware of European differences in career structure and so such a meeting would allow them to probe these differences. Since Brexit and issues surrounding UK research funding from Europe cannot be totally ignored, it was also considered important to consider how future research collaborations can be worked at this stage.
The structure of the meeting was also very attractive to ECRs with over 100 slots for oral communications; they feel that this is a wonderful opportunity to showcase their research.

It is clear that all levels of physiologist are looking forward to this meeting of scientific minds but it is especially rewarding to know how highly our 'future physiologists' rate such an opportunity to attend such conferences.

'For me the conference will be a fantastic opportunity to meet colleagues and friends, to enjoy science in different talks and poster presentations. Discovering new advancements and ideas in the different fields of physiology will be an opportunity to strengthen already existing friendships, and to make new ones,' Anaclet Ngezahayo from Leibniz University Hannover, Institute of Biophysics, Germany.

We look forward to welcoming you all, whatever your career stage, at Europhysiology 2018!

\section{The Europhysiology series of conferences}

In 2016, The Physiological Society, the Scandinavian Physiological Society, the Deutsche

Physiologische Gesellschaft and the Federation of European

Physiological Societies (FEPS)

initiated an agreement to co-host a series of biennial joint conferences.

The series will begin in London, UK, in 2018 and will subsequently be organised in Berlin, Germany, (2020) and Copenhagen, Denmark (2022). FEPS will be a joint organiser of these biennial conferences.

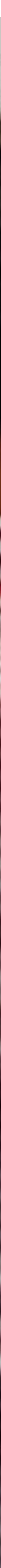




\title{
From the Archives:
}

\section{reports by the Meetings Secretary J.S. Gillespie of the Charing Cross/Ciba and University College London meetings of 1968}

\author{
Transcribed by Roger Thomas, who adds that these reports were read by the meetings secretary during the meeting \\ dinner at the next event, and then signed as a correct record by the presiding host. The original reports (or 'minutes') \\ are held in the Wellcome Library. Younger members may not realise that The Society started as a dining club.
}

\section{The Physiological Society's Charing Cross/Ciba Meeting, 12-13 January 1968}

At the invitation of W. Burns and G.P. Lewis, a meeting of the Society was held in the Department of Physiology, Charing Cross Hospital Medical School on Friday 12 January 1968 and at the Ciba Laboratories, Horsham, on Saturday 13 January 1968.

Beginning at 2 p.m. on Friday with W. Burns in the chair, ten papers were heard before tea followed by demonstrations until 6 p.m., when it was time for members and guests to make their way to the House of Lords where dinner had been arranged through the kindness of Lord Pargiter. Before dinner members were shown round both Houses of Parliament after which sherry, generously provided by members of the department, was served to ensure the proper mood for the appreciation of the excellent dinner which was to follow.

After dinner, G.W. Theobald, in proposing the Society's thanks to their hosts, very properly paid tribute to the excellent choice of sherries and somewhat improperly raised the question of the distinction between English and Scottish Peers. W. Burns, in reply, expressed his pleasure at entertaining the Society and his gratitude for the help he had received from so many members of his staff in arranging the meeting. He was particularly grateful to Lord Pargiter, an old friend of the Charing Cross Hospital, for arranging the splendid dinner they had just eaten. W. Burns then proposed the health of Lord and Lady Pargiter. Lord Pargiter, in his reply, returned to the vexed question of Scottish and English Peers and wondered what effect Scottish Nationalism might have on the former: on this thought, at least one of the Secretaries relapsed into unaccustomed contemplation.

Saturday started badly, with heavy snow and a biting wind. In spite of this, 40 members turned up at 9.15 a.m. in the Board Room at Charing Cross Hospital, awaiting the Ciba bus to take them to Horsham. By 9.30 doubt had set in, which the automatic telephoneanswering service at Horsham did not dispel. At 9.45 members and guests rushed off into the snow to try to catch the 10.02 from Victoria: surprisingly, almost everyone did. From then on the day steadily improved. The train was warm, comfortable and on time. Ciba quickly arranged cars to collect members from the station, so that finally some 80-90 members guests gathered for coffee only 15 minutes late. The meeting started at 11.30 with G.P. Lewis in the chair and all the papers were heard by 1.15 . Paper 12 was not accepted for publication.

The lunch which followed was one of the best that the present minutes-writer can remember. After lunch the programme of demonstrations by Eidophor large-screen television showed exactly how a single muscle fibre or a single active nerve unit is dissected, and the demonstration in 12 minutes flat by W. Feldberg of perfusion of the lateral ventricles in the cat was a delight to watch.

The meeting ended with tea at 4.30, after which five people returned to London in the bus which had by now arrived.

\section{Signed: E.C. Amoroso}

Friday, 12 January

Tea 120 - Dinner 70

Saturday, 13 January

Coffee 100 - Lunch 93 - Tea 100

The Physiological Society's University College London Meeting, 22-23 March 1968

On the invitation of A.F. Huxley, a Meeting of the Society was held in the Department of Physiology, University College London, on the 22nd and 23rd March. Beginning at 2 p.m. on Friday in the Botany Lecture, with A.F. Huxley and H.O. Schild successively in the chair, ten papers were heard before tea. The new lecture theatre was a great improvement in comfort for members used to the packed and tropical atmosphere at the rear of the Physiology Theatre. The one disadvantage, the absence of communication with the projection room other than a buzzer, affected only the Chairman, who was required on occasions to bound from the theatre at great speed and, as members could judge, to great effect.

Tea at 4.30 was followed by some excellent demonstrations, including one extra by M.J. Holmes. Dinner was notable first for a striking reversal of the increasing prices over the past two or three years, and secondly for the clear evidence of a very poor correlation between price and the standard of food provided. After dinner A.L. Hodgkin proposed the Society's thanks to their hosts and expressed the pleasure he was sure all members felt at the large number of distinguished scientists from Europe who were present. A.F. Huxley, in reply, welcomed members and their guests and particularly the many members from other countries, including Professor S. Weidmann from Berne and Professor S. Thesleff from Lund. Both he and the Society were indebted to Miss Mollie Kirk and Charlie Evans for once again taking most of the responsibility for organizing the meeting.

Beginning at 9.45 a.m. on Saturday, with B. Katz in the chair, a further thirteen papers were taken in one continuous stretch until lunch at 1 p.m., and it says much for members that the discussion at the end was as vigorous as at the beginning. The remaining four papers were heard in the afternoon, beginning at 2.15 with A.F. Huxley in the chair, and the scientific meeting ended at 3.15 to be followed immediately by the Annual General Meeting.

\section{Signed: J.N. Mills}

Friday, 22 March

Tea 337 - Dinner 198

Saturday, 23 March

Coffee 49 - Lunch 143 - Tea 244 


\section{Early to bed and early to rise}

\section{Makes a teen healthy, wealthy and wise?}

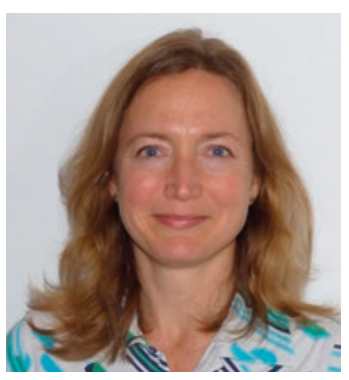

Gaby Illingworth

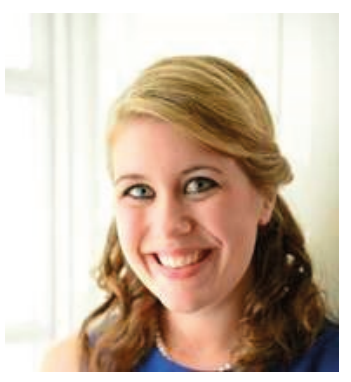

\section{Rachel Sharman}

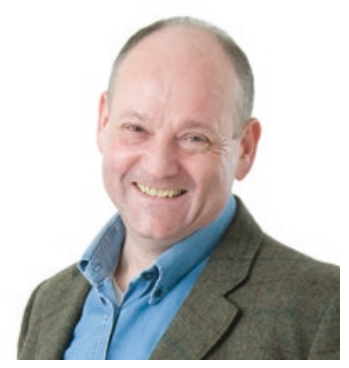

Russell Foster

Sleep and Circadian Neuroscience Institute, Nuffield Department of

Clinical Neurosciences,

University of Oxford, UK

\section{In adapting this well-known saying to suit our purposes, we haven't entirely used poetic licence. How many times have you heard people commenting that, given the option, their teenage offspring routinely stay up late at night and then have a long lie-in the next day? Sometimes this is put down to laziness or an individual's transition from childhood into 'Kevin the Teenager'. However, there are biological reasons which help explain why teenagers have a tendency to be late to bed and late to rise, and why they might not actually be getting enough sleep to make them healthy, wealthy and wise.}

Sleep matters. A wealth of evidence supports the importance of sleep for our physical, cognitive and emotional functioning. For example, insufficient sleep has been linked with impairments in attention, creativity, memory consolidation and academic performance. It has also been associated with behaviour problems, increased impulsivity and difficulties with mood regulation (Table 1). We are therefore interested in the characteristics of teenage sleep, and how sleep during this key stage of human development may be improved.

\section{The biology of sleep}

In order to understand the bioregulation of teenage sleep patterns, you first need to know about the drivers of sleep. Borbély proposed the two-process model of sleep in 1982, which has since become the most widely used model. Sleep is explained as driven by two processes working in tandem: the circadian rhythm and the sleep/wake homeostat. A circadian rhythm is a roughly 24-hour cycle of internally-generated oscillations in physiology and behaviour. These endogenous rhythms are generated through the activation and suppression of clock genes within almost all cells throughout the body creating a cellular timing network. The 'master biological clock', the suprachiasmatic nucleus (SCN), situated in the hypothalamus, coordinates these rhythms within the peripheral cellular clocks; this network is collectively known as the 'circadian system'.

The timing of sleep and wakefulness is perhaps one of the most easily observed circadian behaviours. 'Chronotype' refers to our preferred sleep/wake timing, demonstrated by the time of day when you feel most sleepy or alert. Small changes in clock genes have been linked to a genetic basis for chronotype. A biological clock (or internal circadian period) that runs faster would mean that, left to your own devices, you would go to sleep and wake up early, colloquially known as being a 'lark'. On the other hand, a slower clock will drive the sleep/wake cycle to a later time and you would be an 'owl'.

The endogenous period of our internal clock isn't exactly 24 hours so needs to be adjusted daily through zeitgebers, or time-givers, with changes in light intensity at dawn and dusk being the principal entraining factor. The SCN 


\begin{tabular}{|c|c|c|}
\hline Emotion & Cognition & Physiology and Health \\
\hline Increased: & Impaired: & Increased risk of: \\
\hline Fluctuations in mood & Cognitive performance & Drowsiness \\
\hline Depression and psychosis & Ability to multi-task & Micro-sleeps \\
\hline Irritability & Memory & Unintended sleep \\
\hline Loss of empathy & Attention & Sensations of pain and cold \\
\hline Frustration & Concentration & Cancer \\
\hline Risk-taking and impulsivity & Communication & Metabolic abnormalities \\
\hline Stimulant use (e.g. caffeine) & Decision-making & Diabetes II \\
\hline Sedative use (e.g. alcohol) & Creativity & Cardiovascular disease \\
\hline Illegal drug use & Productivity & Reduced immunity \\
\hline Dissociated mental processing & Motor performance & Altered endocrine function \\
\hline \multicolumn{3}{|c|}{$\begin{array}{l}\text { Table 1. Summary of the negative impact of sleep and circadian rhythm disruption on emotion, cognition, physiology and health. Note that } \\
\text { short-term sleep disruption can have a big impact upon emotion and cognition, whereas, longer-term sleep and circadian rhythm disruption } \\
\text { (years) as experienced by some shift workers has been shown to increase the risk of several diseases including cancer and cardiovascular } \\
\text { disease (Foster and Kreitzman, 2017). }\end{array}$} \\
\hline
\end{tabular}

receives light signals via a direct pathway from specialised photoreceptors in the eye (photosensitive retinal ganglion cells) which are most sensitive to blue light (Foster and Kreitzman, 2017). A reduction in brightness at dusk triggers the production of melatonin (the 'vampire hormone'!) in the pineal gland, via the SCN. Although not a sleep-inducing hormone, melatonin serves as a cue for rest in humans, with levels increasing as we approach sleep and remaining high during the course of the night. In contrast, with dawn light, the SCN tells us it is time to be awake and melatonin levels are suppressed. The circadian clock responds differently to light depending on the timing of exposure, so that morning light advances the clock (making us get up earlier) and evening light delays the clock (making us get up later the next day) (Foster and Kreitzman, 2017). As well as playing a role in sleep regulation via the circadian system, light affects how alert you feel. You may have noticed that bright light increases your alertness, and so relatively bright light before bedtime will increase the likelihood that you will feel sleepier later that night than you might have done otherwise.

\section{The second sleep system involves a} homeostatic process. Put simply, the longer you have been awake, the greater the need for sleep will become. The homeostatic drive for sleep seems to be due to the build-up of various neurochemicals, for example adenosine, which increases while we are awake as a consequence of energy (adenosine triphosphate; ATP) use in the brain. Adenosine inhibits wake-promoting neurons in the basal forebrain and stimulates sleep-promoting neurons in the hypothalamus. As we sleep, adenosine is cleared and sleep pressure reduces.

The timing of sleep involves both of these systems as we would feel very sleepy midafternoon due to increasing homeostatic sleep pressure if it were not for an opposing circadian drive for wakefulness. Sleep occurs when the circadian drive for wakefulness ends and the homeostatic drive for sleep kicks in. Then, when the 'sleep debt' you have accumulated during the day has been re-paid, with an accompanying reduction in sleep pressure, and the circadian drive for wakefulness is sufficiently strong, we wake up.

\section{Shedding light on teenage sleep}

Biological, psychological and socio-cultural influences all play a part in the diminished sleep seen during adolescence (Carskadon, 2011). Teenagers are known to fall asleep and wake up at increasingly later times throughout this developmental period (Gradisar, Gardner and Dohnt, 2011). A tendency for a further delay to bedtimes at the weekend and a much later weekend wake time results in a widening disparity between the amount of sleep obtained on a school night compared with the weekend (Carskadon, 2011). Sleep requirements differ throughout the life cycle as well as from person to person. In 2015 , the National Sleep Foundation recommended that teenagers, aged 14 to 17 years, should be getting eight to 10 hours' sleep a night.
'There are biological reasons which help explain why teenagers have a tendency to be late to bed and late to rise, and why they might not actually be getting enough sleep to make them healthy, wealthy and wise' 
A review of studies across much of the globe concluded that teenagers are routinely not getting enough sleep, older adolescents obtain less sleep, and daytime sleepiness, a consequence of insufficient sleep, is prevalent in many countries (Gradisar, Gardner and Dohnt, 2011).

\section{Sleep biology during the teenage years}

\section{'A review of studies} across much of the globe concluded that teenagers are routinely not getting enough sleep, older adolescents obtain less sleep, and daytime sleepiness, a consequence of insufficient sleep, is prevalent in many countries'
A developmental change in the two sleep processes occurs in adolescence. Sleep duration shortens drastically (by almost 2 hours) from the age of 10 to 17 (Fig. 1). Biological chronotype not only changes with age but also shows gender differences, delaying markedly through adolescence, as well as following the general pattern of females developing earlier than males, reaching its maximum at about 19.5 years in women and 21 years in men (Roenneberg et al., 2004). After this, chronotype advances so that the elderly have early sleep timing similar to children.

The circadian delay at puberty isn't just confined to humans but has been found in a number of mammalian species, with a one to three hours' delay in circadian phase in humans (Hagenauer, Perryman, Lee and Carskadon, 2009). This means that teenagers are biologically predisposed to going to bed late and getting up late. On a school night, teenagers may struggle to sleep at an early bedtime but they also need to wake up in time for lessons, which contributes to a reduction in total sleep time.

A couple of mechanisms have been suggested as the explanation for this shift in teenage circadian timing. The biological clock has been proposed to run more slowly at this age so adolescents have a longer circadian period. Alternatively, the SCN may have an altered sensitivity to light depending on whether it is dusk or dawn. Teens may experience a greater delaying effect of evening light yet a reduced advancing effect of morning light (Carskadon, 2011).

Sleep timing is also considered to be influenced by alterations to the sleep/wake homeostatic system. Sleep homeostatic pressure is thought to accumulate more slowly during adolescence than childhood, so the pressure to sleep builds up more slowly during the day (Carskadon, 2011). This helps to explain why a teenager is able to stay awake for longer than they could when they were a child.

\section{Social jetlag}

We know what jetlag feels like when we travel across time zones and how our internal time takes a while to adjust to the new external time. Teenagers experience something similar with 'social jetlag', when their internal time (chronotype) is misaligned with social time (school commitments), demonstrated by the disparity between sleeping in accordance with chronotype (weekend sleep) and sleep during the school week. Social jetlag isn't confined to the teenage years but it is most pronounced in this age group. At the weekend, when a teenager is more likely to be able to go to bed and wake at their desired time (their chronotype), their bedtimes and wake times are slightly more than two hours' later than during the school week (Gradisar, Gardner and Dohnt, 2011).

\section{Psycho-social factors and sleep hygiene}

Psycho-social factors interact with the bioregulation of sleep. Teenagers may be engaging in behaviours that are not conducive to routinely sleeping well. Improving sleep hygiene, the habits and practices that impact sleep, may help to minimise social jetlag and the delayed sleep intrinsic to adolescent sleep/wake timing. A couple of examples are described below which may have particular relevance for the teenage years.

The effect of light exposure on sleep has received increasing attention with the proliferation of electronic device use in recent years. However, the results are mixed. One study on young adults asked individuals to read an e-book at maximum intensity under dim room light for around 4 hours (18.0022.00h) before bedtime on five consecutive evenings, whilst the control group read a printed book. The study concluded that those that read the e-book took longer to fall asleep, had lower morning alertness and a delay of the circadian clock compared with reading a printed book, but the effects were relatively small. Those participants who read e-books took only 10 minutes longer to fall asleep (Chang et al., 2015). As a result, some caution needs to be exercised when the press reports 'reading an e-book in the hours before bedtime has unintended biological consequences that may adversely impact performance, health, and safety' (Foster and Kreitzman, 2017).

Nevertheless, the impact of using electronic devices prior to sleep does seem to be important. In a large US survey, adolescents were shown to have increased the time spent using electronic media devices from 2009 to 2015. This was correlated with a decline in sleep duration (Twenge et al., 2017), and light from such devices has been blamed. Such studies have encouraged the use of in-built/downloadable applications that can dim the brightness of screens and/or reduce the light emitted. Light interventions are now being considered as a tool for adolescents experiencing difficulties with sleep, including reducing their exposure to evening light and increasing morning light to advance the clock to a time more suited for school. Unfortunately, the evidence showing that 


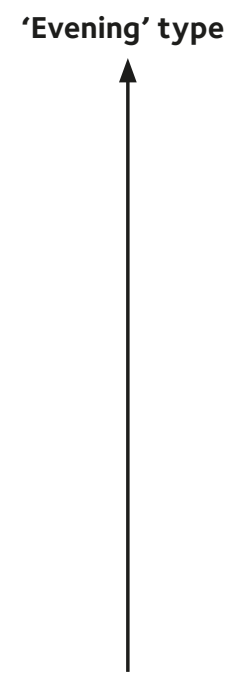

‘Morning' type

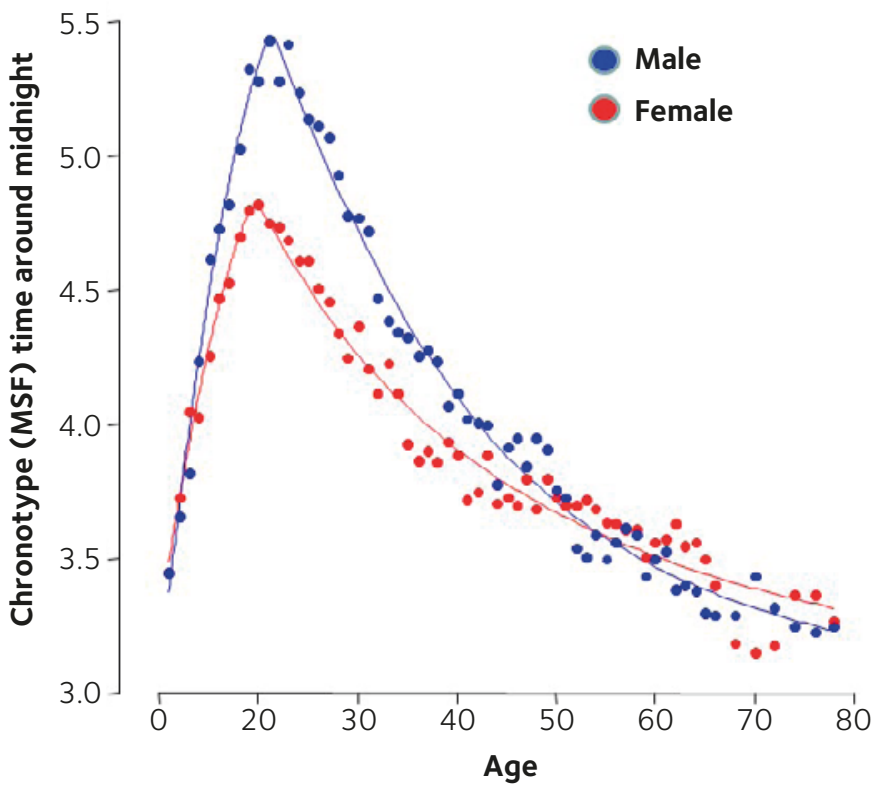

Figure 1. Age-dependent changes of chronotype are different for males and females. The reference point to assign chronotype is based on the midpoint of sleep on free days (MSF, i.e. sleep without social obligations corrected for 'oversleep' on free days). Interestingly, the general tendency of females to develop earlier than males is seen in chronotype, where young women are already more delayed than young men, and women reach their maximum in lateness earlier (19.5 y). Men continue to delay their sleep until around the age of 21 (20.9 y) and are, on average, later chronotypes for most of their adulthood. This sex (and/ or gender) difference disappears at around the age of 50, which coincides with the average age of menopause. Redrawn after Roenneberg et al., 2004.

such interventions can be helpful is lacking. Furthermore, it is important to stress that game use, social media and watching TV are all likely to be cognitively arousing so teens may simply feel like staying up when they use electronic media devices. As a result, disentangling the light effects versus the alerting effects of devices is complex and awaits good experimental studies.

Caffeine is a stimulant with a half-life of approximately six hours in healthy adults. Caffeine blocks adenosine receptors in the brain, masking the build-up of homeostatic sleep pressure and consequently promoting wakefulness. Consuming caffeine later in the evening or excessive consumption may be another contributory factor to delayed sleep, and highly-caffeinated energy drinks are popular with teenagers. Correspondingly, the National Sleep Foundation 2006 'Sleep in America' poll found that adolescents who drank two or more caffeinated beverages each day were more likely to have insufficient sleep on school nights and think they have a sleep problem, than those who drank one beverage or fewer.

\section{Conclusions}

Changes in the bioregulation of sleep predispose teenagers to experience insufficient sleep during the school week. This may be exacerbated by light exposure and sleep hygiene practices that impact sleep. Given the importance of getting enough sleep and its links to our health and wellbeing, sleep is an area which should be prioritised. Consequently, school-based interventions are now underway that aim to improve teenage sleep. Sleep education programmes inform teenagers about the lifestyle factors that may be affecting their sleep and how they can improve sleep hygiene. There is also a movement to delay school start times to better suit the adolescent clock by giving teenagers the opportunity to sleep at hours more aligned with their chronotype. So one could suggest that 'early to bed, later to rise, may help the teen be healthy, wealthy and wise' would be a better amendment to the age-old quote for our average teenager.

\section{'Given the importance of getting enough sleep and its links to our health and wellbeing, sleep is an area which should be prioritised'}

\section{References}

Borbély AA (1982). A two process model of sleep regulation. Human neurobiology, 1(3), 195-204.

Carskadon MA (2011). Sleep in adolescents: the perfect storm. Pediatric Clinics of North America, 58(3), 637-647.

Chang AM, Aeschbach D, Duffy JF \& Czeisler CA (2015). Evening use of light-emitting eReaders negatively affects sleep, circadian timing, and next-morning alertness. Proceedings of the National Academy of Sciences, 112(4), 1232-1237.

Foster RG \& Kreitzman L (2017). Circadian Rhythms: A very short introduction. Oxford University Press, Oxford.

Gradisar M, Gardner G \& Dohnt H (2011). Recent worldwide sleep patterns and problems during adolescence: a review and meta-analysis of age, region, and sleep. Sleep medicine, 12(2), 110-118.

Hagenauer MH, Perryman JI, Lee TM \& Carskadon MA (2009). Adolescent changes in the homeostatic and circadian regulation of sleep. Developmental neuroscience, 31(4), 276-284.

Roenneberg T, Kuehnle T, Pramstaller PP, Ricken J, Havel M, Guth A \& Merrow M (2004). A marker for the end of adolescence. Current Biology, 14(24), R1038-R1039.

Twenge JM, Krizan Z \& Hisler G (2017). Decreases in self-reported sleep duration among US adolescents 2009-2015 and association with new media screen time. Sleep medicine, 39, 47-53. 


\title{
Future directions in cardiac and respiratory physiology
}

\author{
A Theme Leads' report
}

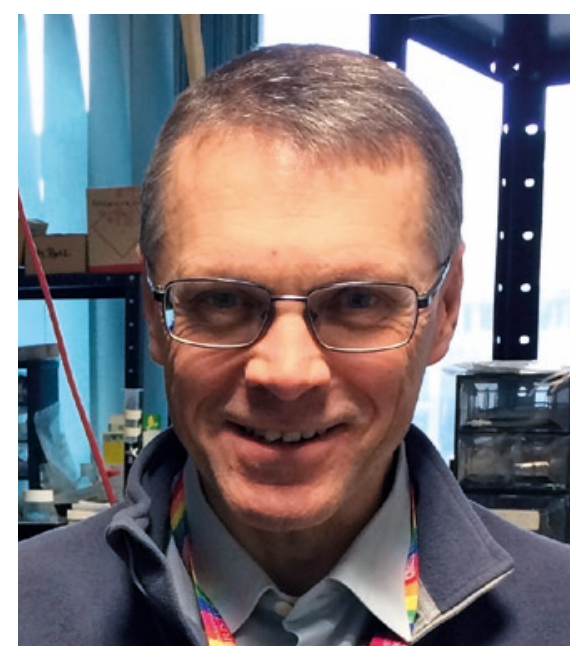

Andrew F. James

University of Bristol, UK

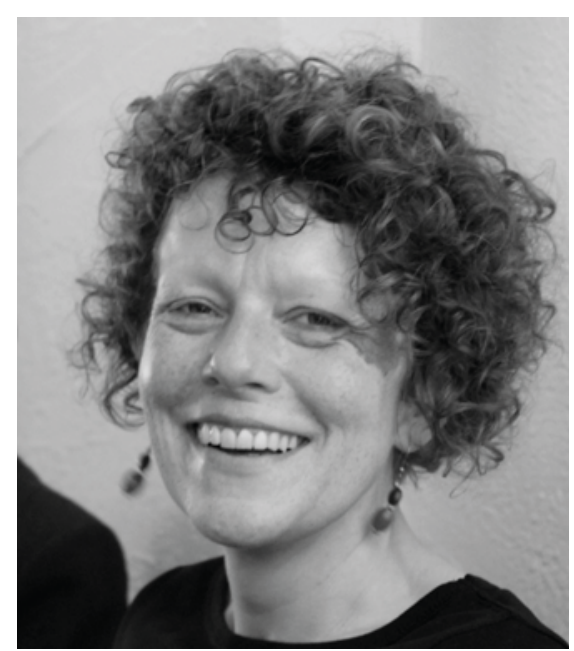

Sarah Calaghan

University of Leeds, UK

The membership of the Cardiac and Respiratory Physiology Theme (417 Full and 1137 other Members of The Society in 2018) encompasses an enormously diverse range of interests and experimental approaches in cardio-respiratory physiology, from cellular through organ level to in vivo function. We have not attempted to identify all abstracts in this area over the last two years but have found a total of 238 communications describing work relevant to this theme (www.physoc.org/proceedings). They are classified on the website in categories which emphasise the breadth and depth of activity of the Theme, for example: 'Cardiovascular, Respiratory and Autonomic Control', 'Heart \& Cardiac Muscle', 'Respiratory Physiology' and 'Ion Channels'.

According to the World Health Organization (https://www.who.int/), cardiac and respiratory diseases remain the leading causes of death globally. Disease-focused research that may open novel therapeutic avenues for relatively large numbers of people can readily be justified to funding organisations. In terms of heart disease, death rates are falling in many developed countries, presumably because of improved healthcare arising from a better understanding of the disease process. For example, within the UK, deaths from heart disease in England and Wales have halved since 2001 and Alzheimer's disease and dementia are now the leading causes of death (Patel, 2017).

This remarkable change in less than two decades likely reflects a range of factors, including a real fall in deaths attributable to heart disease per se, but also changes to the classification of causes of death (Patel, 2017). However, as shown in figures recently reported by the British Heart Foundation (https://www.bhf.org.uk/research/heart- statistics), recent improvements in acute treatment and therefore survival for major cardiovascular events (e.g. myocardial infarction), combined with increased longevity, means that the number of people living with heart failure is showing an upward trend. Overall, cardiac and respiratory disease remains a major contributor to the global burden of disease.

There are many avenues for future research within this theme to be explored, employing the vast array of techniques available to the $21^{\text {st }}$ century physiologist. Here we have chosen to highlight recent advances in imaging and gene editing technologies which are fuelling major developments in the cardiac and respiratory fields.

In order to fully understand normal physiology and the impact of disease, we need to be able to describe cellular structures on a nanoscale, and advances in microscopy techniques are making this possible. For example, 3D electron 


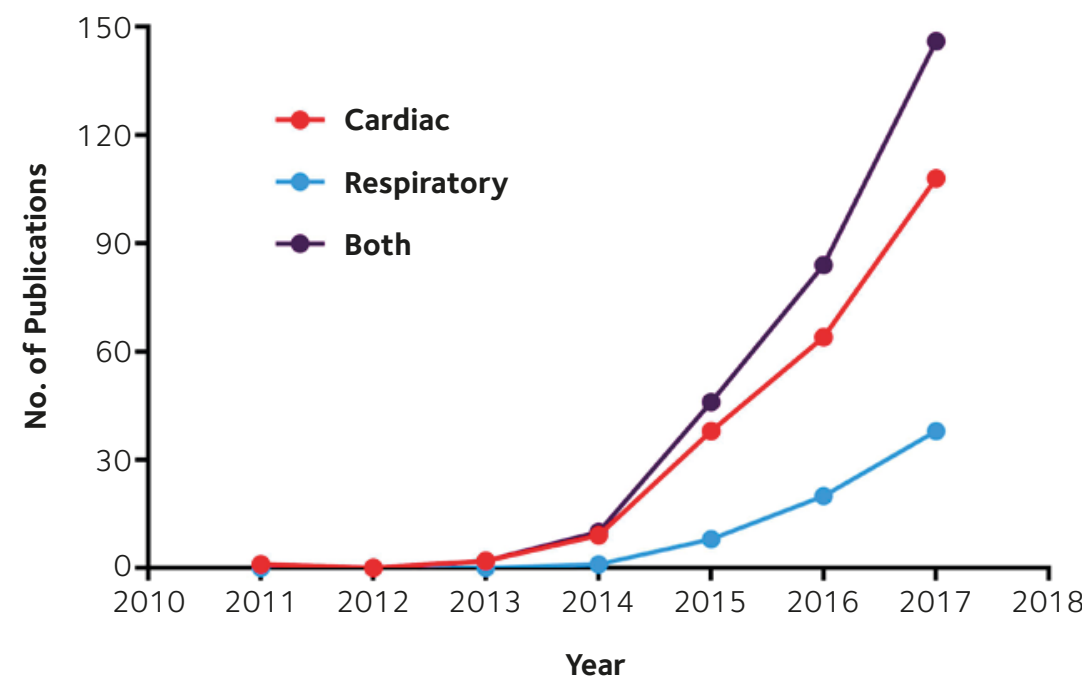

Figure 1. Publications per year using PubMed search terms, 'CRISPR' AND 'Cardiac/ Respiratory'. Date of search: 01/02/2018.

'Here we have chosen to highlight recent advances in imaging and gene editing technologies which are fuelling major developments in the cardiac and respiratory fields'

\section{References}

block-face scanning) allow visualisation of complex cellular structures such as the cardiac myocyte t-tubules, invaginations of the sarcolemma that play a central role in excitation-contraction coupling in the heart (e.g. Pinali et al., 2017). Single molecule localisation microscopies such as dSTORM and DNA-PAINT (which uses hybridisation of DNA oligonucleotides to localise protein targets) can provide true molecular-scale resolution of proteins such as the ryanodine receptor (Jayasinghe et al., 2018). For more about these techniques, see Carl Harrison's article on p. 36 of this issue. The ability to directly correlate nano-anatomy with aspects of myocyte function will prove invaluable in understanding the process of cardiac disease.

This year will mark the $15^{\text {th }}$ anniversary of the announcement of the sequencing of the human genome. While this important milestone triggered a flurry of studies investigating the links between genomic variation and human disease through genome-wide association studies, in many cases, the physiological mechanisms linking the observed variation with disease remain unclear. A major step forward in this field may come from the UK-based '100,000 Genomes Project' which started in 2012; this ground-breaking enterprise combines medical data with genomic sequences in 70,000 individuals, permitting links to be made between the genome and disease.

Gene editing allows the precise targeting of genes in a range of species and has generated a wealth of information over the last three decades regarding gene function. A fuller introduction to the topic is available in an excellent review by Patrick Harrison (UC Cork) and Stephen Hart (UCL, London) published very recently in Experimental Physiology (Harrison \& Hart, 2018). New gene editing technologies, particularly CRISPR/Cas9, have given recent impetus to research (Fig. 1). In the cardiac and respiratory fields, gene editing is used in rodents and human inducible pluripotent stem cells (hiPSC) to create models and treatment for diseases which are both genetic (long QT syndrome, cystic fibrosis) and multi-factorial (heart failure, chronic obstructive pulmonary disease). However, these approaches are limited by the translational relevance of rodents to humans, and the need to work in the in vitro setting with hiPSCs. This has stimulated the use of genome engineering in species of translational relevance to the human, such as the pig (Yao et al., 2016). These approaches are likely to be valuable in understanding the mechanisms of both common, multifactorial diseases and rare, inherited diseases. To those of us based in the UK, it is encouraging that the British Heart Foundation, a major supporter of cardiovascular research, has emphasised the importance of targeting both common and rare diseases in their research strategy.

As researchers, we may worry what the future holds in terms of funding and our personal financial security, particularly in the UK with uncertainties over Brexit and university pensions. However, in terms of available technologies, there has never been a more exciting time to be a cardiac or respiratory physiologist.
Harrison PT \& Hart S (2018). A beginner's guide to gene editing. Exp Physiol in press. DOI: 10.1113/ EP086047

Jayasinghe et al., (2018). True molecular scale visualization of variable clustering properties of ryanodine receptors. Cell Rep, 2(2), 557-567. DOI: 10.1016/j.celrep.2017.12.045

Patel V (2017). Deaths registered in England and Wales (series DR): 2016. Statistics OfN, London. bit.ly/2GNakGG

Pinali C et al., (2017). Post-myocardial infarction T-tubules form enlarged branched structures with dysregulation of Junctophilin-2 and Bridging Integrator 1 (BIN-1). J Am Heart Assoc, 6. DOI: 10.1161/jaha.116.004834

Yao J, Huang J \& Zhao J (2016). Genome editing revolutionize the creation of genetically modified pigs for modeling human diseases. Hum Genet, 135 1093-1105. DOI: 10.1007/s00439-016-1710-6 


\title{
Alveolar ventilation-perfusion ratios and pulmonary gas exchange: 100 years since recognition
}

\author{
A debate about physiological measurement provides insight into a \\ practical problem
}

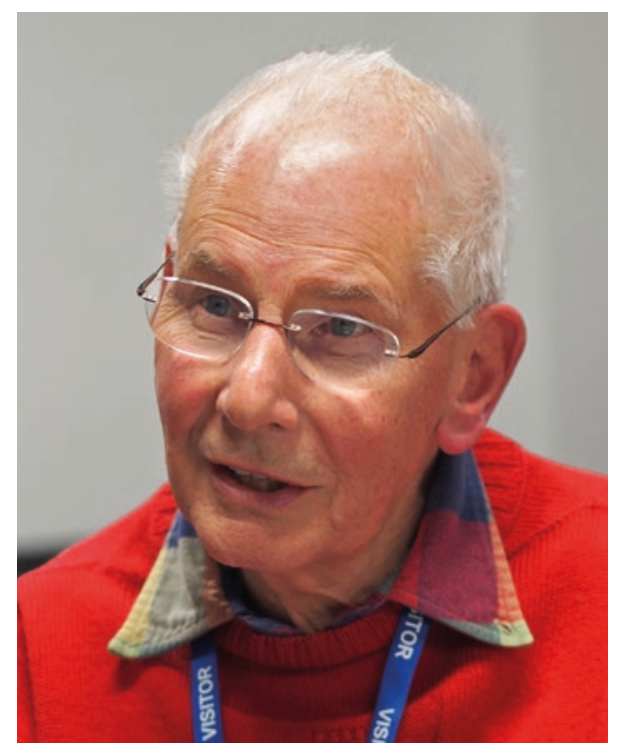

\section{CG Michel}

Department of Bioengineering, Imperial College London, UK
Large differences in the ratio of alveolar ventilation to alveolar capillary blood flow, $V_{A} / Q_{C}$, in different regions of the lungs have been recognised as a principal cause of hypoxaemia in respiratory disease since the 1950s. The concept was first suggested in a paper published in the 1918/1919 volume of The Journal of Physiology to account for the crippling breathlessness suffered by the soldiers who had survived gas attacks in the First World War. The importance of the ratio, $V_{A} / Q_{C}$, in pulmonary gas exchange did not appear in this paper de novo but emerged in two papers, published by physiologists in 1915 and 1917, concerned with the volume of the respiratory dead space.

The author of the 1915 paper was John Scott Haldane (Fig. 1A) and he was also senior author with JC Meakins and JG Priestley of the 1918/1919 paper. At the time, Haldane was a Fellow of New College, Oxford, and was well-known, not only for developing new methods of gas and blood analysis and for his researches in respiratory physiology but also for his success in solving a range of practical problems arising in clinical medicine, in coal mines and from the Royal Navy's concerns for the survival of submariners and divers.

The Danish authors of the 1917 paper were August Krogh and Johannes Lindhard (Fig. 1B). Lindhard was a lecturer in the Theory of Gymnastics at the University of Copenhagen where Krogh had recently been promoted to be Professor of Zoophysiology. Krogh had earlier worked with Christian Bohr, Professor of Physiology in Copenhagen, and carried out most of the experimental work for Bohr's most famous paper on the $\mathrm{O}_{2}$ dissociation curve. In 1910, he had published seven papers, some with his wife Marie Krogh, providing the strongest evidence for believing that the uptake of $\mathrm{O}_{2}$ in the lungs occurred by diffusion alone. For this and his later work on $\mathrm{O}_{2}$ exchange in muscle capillaries, he was awarded the Nobel Prize in 1920.

First suggestion that non-uniformity of $V_{A} / Q$ might be important

The 1915 and the 1917 papers were part of a series, published in The Journal of Physiology and The American Journal of Physiology between 1912 and 1917, debating whether the volume of the airways where no gas exchange occurs, the respiratory dead space, $V_{D}$, increased significantly with increased tidal volume $\left(V_{T}\right)$ and total ventilation: Haldane and his colleagues believed that it did; Krogh and Lindhard, that it did not. Both groups agreed that expired air was a mixture of gas from the alveoli (which, at the outset of the debate was believed to have a uniform composition) and a smaller volume of inspired air from the conducting tubes of the lungs and pharynx, the respiratory dead space, which had not been involved in gas exchange. The tidal volume, the composition of the alveolar air, the expired air and the inspired air could all be measured. The dead space volume was 

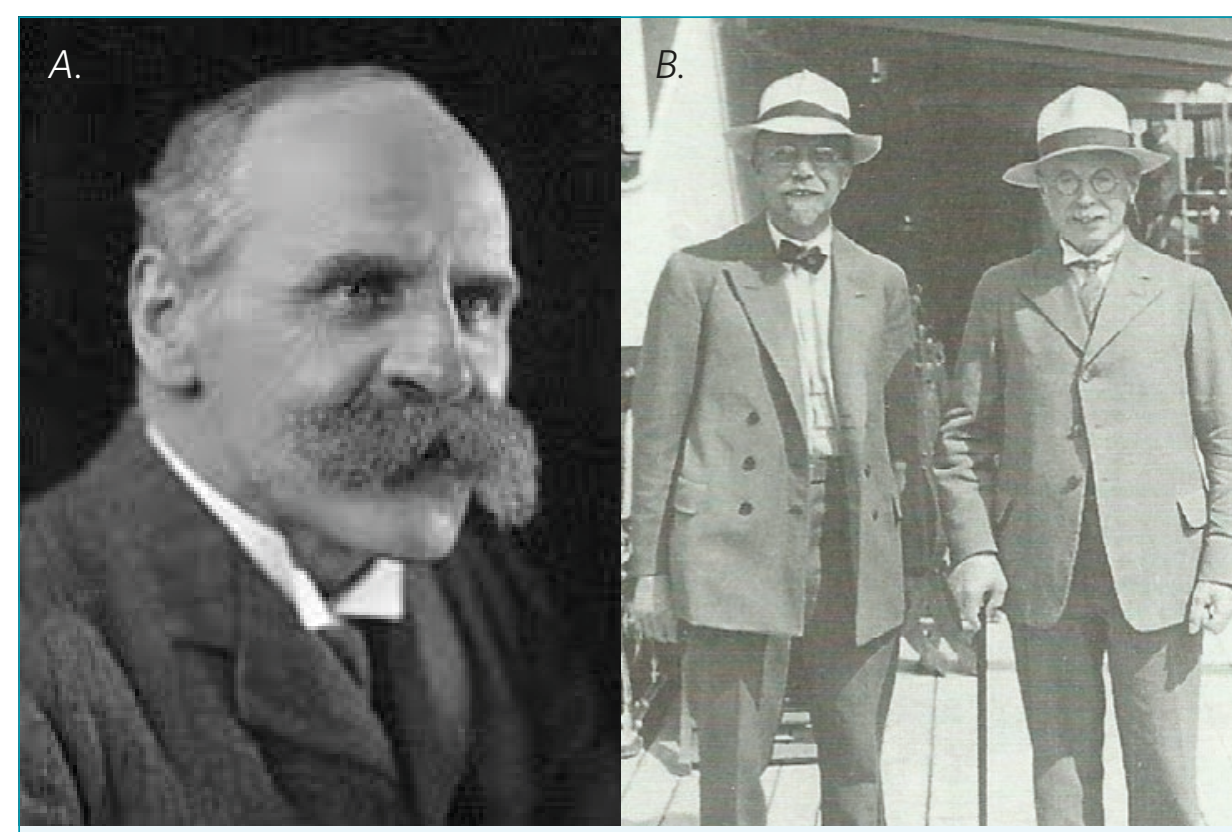

Figure 1. A. John Scott Haldane B. August Krogh \& Johannes Lindhard. Photos used with the permission of the American Physiological Society.
'In 1915, Haldane was removed from all official committees after the Daily Mail had accused his brother of German sympathies' calculated as that volume of inspired air that was necessary to dilute the alveolar gas so that the concentrations of $\mathrm{CO}_{2}$ and/ or $\mathrm{O}_{2}$ would equal those in the expired air. Earlier, Haldane and Priestley had shown that in healthy resting subjects, the fractional concentrations of $\mathrm{CO}_{2}, \mathrm{O}_{2}$ and $\mathrm{N}_{2}$ in alveolar air could be measured in samples taken at the end of a forced expiration. The technique was widely accepted but Krogh and Lindhard (quite correctly) questioned its use in exercising subjects when gas exchange rates were greatly increased with metabolic rate.

Haldane's 1915 paper reported experiments on himself sitting at rest. He had breathed in time to a metronome at different frequencies and allowed his tidal volume to find its most comfortable value. He found not only that $V_{D}$ increased with $V_{T}$ but that when $V_{D}$ was calculated from the $\mathrm{O}_{2}$ concentrations in the alveolar and expired air, it had a larger value than when calculated from $\mathrm{CO}_{2}$ concentrations. To account for this, Haldane argued that $V_{D}$ was a functional as well as an anatomical volume. He cited descriptions of the terminal airway by Miller (1893) who had reported that the walls of the terminal conducting components, the atria, which led into the alveoli, had a similar fine structure to the alveoli. Haldane believed the atria were sites of gas exchange and that they would be better ventilated than the alveoli. Therefore, he argued, that just as the respiratory exchange ratio, $R$, was raised for both lungs during voluntary hyperventilation, hyperventilation of the atria would 'extract much extra $\mathrm{CO}_{2}$ from the blood but cannot impart $\mathrm{O}_{2}$ to it' and have a permanently high $R$. The overall value of $R$ for the lungs, however, had to reflect $R$ of the body's metabolism and, to compensate for the hyperventilated atria, some alveoli would be hypoventilated. Without being explicit, Haldane concluded that the larger $V_{D}$ for $\mathrm{O}_{2}$ than for $\mathrm{CO}_{2}$ resulted from the smaller volume of $\mathrm{O}_{2}$ that the air 'can impart' to the blood. Despite the lack of clarity, this paper is the first suggesting that the composition of the alveolar gas might vary in different parts of the lungs.

Krogh and Lindhard (1917) acknowledged that they had previously assumed that alveolar $\mathrm{PO}_{2}$ and $\mathrm{PCO}_{2}$ were the same in all alveoli. They pointed out that, if different parts of the lungs were less well-ventilated than others, differences in composition would occur in both $\mathrm{O}_{2}$ and $\mathrm{CO}_{2}$ and 'other gases in special mixing operations' adding 'unless indeed the circulation through each lobe should be in proportion to the ventilation'. As West (2004) has pointed out, this proviso suggests that they really understood the general consequence of averaging flows of different composition upon the alveolar-arterial $(A-a) \mathrm{PO}_{2}$ and $\mathrm{PCO}_{2}$ differences. Krogh and Lindhard recognised that the mean fractional concentration of gas derived from many alveoli with different ventilations should be calculated as the sum of the product of ventilation and the fractional concentration of the gas in each alveolus divided by the sum of ventilations of each alveolus.

This correct average revealed that overventilated alveoli made a greater contribution to the composition of the alveolar gas than their numbers in the alveolar population. Similarly, the over-perfused, under-ventilated alveoli made a greater than average contribution to the composition of the mixed arterial blood. When calculated correctly, non-uniformity of $V_{A} / Q_{C}$ affects the overall alveolar-arterial difference for all gases.
Haldane did not see this general consequence of $V_{A} / Q$ variation. He did, however, recognise a second effect, which arises from the curvature of the oxygen dissociation curve and increases the $\mathrm{A}$-a difference for $\mathrm{PO}_{2}$. This effect was explained clearly in his 1918/1919 paper with Meakins and Priestley where the authors identified large variations in $V_{A} / Q_{C}$ as a cause of systemic hypoxia.

\section{Hypoxaemia in survivors of gas warfare}

After poisonous gas was first used as a weapon in World War 1, Haldane was asked by the British government how the Allied troops might be protected in gas warfare. Subsequently, he designed the first effective gas mask but its introduction was delayed largely because in 1915, Haldane was removed from all official committees. This occurred immediately after his politician brother, Lord Richard Haldane, had been forced to resign from the Cabinet after the Daily Mail had accused him of German sympathies. It seems that several years before the war, Richard Haldane had written praising German Universities (he had studied at Göttingen in the 1880s).

John Haldane's restoration as an advisor started informally (Goodman, 2007). In 1917, a Canadian medical officer, JC Meakins, who was caring for survivors of gas warfare, sought advice from fellow-Canadian, Sir William Osler, then Regius Professor of Medicine in Oxford. Osler arranged for Haldane to visit Meakins at the Canadian Military Hospital at Taplow, outside Reading. Very soon, Haldane and Meakins were collaborating on an experimental programme and were joined by Haldane's former colleague, JG Priestley, who was a medical 
Kymograph recording

tidal volume and

respiratory frequency

Adjustable inspiratory reservoir

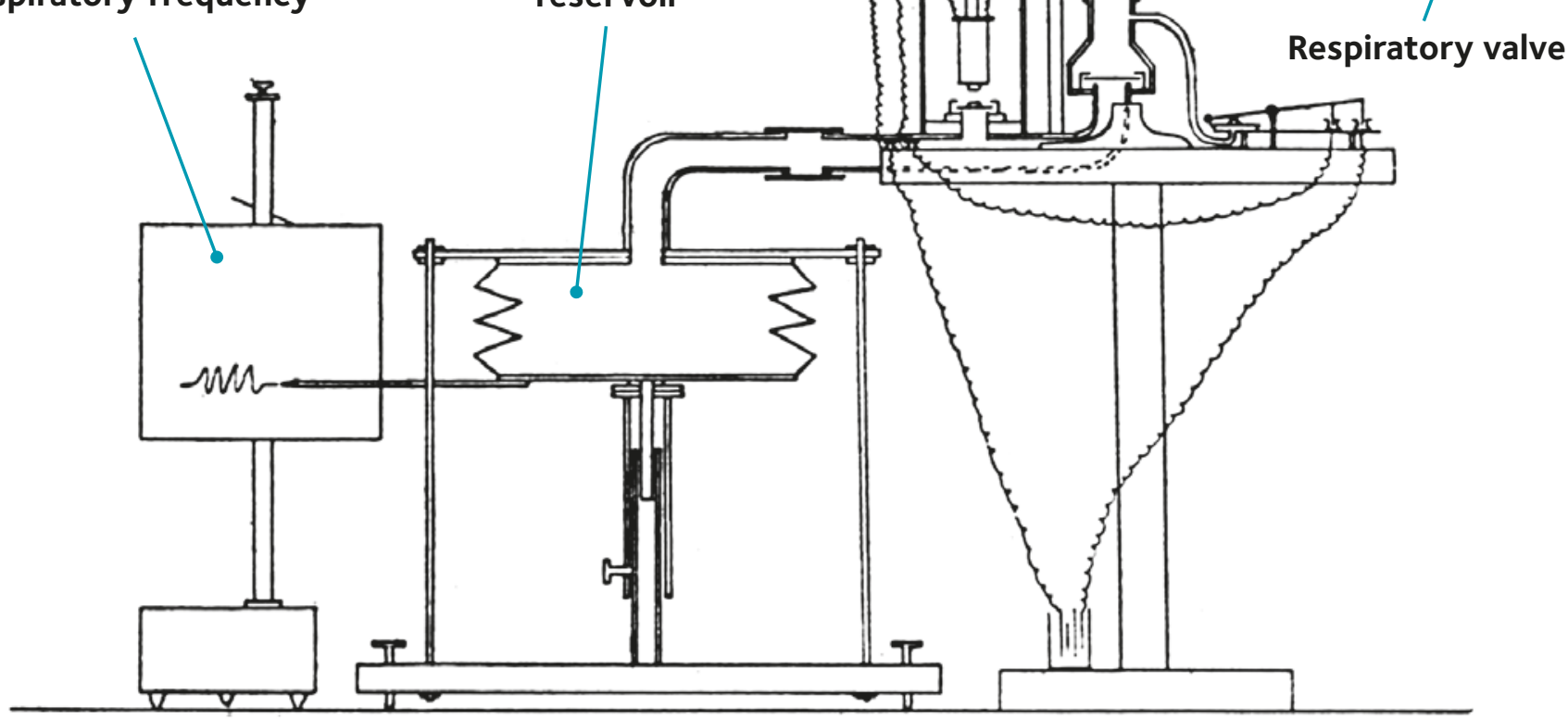

Figure 2. Apparatus used by Haldane, Meakins \& Priestley to investigate the effects of restricting the inspired volume of a subject.

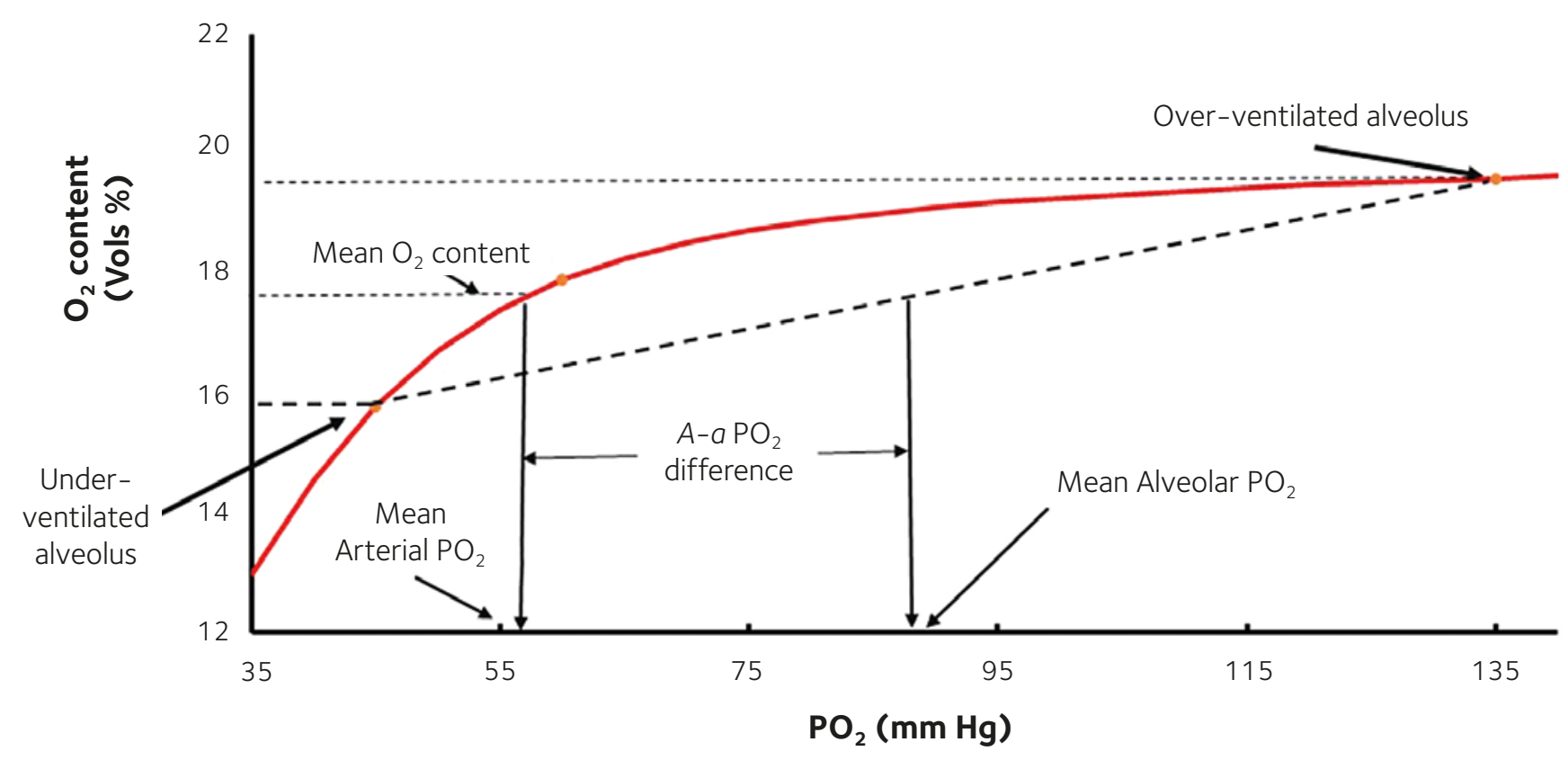

Figure 3. Haldanes's concept of how mean values of $\mathrm{PO}_{2}$ in the alveolar air could be considerably greater than the mean $\mathrm{PO}_{2}$ in arterial blood, in spite of complete equilibration between blood and gas phases in the alveoli. The red curve represents the upper part of the $\mathrm{O}_{2}$ dissociation curve of blood. Equal volumes of gas and blood from an over-ventilated alveolus $\left(\mathrm{PO}_{2}=135 \mathrm{~mm} \mathrm{Hg}\right)$ and an under-ventilated alveolus $\left(\mathrm{PO}_{2}=45 \mathrm{~mm} \mathrm{Hg}\right)$ are mixed, resulting in a mean value of $\mathrm{PO}_{2}$ in the gas of $90 \mathrm{~mm} \mathrm{Hg}$ and a mean $\mathrm{PO}_{2}$ in the blood of $58 \mathrm{~mm} \mathrm{Hg}$. 
officer in the Royal Army Medical Corps. Meakins' patients were breathless and their rapid shallow breathing limited their exercise capacity so severely that their condition was described as 'effort syndrome'. They had raised numbers of circulating red cells and their symptoms were relieved by breathing oxygen, indicating they were hypoxic although their alveolar $\mathrm{PO}_{2}$ 's were often in the normal range. Suspecting that exposure to toxic gases had scarred the lungs, reducing their distensibility and so limiting the tidal volume $\left(V_{T}\right)$ of these patients, Haldane speculated that a reduced $V_{T}$ increased the $A-a \mathrm{PO}_{2}$ difference and hence the arterial $\mathrm{PO}_{2}$.

Haldane and his colleagues now investigated (on themselves) the effects of limiting $V_{T}$ while they could adjust their frequency of breathing. Using the apparatus shown in Fig. 2, they breathed through respiratory valves, inspiring from a concertinalike reservoir, whose volume could be adjusted. The recordings of inspired volume and frequency were supplemented by measurements of alveolar and expired gases at the start and end of each experiment. They found that as inspired volume was reduced, respiratory frequency rose with the subject feeling increasingly uncomfortable until, with tidal volumes of less than $150 \mathrm{ml}$ and frequencies of 100 per minute or more, the experiment had to be stopped.

Haldane argued that if different parts of the lung opened sequentially during inspiration, then some areas of the lungs would be ventilated better than others during each respiratory cycle and these differences would be accentuated when $V_{T}$ was restricted. If a volume of gas from a well-ventilated area were mixed with an equal volume of gas from a poorly ventilated area, the mean $\mathrm{PO}_{2}$ of the mixture would equal the mean of the $\mathrm{PO}_{2}$ 's in the two regions of the lungs. For equal volumes of blood leaving the two regions of the lungs and mixing in the pulmonary veins, the situation was different. The mixture would have an $\mathrm{O}_{2}$ content equal to the mean oxygen content of its components, but its $\mathrm{PO}_{2}$ would be determined by the oxygen dissociation curve of blood. Haldane explained that because the slope of the oxygen dissociation curve becomes less steep as $\mathrm{PO}_{2}$ rises between its value in mixed venous blood and its value in the inspired air, the mean arterial $\mathrm{PO}_{2}$ is disproportionately weighted by the blood passing through the under-ventilated alveoli. In this way, the mean $\mathrm{PO}_{2}$ of the arterial blood could be considerably below that in the mean alveolar air (see Fig. 3). Haldane argued that the resulting $\mathrm{A}-\mathrm{a} \mathrm{PO}_{2}$ difference would be greatly increased in soldiers suffering from the chronic effects of gas poisoning and this accounted for their hypoxaemia.
Haldane's explanation for the chronic breathlessness of the surviving soldiers did not lead to a cure for them but their symptoms could be relieved by breathing oxygen. Haldane had earlier recommended the use of $\mathrm{O}_{2}$ in the management of patients with pneumonia and designed a simple apparatus for delivering a mixture of $\mathrm{O}_{2}$ and room air to these patients. He was also one of the first to recognise the complications of breathing pure $\mathrm{O}_{2}$ for any prolonged period.

Haldane's conclusion that uneven ventilation of the lungs could lead to severe hypoxia followed directly from his thinking in his 1915 paper on the respiratory dead space. Here he suggested that differences in ventilation of different areas of the lungs accounted for the difference in $V_{D}$ for $\mathrm{O}_{2}$ and $\mathrm{CO}_{2}$. Although not explicit, his statement that increased ventilation could 'extract much extra $\mathrm{CO}_{2}$ from the blood but cannot impart $\mathrm{O}_{2}$ to it' indicates he was thinking about the differences in the $\mathrm{O}_{2}$ and $\mathrm{CO}_{2}$ dissociation curves which were the basis of his explanation of how uneven ventilation led to hypoxia in surviving gassed soldiers. The academic debate about $V_{D}$ measurement had sharpened Haldane's insight when he faced a clinical problem. Also, Haldane believed his conclusions were of general importance, giving a full account of his paper with Meakins and Priestley in the chapter on 'The causes of anoxaemia' in both editions of his monograph on 'Respiration'. Only after the Second World War and 10 years after Haldane's death, however, was the importance of $V_{A} / Q_{C}$ generally recognised. This story and later investigations on pulmonary gas exchange have been well reviewed by West (2004)

\section{Acknowledgements}

I thank R Maynard, R Michel, G Clough and FE Curry for their helpful comments on earlier drafts of this article.

\section{Glossary}

$V_{A}$ - Alveolar ventilation: volume of inspired gas entering (or exchanging with) the alveolar gas per unit time.

$Q_{c}$-Alveolar capillary blood flow.

$V_{D}$-Volume of respiratory dead space: volume of inspired gas filling the conducting tubes of the lungs at the end of inspiration, remaining unchanged in composition (apart from water vapour) since it is not involved in pulmonary gas exchange.

$R$ - Respiratory exchange ratio: the ratio of the mass of $\mathrm{CO}_{2}$ eliminated divided by the mass of $\mathrm{O}_{2}$ taken up by the inspired air over one or more respiratory cycles.

$\mathrm{PO}_{2}, \mathrm{PCO}_{2}$ etc. - gas partial pressures. In the gas phase this is the fraction of the total gas pressure of a gas mixture exerted by one of its components and is the product of total pressure of the mixture and the fractional concentration of the gas in the mixture (Dalton's Law). In the blood phase, partial pressure of a gas in a liquid is a measure of its potential energy and it is defined as the partial pressure of the gas in equilibrium with the liquid.

Gas content of blood - should really be the gas content per unit volume of blood. It is the total volume of a gas that can be released from a unit volume of blood (often $100 \mathrm{ml}$ when it is expressed as volumes per cent).

A-a gradient - the difference in partial pressure between the mixed alveolar gas and the arterial blood.

\section{References}

Goodman M (2007). Suffer and survive. Gas attacks, Miners' Canaries, Space suits and the Bends: The Extreme Life of Dr J.S. Haldane. Simon and Schuster. London.

Haldane JS (1915). The variations in the effective dead space in breathing. American Journal of Physiology 38, 20-28.

Haldane JS, Meakins JC \& Priestley JG (1918-1919) The effects of shallow breathing. The Journal of Physiology 52, 433-453.

Krogh A \& Lindhard J (1917). The volume of the dead space in breathing and the mixing of gases in the lungs of man. The Journal of Physiology 51, 59-90.

West JB (2004). A century of pulmonary gas exchange. Am J Resp and Crit Care Med 169(8), 897-902. 


\section{Charles Bell's 'sixth sense'}

\section{His deductions on movement and position sense}

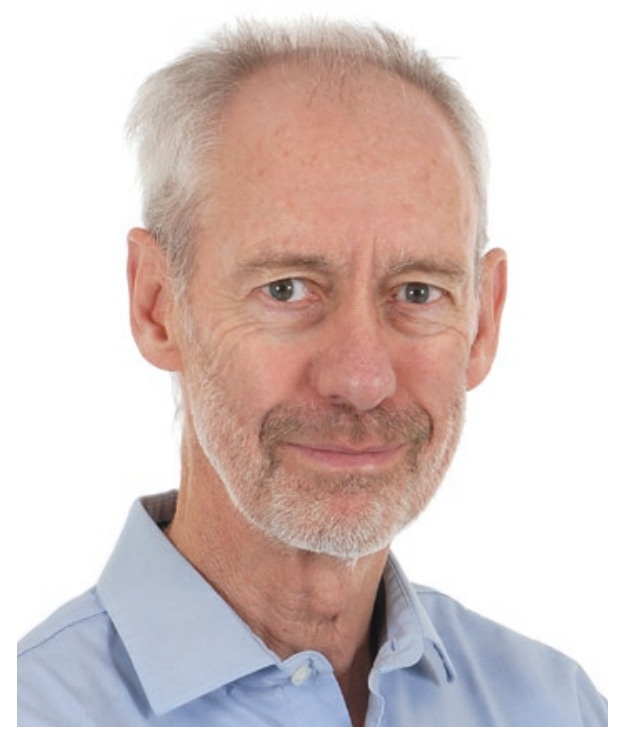

Fonathan Cole

Poole Hospital and University of Bournemouth, UK

\section{The discovery of rare human subjects with absences of discriminatory touch and proprioception, either acquired or from birth, has allowed insights into the role of these senses in the control of movement and other functions. Many of these were anticipated in the 1820 s by the remarkable, largely theoretical, work of the Scottish physiologist and anatomist, Sir Charles Bell.}

It is rare for clinical neurological syndromes to overlap exactly onto neurophysiological classifications, but this does occur in the acquired, acute sensory neuronopathy with a selective loss of large myelinated sensory nerves, leading to the complete loss of touch and movement/position sense in the body (Cole, 1991). More recently, patients have also emerged with a selective loss of discriminative touch and profoundly decreased proprioception due to an inherited inactivating variant in the stretch-gated ion channel PIEZO2 (Chesler et al., 2016). Many of the problems these participants face were anticipated in one of the first descriptions of proprioception in the early $19^{\text {th }}$ century by Charles Bell.

When King William IV, in 1831, was looking for eminent scientists to knight, alongside the usual politicians and military men, Bell was an obvious choice. (Hershel and Babbage were two of the other six, though the latter declined the honour).

He was born in 1774 in Edinburgh, and trained there in medicine before moving to London in 1804. Initially, he taught anatomy and assisted at operations. He must have been good since he became Professor of Anatomy at the Royal College of Surgeons, the first Professor of Surgery at UCL and helped found The Middlesex Hospital
Medical School. He was a fine artist too, and at one time hoped for a chair at the Royal Academy of Arts. His book on facial expression, written and illustrated by him, influenced artists in Britain and abroad, including the pre-Raphaelites, Gericault and Delacroix. In the aftermath of Waterloo, he travelled to Brussels to assist in surgery, and subsequently wrote and - naturally illustrated a book on gunshot wounds.

His main area of expertise, and the reason he is remembered today, was the function and diseases of the nerves and brain. His name is most closely associated with Bell's Palsy (inflammatory facial palsy), and with Bell's phenomenon (upward rotation of the eye as the lid closes). He described forms of muscular dystrophy, writer's cramp and motor neurone disease as well as phantom limb sensation (and how these absent limbs may be felt to move with gesture) and how the arch of the foot acts as a spring during propulsion. He was elected to the Royal Society in 1826 and was later awarded its Gold Medal. Commenting on his knighthood, The Lancet effused, 'There is not in England an anatomist or physiologist toward whom the favour of the sovereign could have been bestowed with more propriety.'

In addition to his anatomy and neurology, he also made key physiological observations. 


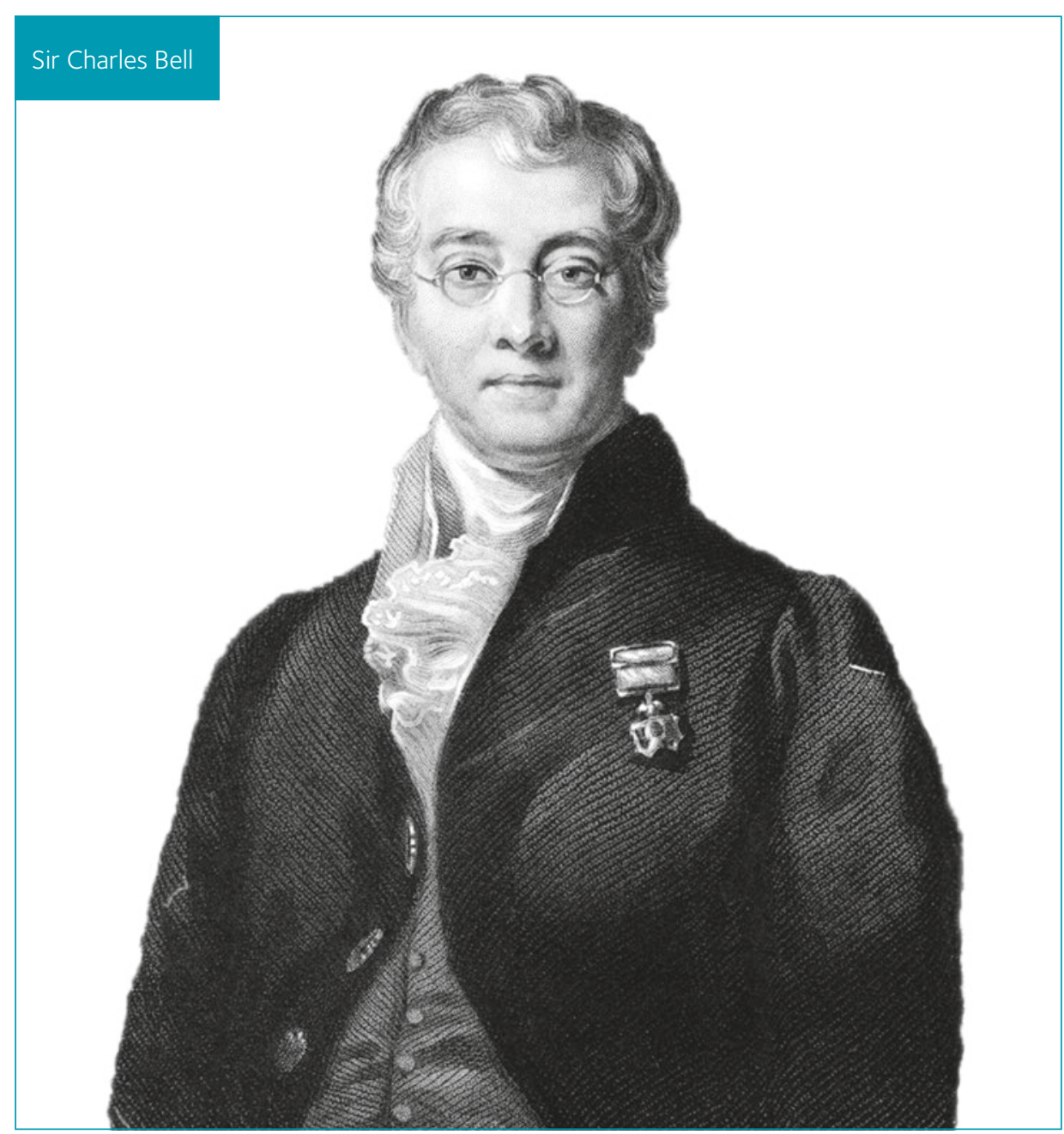

Bell described how the different senses arise in the brain rather than being due to different properties of sensory afferent nerves, before Muller's formal doctrine of specific nerve energies. He gained experimental evidence for reciprocal inhibition and realised that some integrative functions occurred in the spinal cord. He wondered if babies feel pain, 'He is capable of the expression of pain... but the infant during operations makes no effort to repel the instrument of surgeon when being operated on.' He also suggested that, 'For the nervous system it holds universally that variety of contrast is necessary for sensation, the finest organ of sense losing its property by the continuance of the same impression.' At other times his ideas, based on inadequate data, were wrong; for example, he thought the cerebellum was an autonomic centre.

In his thorough and scrupulously fair recent biography (Aminoff, 2017), Michael Aminoff calls him an anatomist and theoretician. This seems reasonable, in part because of his attitude to experimentation. This required vivisection without anaesthetic (as surgery was then also performed). He distrusted results under such circumstances and thought it distasteful;

'I should be writing a third paper on the nerves, but I cannot proceed without making some experiments, which are so unpleasant ... that
I defer them - I cannot convince myself that I am authorised in nature, or religion, to do these cruelties - for what? - for anything else than a little egotism and self-aggrandisement' (Gordon-Taylor \& Walls, 1958).

Despite his worldly success and his many, acclaimed, contributions, Bell was easily aggrieved, resigning from many of the posts to which he was appointed. There were also controversies from which he emerges poorly. In 1811, during an experiment, he had shown that touching an animal's ventral root led to convulsion while cutting the dorsal ones did not. His interpretation was that dorsal roots project to cerebellum; crucially he did not write this up adequately. In 1822, Magendie cut dorsal and ventral roots in young puppies, allowed them to recover and observed the consequences, and concluded correctly that ventral roots were motor and dorsal ones sensory, completely independently of the previous work. Bell was indignant and, Aminoff suggests, revised his own writings to imply that he made the correct deduction himself earlier. Around the same time, he also altered his papers on the sensory and motor innervation of the face, by the Vth and VIIth cranial nerves, following correct observations by the British anatomist Herbert Mayo. Much acrimony over many years followed and the episodes bring Bell no credit.

\section{'One of his major physiological contributions was his description of the 'sixth sense', muscle sense, in a paper to the Royal Society in 1826'}

Beyond this, however, one of his major physiological contributions was his description of the 'sixth sense', muscle sense, in a paper to the Royal Society in 1826,

'weighing in the hand - what is this but estimating muscle force? We are sensible of the most minute changes of muscular exertion, we know the position of the body and limbs. In standing, walking and running, every effort of the voluntary power which gives motion to the body, is directed by a sense of the condition of the muscles.'

Many of his conclusions about what Sherrington subsequently termed proprioception are within his book, The Hand, which was one of the Bridgewater Lecture series published in 1833 (Bell, 1834). These were designed to defend Christianity from the then current scientific advances. Bell was religious and a supporter of creationism and intelligent design, neither of which impressed Darwin. Though the books were meant to convey 'safe science' and religion to the everyman, Bell sneaked in some astonishingly, prescient ideas which followed one of his original experimental observations;

'muscles had two classes of nerves on exciting one the muscle contracted; on exciting the other, no action ... 
'We awake with a knowledge of the position of our limbs. This cannot be from a recollection of the action which placed them where they are; it must, therefore, be a consciousness of their present condition'
2.

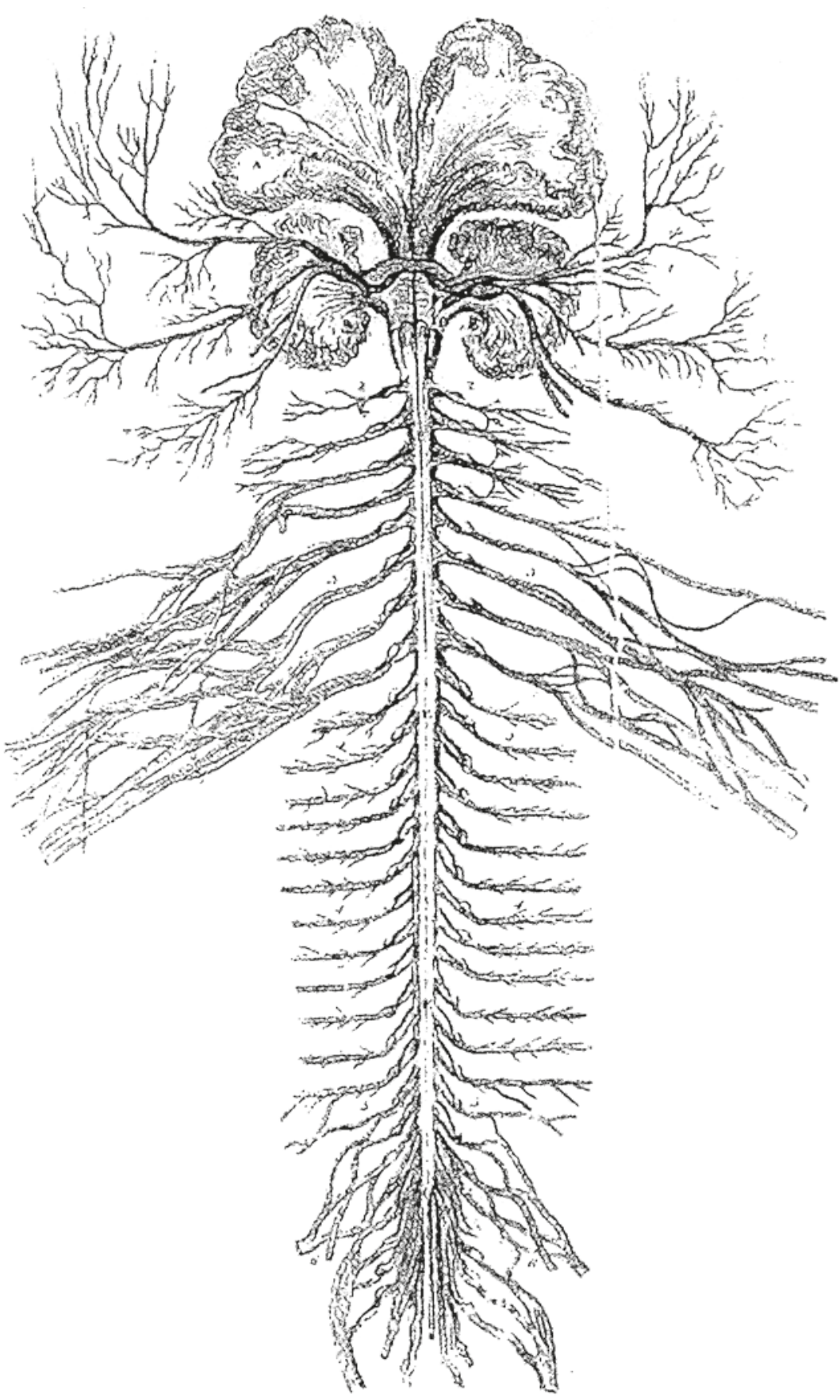

3.

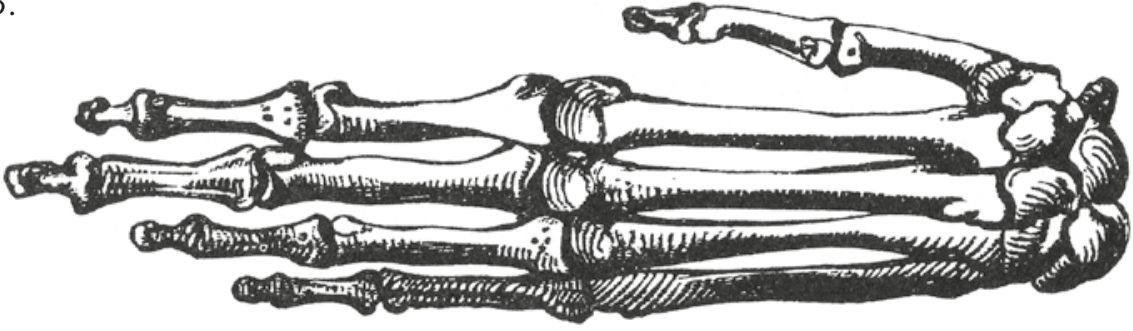

Figure 2. Bell, C (1834). An exposition of the Natural System of the Nervous System of the Human Body. Spottiswoode, London. Also reproduced as Figure 8.1 in Aminoff, M (2017).

Figure 3. 'Sketch from the bones of the paw (sic) of the adult chimpanzee from Borneo.' (So likely to be an orangutan). Bell, C (1834). 
Thus, it was proved that there is a nervous circle connecting the muscles with the brain ... there is a muscle of sensibility to convey a sensation of the condition of the muscles to the sensorium, as well as conveying the mandate of the will to the muscles.'

From here he concluded;

'We awake with a knowledge of the position of our limbs. This cannot be from a recollection of the action which placed them where they are; it must, therefore, be a consciousness of their present condition.'

Much of my own research has been in participants with touch and proprioceptive loss, and many of Bell's insights are directly applicable. For instance, these participants on wakening actually do move their limbs to see where they are in bed.

'In truth we stand by so fine an exercise of this power, and the muscles are, from habit, directed with so much precision and with an effort so slight, that we do not know how we stand. But if we attempt to walk on a narrow ledge, or stand in a situation where we are in danger of falling we become subject to apprehension; the actions of the muscles are magnified and demonstrative to the degree in which they are excited.'

Here he suggests that though describing them as a 'sense', proprioception and intention lie between the conscious and the automatic. Even similar actions can be either, according to context, his example being walking across a narrow ledge. The choreographers Siobhan Davies and Matthias Sperling recently developed a piece, 'Manual', in which they asked members of the audience to instruct a dancer how to stand from lying. We do this easily, without thought, but it is extraordinarily difficult to analyse exactly what we do and to put that in words to instruct someone else.

'Nothing appears simpler to us than raising an arm ... yet in that single act, not only are innumerable muscles put into activity, but as many are thrown out of action, under the same act of volition.'

Here he describes reciprocal action and the complexities of even a simple action. In the next passage he considers what we now know as active touch,

'... in the use of the hand there is a double sense exercised; we must not only feel the contact of the object, but we must be sensible to the muscular effort which is made to reach it, or to grasp it with the fingers ... Without a sense of muscular action or consciousness of the degree of effort made, the proper sense of touch could hardly be an inlet to knowledge at all ... the motion of the hand and fingers, and the sense or consciousness of their action must be combined with the sense of touch ...'

'The motion of the fingers is especially necessary to the sense of touch. These bend, extend, or expand, moving in all directions like palpa, embracing the object and feeling it on all surfaces, sensible to its solidity'

He even considered whether this sixth sense was all due to peripheral feedback or whether to internal efferent signals,

'At one time I entertained a doubt whether this proceeded from a knowledge of the condition of the muscles or from a consciousness of the degree of effort directed to them in volition'

Lastly, he mused on what might be called affective or pleasurable aspects of proprioception, to parallel pleasant touch,

'The exercise of the muscular frame is the source of some of our chief enjoyments. This activity is followed by weariness and a desire for rest ... diffused through every part of the frame a feeling almost voluptuous.'

Bell was a founder of neurology and neuroscience, and a pre-eminent medical figure of his time, so it is curious how readily he took offence. He resigned from UCL for not being given the Senior Chair of Anatomy and even baulked at the Chair of Physiology, protesting that he had not lost interest in 'practical subjects', and demanded the Chair of Surgery or Clinical Surgery as well. Having a thin skin is less reprehensible than his responses to the dorsal and ventral root and the cranial nerve controversies. One simple lesson is to write up experimental results and publish in a widely read journal.

His behaviour, however, should not blind us to his huge contributions to clinical neurology and to his insights into proprioception and the consequences of its loss. Bell lived at the dawning of empirical physiology and one presumes would have embraced experimentation under more humane conditions. His observations and subsequent theories and deductions remind us that ideas are often not a new as we may think; the importance is in their experimental verification. His life also reminds us that even a scientist of extraordinary gifts can have flaws.

\section{References}

Aminoff M (2017). Sir Charles Bell. Oxford, New York: OUP

Bell C. Sir. (1834). The Hand; Its Mechanism and Vital Endowments, as Evincing Design. London: W. Pickering. Reprinted 1979, Brentwood: The Pilgrim's Press.

Chesler AT et al. (2016). The role of PIEZO2 in human mechanosensation. N Engl J Med 375, 1355-1364. DOI: 10.1056/NEJMoa1602812.

Cole J (1991). Pride and a Daily Marathon, London; Duckworth, 1995 Cambridge, MA: MIT Press and (2016). Losing Touch. Oxford: OUP.

Gordon-Taylor G \& Walls EW (1958). Sir Charles Bell: His Life and Times. Edinburgh, London: E \& S Livingstone. 


\title{
Nanoscopy and cardiovascular physiology
}

\author{
Advances in single molecule localisation
}

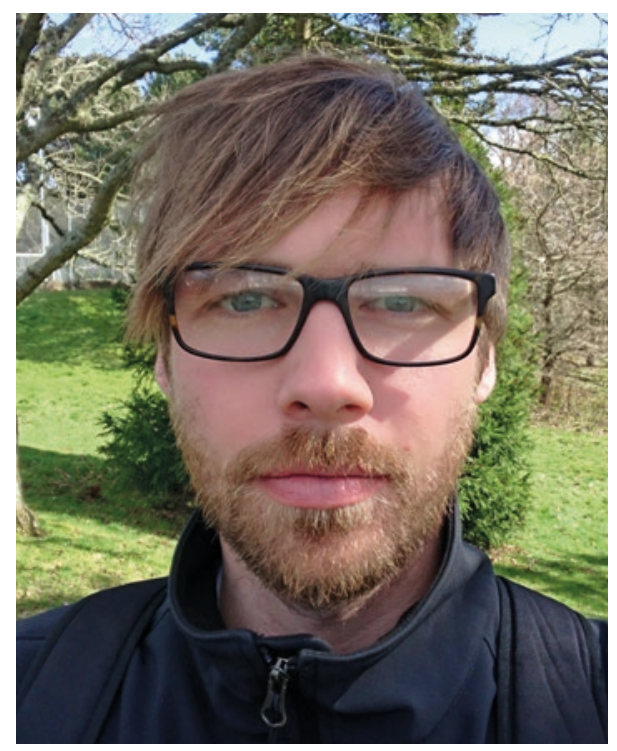

\section{Carl Harrison}

Living Systems Institute, University of Exeter, UK

While microscopy observes down to the micron level, nanoscopy aims towards a 10-fold increase in resolving power. Steps towards this aim are reported here in studies on the cardiac muscle ryanodine receptor type 2. As the RyR2 seems to be central to both physiological function and is altered in pathology, it is of great interest to the experimentalist and modeller alike.

In the last few decades, functional techniques have moved towards the molecular scale, such as patch clamp electrophysiology, atomic force microscopy or fluorescence resonance energy transfer (FRET) imaging. One key advance for these techniques was the ability to observe single molecules, rather than relying on ensemble averaged data. For nearly 150 years, it was widely accepted that the maximum resolution of a light microscope would be limited by the very nature of light itself to $\sim 200 \mathrm{~nm}$. Immunofluorescence's specificity has allowed so many details to be observed about protein distribution, whilst electron microscopy (EM) unveiled amazing ultra-structural details at the nanoscale. Now, powerful new light microscopy techniques collectively called super-resolution microscopy (or nanoscopy) are bridging this gap towards single molecule information. There are numerous forms of nanoscopy, but here we discuss recent advances in single molecule localisation microscopy (SMLM) applied to cardiomyocytes.

SMLM techniques such as STORM or PALM rely on high laser power intensities, reducing buffers and some fundamental physics of fluorescence. Fluorophores are typically excited by a certain excitation wavelength being absorbed. When the molecule relaxes back to its ground state, the energy is then released (with a slight red shift) in the form of a photon, and the molecule is able to then be excited again. It is this constant cycling that results in a stable fluorescent signal in fluorescence microscopy. This property can be manipulated in the presence of high laser intensities and certain buffers. These conditions preferentially shift the fluorophore into a rarer meta-stable excited, 'dark state', whilst the remaining few molecules cycle through the fluorescence cycle rapidly, resulting in a brief, bright, 'blink' of light. The net result is that from an entire field of stable fluorescence one sees individual molecules blinking as diffraction-limited spots. The sample is imaged over time, each individual blink can then be localised around 10x more accurately than the blink itself and a composite super-resolution image is created. By introducing specific optical components, the shape of the blinks can be manipulated to divulge z-position information, resulting in three-dimensional super-resolution images.

The study of the heart requires all the tools in physiology combining electrical, mechanical, biochemical, genomic, proteomic, and metabolomic aspects. Luckily, the cardiomyocytes that make up the muscular ventricular walls are fundamentally homogenous and so the study of isolated cardiomyocytes is considered to be approximately representative of the whole cardiomyocyte population. Within the 

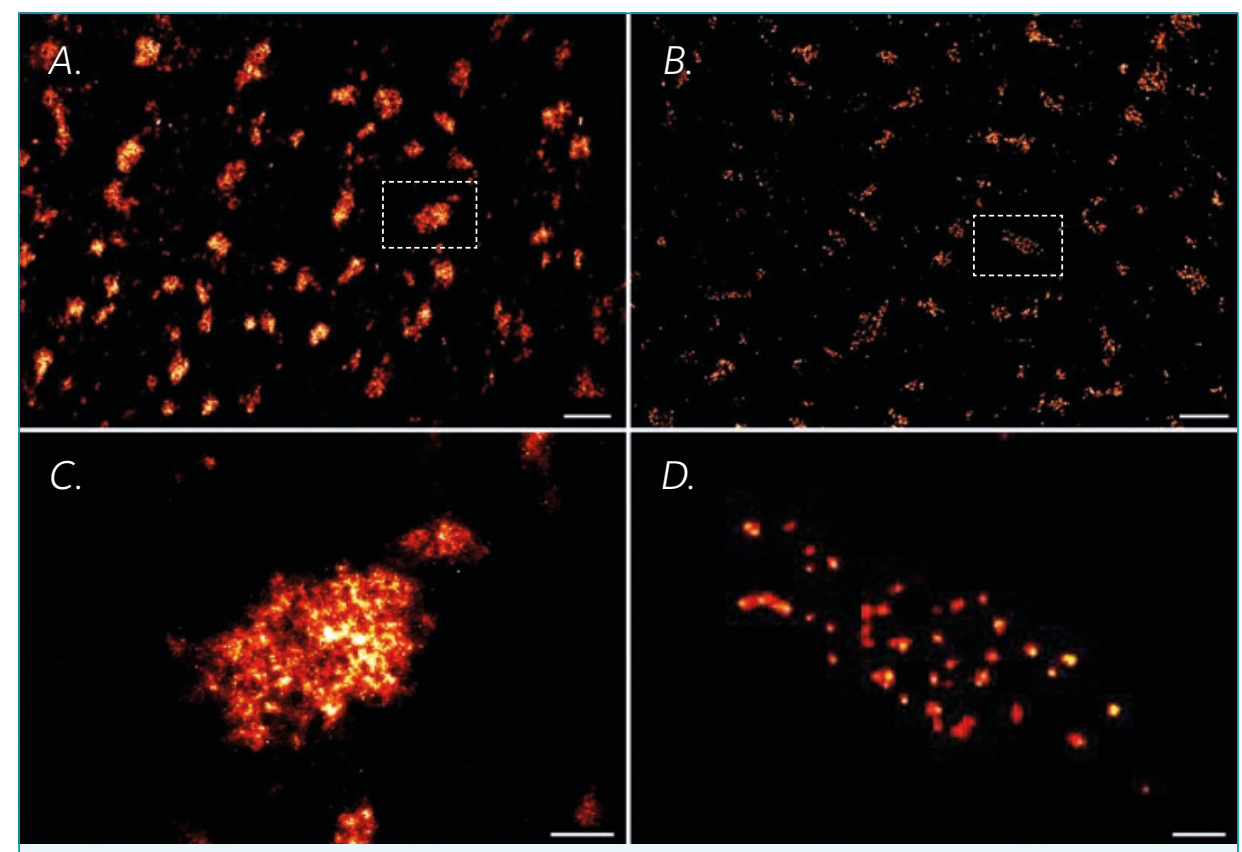

'The study of the heart requires all the tools in physiology combining electrical, mechanical, biochemical, genomic, proteomic and metabolomic aspects'

Figure 1. Visualisation of RyR2 in peripheral couplons of ventricular cardiomyocytes. dSTORM $(A)$ and DNA-PAINT (B) typically show RyR2 in clustered nanodomains (which are loosely in a transverse striated pattern) facing the surface plasmalemma (parallel to image plane). ( $C$ and $D$ ) Magnified views of clusters from these images (boxed regions in $A$ and $B$ ) show the unresolved cluster substructure in ASTORM data $(C)$, which contrasts with resolved punctate RyR2 patterns mapped with DNA-PAINT $(D)$. Scale bars $1 \mu \mathrm{m}$ ( $A$ and $B)$, 100nm ( $C$ and $D$ ). Adapted from Jayasinghe and Clowsley et al. (2018).

cardiomyocyte, structures are highly ordered into longitudinal filaments for contraction and transverse membranous invaginations, known as t-tubules (first observed with EM). T-tubules facilitate the rapid distribution of electrical signals into the depths of the cell for the simultaneous activation of the muscle's machinery. The tubules are directly opposed by internal organelles (sarcoplasmic reticulum; $\mathrm{SR}$ ) and close to the contractile machinery. The currents flowing through ion channels in the $\mathrm{t}$-tubules activate signalling pathways and internal ion channels such as the ryanodine receptor (RyR2) on the SR. RyR2 cluster activation results in quantal release of calcium, commonly observed as 'calcium sparks', and it is this calcium that activates the contractile machinery.

This nanodomain is where cardiomyocyte function is tightly regulated. Pathologies may arise if this orderly structure is perturbed, such as the loss of t-tubules in heart failure or arrhythmia. RyR2 are heavily implicated across a host of pathologies, and so there is great interest in their physiology. The Soeller lab at the University of Exeter has unveiled the spatial distribution of RyR2 at the nano scale since SMLM was demonstrated in biological samples. RyR2 clusters have been shown to follow a stochastic assembly with a near exponential size distribution. By utilising electrophysiological data and computer modelling, clusters within $100 \mathrm{~nm}$ of each other can be thought of as superclusters. These act functionally as single calcium release units. By applying three-dimensional imaging, the lab has been able to estimate mean receptor capacities of $\sim 63$ RyR2 for the larger internal clusters and $\sim 14$ channels in the effectively flat peripheral clusters.

The apparent colocalisation of RyR2 with another SR protein, Caveolin3 was shown to be anti-correlated when seen at superresolution. We demonstrated that another channel is involved in calcium handling, the sodium-calcium exchanger (NCX), and RyR2 showed a reduced colocalisation using super-resolution microscopy that would be indiscernible in diffraction-limited imaging, in a tamoxifen-induced junctophilin (JPH2) knockdown mouse. These findings, when taken together with findings that JPH2 knockdown mice exhibited an increased calcium spark frequency width and spark morphology, resulting in SR-calcium leakage, demonstrates how the use of fluorescence nanoscopy helps to explain findings in functional paired experiments.

An equal amount of our effort goes into tackling the technical challenges that come with imaging deep into optically thick tissues. Coupling a custom-built microscope with the development of PYME microscope environment software allows a great deal of technical control and flexibility. Our lab has published on the considerations about different cameras, fluorophores and imaging buffers and how they stand up to biological imaging. Whilst it is not possible to discuss it here, it must be mentioned that other super-resolution techniques, such as stimulated emission depletion (STED) confocal imaging achieves similar resolution and results for RyR2. Structured illumination microscopy (SIM) or Airy Scan both provide $2 x$ super-resolution and lend themselves to live cell imaging far more easily. These various techniques trade off speed, absolute resolution, technical difficulty and difficulty of live imaging.

More recently, we have been applying our expertise in imaging optically thick samples to other important physiological questions. We have collaborated on investigations into skeletal muscle physiology, the neuromuscular junction and neuronal cells. Nanoscopy is now starting to permeate through the biological and physiological journals and inform wider research. dSTORM microscopy has achieved protein cluster scale resolution, tantalisingly close to single molecule microscopy.

Our most recent work has allowed us to push into this regime by applying the DNAPAINT method of staining pioneered by the 


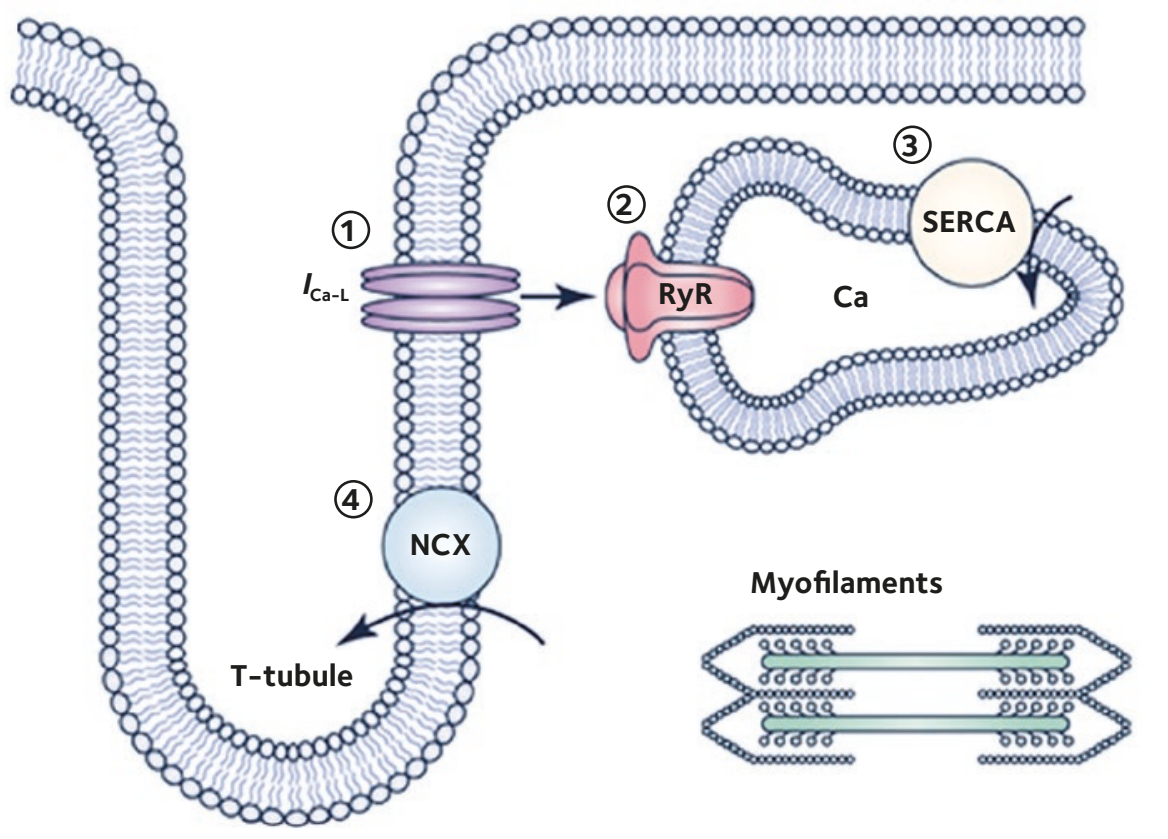

Figure 2. Schematic diagram showing classical players in the calcium handling cycle. (1) $\mathrm{Ca}^{2+}$ enters the cell via the L-type $\mathrm{Ca}^{2+}$ current. (2) $\mathrm{Ca}^{2+}$ is released via the RyR2 from the $\mathrm{SR}$. (The amplitude of the $\mathrm{Ca} 2+$ transient depends, therefore, on the sum of the $\mathrm{Ca}^{2+}$ entry and release from the SR.) (3) $\mathrm{Ca}^{2+}$ is pumped back into the SR by SERCA and pumped out of the cell largely via the NCX. JPH2 (not shown) typically anchors the SR from close proximity of RyR2 to the T-tubule membrane. Adapted from Eisner (2017).
Jungmann group at the Max Planck Institute of Biochemistry. The fundamental limits in dSTORM microscopy are the fluorescence capacity of the dye and finite number of these molecules. These properties are intrinsic to the fluorophore. DNA-PAINT uses antibodies that have a short, singlestranded DNA oligo attached to them. Then attached, is suspended free in the imaging media. At the right concentration of 'imager 'docking strands'. The length of the oligo dictates the binding time. By selecting an appropriate concentration of imagers with the right length, DNA-PAINT data resembles stochastic 'blinks' that we see in ISTORM. As the imagers are free in solution and can be replenished, they can be considered limitless, resulting in better resolution. Of equal power is the capability to perform multiplex imaging in series by using different sequences of oligos and wash steps. Crucially, this can be performed using the same fluorophore, reducing the optical complexity of the set-up and issues around chromatic aberrations. the complimentary oligo, with a fluorophore strands', they will stochastically bind to the using dSTORM in JPH2 overexpression and tamoxifen-induced knockdown transgenic mice. JPH2 overexpression was associated with larger RyR2 clusters, but surprisingly these had a mild reduction in calcium release, consistent with a direct inhibition of RyR2 by JPH2. Our latest paper, published in Cell Reports, clearly shows that RyR2 receptors occupy the cluster areas observed in ISTORM images, with adequate space for accessory proteins such as JPH2 within the cluster. This intra-cluster detail will allow us to unravel the intricate architecture of these functional clusters. Hopefully, this will allow scientists to directly observe in situ molecular detail in health and disease.

\section{'The fundamental limits in dSTORM microscopy are the fluorescence capacity of the dye and finite number of these molecules'}

\section{References}

Baddeley et al. (2009). Optical single channel resolution imaging of the Ryanodine receptor distribution in rat cardiac myocytes. PNAS 106(52), 22275-22280. DOI: $10.1073 /$ pnas.0908971106

Eisner D (2017). Ups and downs of calcium in the heart. J Physio/ 596(1), 19-30. DOI:10.1113/JP275130

Jayasinghe et al. (2018). True molecular scale visualization of variable clustering properties of ryanodine receptors. Cell Rep, 2(2), 557-567. DOI: 10.1016/j.celrep.2017.12.045

Jones et al. (2017). Cellular and molecular anatomy of the human neuromuscular junction. Cell Reports 21(9), 2348-2356.

DOI: 10.1016/j.celrep.2017.11.008

Jungmann et al. (2014). Multiplexed 3D cellular super-resolution imaging with DNA-PAINT and Exchange-PAINT. Nature Methods. 11, 313-318. DOI: $10.1038 /$ nprot. 2017.024
These two powerful benefits to DNAPAINT have allowed us to observe single RyR2 (a 30 x $30 \mathrm{~nm}$ protein) channels within clusters for the first time at $<10 \mathrm{~nm}$ resolution. We recently showed that RyR2 cluster morphology is dependent on JPH2 


\section{The Journal of

\section{Here's why you should publish in The Journal of Physiology...}

The Journal of Physiology publishes important advances in our knowledge of physiology and pathophysiology that increase our understanding of how our bodies function in health and disease.

JP Free to publish - no submission fees

JP No page or figure limits - no restirctions on page length or the number of tables and figures

JP Expert and comprehensive review - two reviewer reports and first decision in less than five weeks

IP Rapid publication - articles published online within days of acceptance

JP Open Access option available - compliant with all major funders' policies

JP Excellent visibility- the most highly cited Physiology journal

IP Be amongst the most trusted research - cited half-life of over 10 years - the highest in Physiology

JP Prestigious history - authors include over 40 Nobel Prize winners

JP Outstanding author services - pre-submisison queries welcome Email us at jphysiol@physoc.org

JP Prior publication on preprint servers allowed

\section{Submit your research jp.physoc.org}




\section{The genesis of a new Sports and Exercise Science degree}

\author{
Christopher Gaffney \\ Lancaster University, \\ Lancashire, UK
}

\begin{abstract}
There are not many opportunities in your career to be involved in the development of new undergraduate courses from inception. The reason I joined Lancaster was that it offers a Sports and Exercise Science degree delivered from a Medical School and there is no better environment to combine my interests that span these areas in research and teaching.
\end{abstract}

My role is all encompassing. From joining the team at Lancaster, I have been involved in the admissions process for new students; reviewing personal statements and participating in decisions to offer places. It's difficult to understand the complexity of applicant visit days until you realise the work involved creating posters and marketing for the course; training student ambassadors; and preparing lectures and lab demonstrations to give to prospective students and accompanying guests.

One of the most exciting aspects in the early stages of my role is my involvement in the design of our new Human Performance Lab (HPL). Less than a month ago I spent almost all week holding a pipette and now I'm reviewing blueprints; how my job has changed! Alongside the design of the HPL we manage equipment purchasing; making a business case for prospective equipment based upon the return for both research and teaching.

One of the most challenging tasks ahead is the development of a new curriculum. The unique selling point for Sports and Exercise Science at Lancaster is the Medical School, and the strive to ensure there is a clinical focus throughout our degree. This includes capitalising on Lancaster's infrastructure for training medics such as our state-of-the-art Clinical Anatomy Learning Centre (CALC). The first-year content of the Sports and Exercise Science degree was finalised before my arrival but both the second and third years are open to modification, which presents some exciting opportunities for option modules. Whilst development of the curricula from scratch is a daunting endeavour, it's nonetheless a privilege to take aspects of my own degrees that I enjoyed, and others that I believe would be appreciated by students, and incorporate them into our course. My colleagues and I would love to be a student starting Sports and Exercise Science at Lancaster in October 2018, and I believe that's what makes our jobs fulfilling, and will make the course a success.

\section{Bringing inspiring physiology to disadvantaged parts of the UK}

\author{
Tonia Thomas \\ University of Oxford, \\ Oxford, UK
}

Oxford Hands-On Science (OxHOS) is a student-run society in Oxford. We aim to spread our enthusiasm for science to children and their families by taking hands-on experiments drawn from a range of subject areas into schools and public venues, along with a group of student volunteers to assist in demonstrating them. As the co-president of $\mathrm{OxHOS}$ and a member of the society founding committee, I have used my DPhil experience in Physiology, Anatomy and Genetics to engage children and families in basic physiology concepts and their importance in our everyday lives.

Being a first-generation university student who grew up in a small town in South Wales with no aspirations to study at Oxford, I am passionate about improving education and raising aspirations in disadvantaged areas of the UK. For this reason I was part of the OxHOS founding committee, which was established in 2015, and our ethos is to target low-performing state schools in remote areas of the country to encourage children to study science at GCSE and beyond. We ran our first official roadshow in the Summer of 2016, when we visited schools and public venues in Oxfordshire and South Wales, and returning to my home region with a group of Oxford researchers and experiments was incredibly rewarding.

2017 has seen our engagement grow by $70 \%$ as we visited 16 schools and six public venues in Oxfordshire, Portsmouth, Southampton and the Isle of Wight. Reaching out to more remote, disadvantaged areas is our main priority, and this expansion wouldn't have been possible without the generous support of The Physiological Society. We're grateful for their endorsement of a student-led project that is building success with each event held.

Last year we held public events in Oxford in collaboration with the National Association for Primary Education and Oxfordshire Science Festival, which involved street demonstrations of blood pressure and heart rate, and engaged young 'scientists' in determining how blood groups interact. Our Summer roadshow took us across the water to the Isle of Wight, after receiving a request from a school there through our website, and we taught children about digestive enzymes whilst making 'poo'. This experiment also went down well at our public event at Winchester Science Centre, where it was set up next to their Colon Café!

Changing students' view of science and hearing comments like 'science is actually cool' is something that drives us to keep expanding our outreach work, and reminds us that one of the most rewarding aspects of research is the ability we have to share it with the public. 


\section{The road to winning the Outstanding STEM Technician Award}

\author{
Henry Rae \\ University of St Andrews, \\ Fife, UK
}

The STEM Inspiration awards are designed to celebrate individuals and organisations working to inspire young people in STEM subjects. Of the seven categories, I was honoured to receive the Outstanding STEM Technician award. This award recognises efforts to inform and inspire young people with apprenticeships and technician careers. It is aimed at those working in STEM who have a technical, non-graduate background and have used this to help inspire the next generation of technicians.

I especially like activities with Primary 5, 6 and $7 \mathrm{~s}$ as I find they are always excited and interested in cool stuff and not afraid of taking part in whatever is going on. My aim is to entice them into science by giving them interesting, fun and educational activities. By the time they go to high school I won't mind if they have forgotten the details of what they did as long as the feeling of 'science is really interesting and fun' stays with them and hopefully will lead to careers in science.

Although a lot of activities I do can stand alone as a kind of 'wow! that's cool' activity, if I ask the children why this particular thing happens, it makes them think and try to understand what's going on. This puts their brains in gear and gets their attention.
I have found that teachers have a lot to cram into their lessons and have to know a lot about a lot of wide and varying subjects. Having STEM activities delivered by external experts helps both staff and pupils understand the subject more deeply.

Being a part of STEM has made me look at what's being done, and what's needed. I have started my own Primary School Science Days, where I go to a school taking the schools of Biology, Physics, Medicine and Chemistry. All primary 5, 6 and $7 \mathrm{~s}$ engage in fun, educational activities. Showing a wide choice of sciences means there is something for everyone.

In carrying out STEM activities I have delivered sessions to well over 1000 primary 5, 6 and $7 \mathrm{~s}$ and I have been told many stories about the positive impact on the children. One was a student who keeps turning up to our science events and knows truly an amazing amount of anatomy and physiology for a nine-year-old. At a public Science Discovery Day I noticed a three-year-old looking at what we were doing. I handed him an Automated External Defibrillator and said 'Want a shot?' Without instruction he started the Defib, placed the pads in the right positions and shocked the manikin correctly. He didn't say a word, just grinned from ear to ear the whole time.

A lot of the STEM activities I do in my own time. I enjoy doing them and from the feedback I get from teachers the children not only have a great time but they are absorbing the information too.

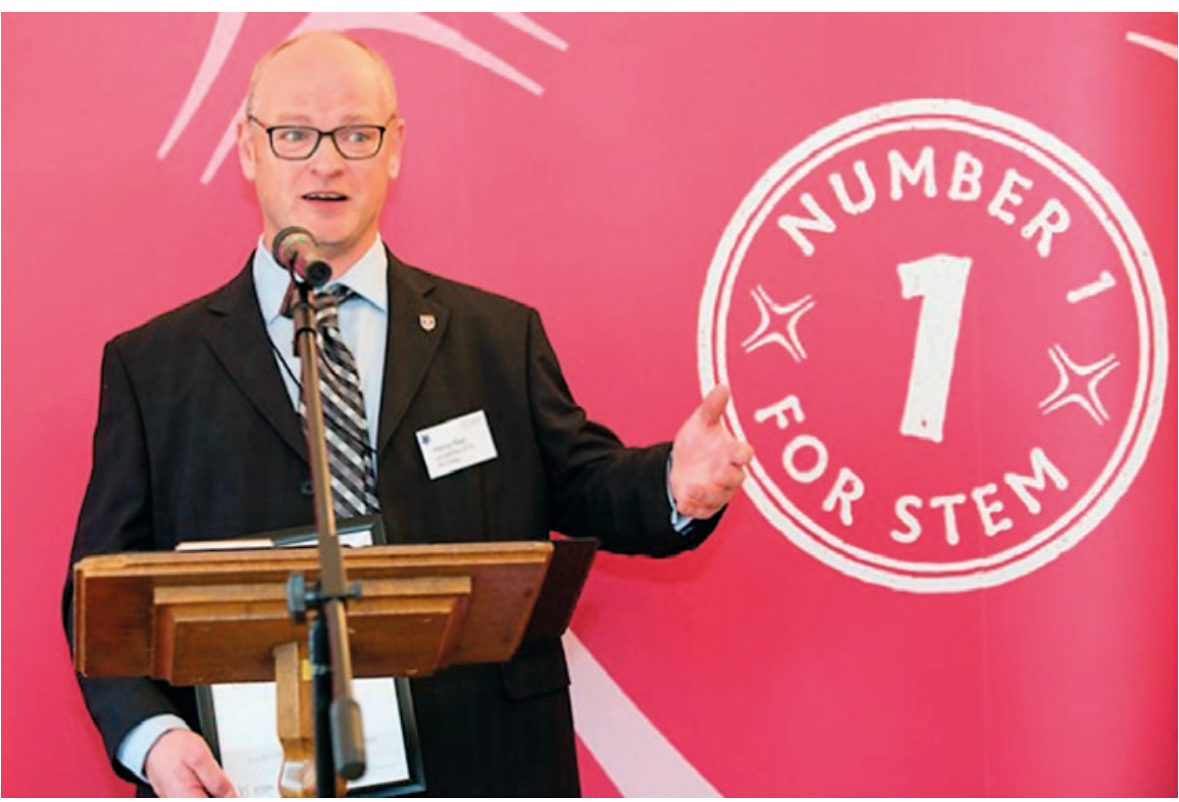

\section{Lisa Jones \\ University of Southhampton, UK}

Halfway through my PhD I came to the realisation that academia is not for me, which was pretty daunting. I absolutely love the science and teaching others about it, but over time I discovered that I do not enjoy the process of 'making' the science in the lab!

Although very rewarding, my $\mathrm{PhD}$ has been a tough journey. When I tried to seek advice, I realised there was very little in the public domain about the trials and tribulations of a PhD. That's what inspired me to start my science blog (inascienceworldblog. wordpress.com) and Instagram (@lisa_ inascienceworld). My PhD SOS feature definitely generates the most engagement. A PhD has many positives but experiencing tough phases is common, and my blog post 'The PhD slump' was one a lot of students related to. Many commented or messaged me saying how they really needed to hear what I shared and they'd put my tips into practice. Knowing people appreciate the advice I share is so humbling.

I love the world of science communication - I learn new things, and there's room to be creative, I interact with people I never would have otherwise, I can share my experiences, I can help others and I can teach people about science. This is the field I now know I want to pursue. 


\title{
Solidifying my career choice of research
} - a Rob Clarke Award winner's account

\author{
Klaudia Toczyska \\ Kings College London, \\ London, UK
}

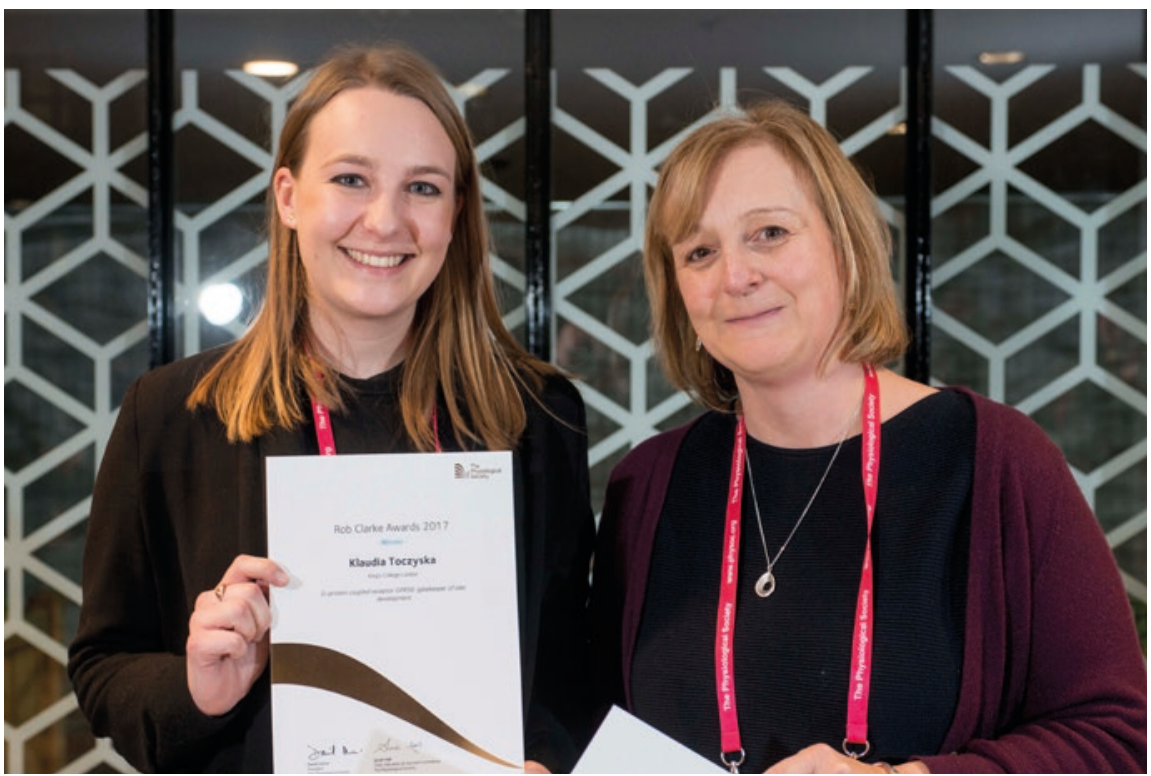

My undergraduate project was important in shaping my career path. It made me realise how much I enjoy research. I learnt to work independently within the team setting and perform experiments with confidence. I was inspired by my supervisor and members of the group with their motivation and excitement about physiology. Through this experience, I decided to apply for a PhD, and I am currently researching the role of antidepressants in diabetes in the same laboratory. I would recommend that everyone doing an undergraduate degree in sciencerelated subjects should experience a research project to gain useful transferable skills and build a CV.

During my project, I looked at a G-protein coupled receptor's role in islet development. The endocrine pancreas is made up of small cell clusters called islets of Langerhans, which are composed of three main cell types, $\alpha-, \beta$ - and $\delta$-cells that produce the hormones glucagon, insulin and somatostatin, respectively. The islet cells act in a coordinated manner to maintain plasma glucose levels within a narrow physiological range. Islet $\beta$-cells are the only site of insulin production in the body, and insulin is essential for promoting cellular uptake and storage of glucose.

Type 2 diabetes (T2D) develops when peripheral cells do not respond properly to insulin, and $\beta$-cell dysfunction means that there is insufficient insulin secretion to compensate for this termed insulin resistance. According to the latest estimations, 425 million adults worldwide have diabetes. There are a number of different drugs approved in the treatment of this metabolic disorder. Therapeutics that increase sensitivity of target organs to insulin (e.g. metformin) or act on $\beta$-cells to promote insulin secretion (e.g. sulphonylureas) have been in use for years.

However, with the increasing incidence of T2D comes a requirement to also increase $\beta$-cell mass so that insulin secretion can be maintained. G-protein coupled receptors (GPCRs) are popular targets for therapeutic development because many drugs in clinical use target GPCRs and these receptors play an

\section{P9 GPR56 WT}
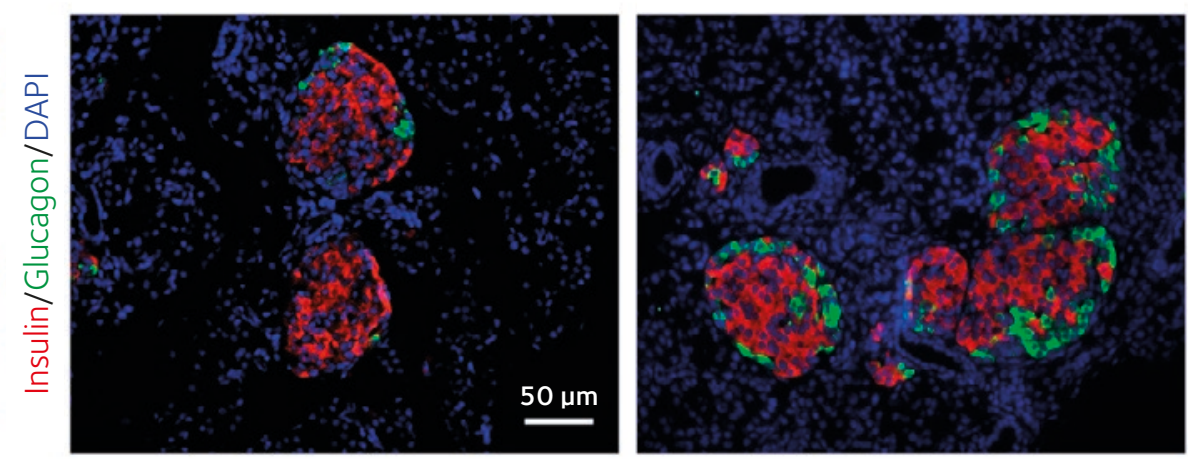

GPR5 6 deletion resulted in an increased number of $\alpha$-cells and decreased $\beta$-cell counts Wild-type and GPR56 knockout P9 mouse pancreases were sectioned to $5 \mu \mathrm{m}$ and stained with antibodies directed against glucagon (green) and insulin (red). important role in the detection of a variety of signals by $\beta$-cells.

G-protein coupled receptor GPR56 has been discovered by my laboratory to be the most abundant GPCR in human islets. In the brain, GPR56 drives cortical development and oligodendrocyte proliferation, but little is known about its role in the endocrine pancreas.

During my undergraduate research project, I worked to determine the role of GPR56 in islet development. Wax and frozen blocks of pancreases from wild-type and GPR56 knockout mice at postnatal day 9 (P9) and mouse embryos at different embryonic days (E11-E18) were sectioned, stained and analysed. I found that GPR56 expression and its co-localisation with transcription factors important in pancreas development (PDX1 and NGN3) were the highest at E15 - the stage of endocrine progenitor cell differentiation into $\alpha$ - or $\beta$-cells. At P9, GPR5 6 was expressed only by $\beta$-cells within the islets. GPR56 deletion resulted in a significant decrease in the number of proliferating cells throughout the pancreas at E16 $(p<0.05)$ and E17 $(p<0.001)$. There was also reduced $\beta$-cell proliferation in GPR56 knockout pancreases at E16 ( $<<0.001)$. These early reductions in proliferation resulted in significant changes in cellular composition of postnatal islets: there was an increased number of $\alpha$-cells $(p<0.01)$ and decreased number of $\beta$-cells $(p<0.05)$ at P9 following GPR56 deletion.

The results of my project show that GPR56 plays an important role in islet development and $\beta$-cell proliferation. Therefore, GPR5 6 could be considered as a candidate drug target in the treatment of T2D, by inducing $\beta$-cell proliferation and insulin production sufficient to compensate for insulin resistance. 


\section{Publishing my first paper in The Journal of Physiology}

\author{
Laura Rich \\ University of Nottingham, \\ Nottingham, UK
}

At the start of my research masters (MRes) my supervisor encouraged me to read The Physiological Society's publication Women Physiologists: Centenary Celebrations and Beyond. The many accounts of how one of their proudest achievements was publishing their first paper were an inspirational start to my career as a woman in science.

Undertaking the MRes at the University of Nottingham gave me the opportunity to pursue my love of glial cells, a love that developed through my undergraduate degree. I was able to investigate the metabolic interactions between Schwann cells and axons in peripheral nerves. My focus for the year was to gain further insight into a career in research, but I never imagined that after only one year I would have sufficient data to consider publication.
Choosing the journal in which to publish was the first big decision. As a former Undergraduate, and now Affiliate Member of The Physiological Society, I was keen to publish in The Journal of Physiology, as throughout both my degrees The Journal's gold standard of quality was highlighted to me. I knew I would be proud of being published in such an influential journal.

We didn't start writing the paper until I had submitted my MRes thesis. Writing my thesis allowed me to determine the most logical flow of the story, and the discussion taught me the complex task of integrating my data with the existing literature. Condensing it from 25,000 words to a publishable paper was the first challenge. After many draft copies passed between my supervisor and I, we finally submitted the final version, calling for a well-earned 'coffee break'.

The process of publishing was new to me, but I now have an appreciation for not only all the work that goes into the experiments for each paper, but also the amount of work that the rigorous peer review entails. Receiving encouraging comments from
The Journal such as 'I am pleased to tell you that it is considered to be potentially acceptable for publication' was an enormous relief after waiting in anticipation for a few weeks over Christmas. Despite this, reading the list of required amendments felt a little disheartening. However, as we addressed each comment I realised their purpose was not to criticise me, but to improve and help me make the paper as good as it possibly could be. After each step I felt more excited and anxious about the prospect of publishing my first paper getting closer.

I feel proud that I can now add my own paper: Fibre sub-type specific conduction reveals metabolic function in mouse sciatic nerve (physoc.onlinelibrary.wiley.com/doi/ abs/10.1113/JP275680), to the collection of literature on this topic. Celebrations will definitely be in order. I am currently in my first year of the BBSRC DTP PhD at the University of Nottingham and as I move forward in my career I hope the art of publishing becomes a familiar experience.

\section{Learning a research career is within my reach: Vacation Studentship Scheme case study}

\author{
Sara Rayhan \\ University of Southampton, \\ Southampton, UK
}

I received a Summer Studentship last year for a project at the University of Southampton, under the supervision of Felino Cagampang and Jane Cleal. My project examined the effects of maternal obesity in pregnancy on the placenta, an organ that supplies the fetus with oxygen and nutrients, in mice. More specifically, we measured placental expression of two growth-related genes in obese pregnant mice. One gene is responsible for blood vessel formation (VEGF) and the other (RAPTOR) for the response to nutrient and insulin levels. Both have been linked to cardiovascular disease. We also examined the effect of maternal metformin treatment in obese pregnancy on the expression levels of these genes in the placenta. Metformin is a drug used to treat gestational diabetes but its effect on the placenta and the developing fetus is unknown. Maternal high-fat diet (HFD) during pregnancy reduced VEGF mRNA expression in the placenta depending on metformin treatment, while placental RAPTOR expression increased with maternal HFD. These changes in gene expression could alter placental function and fetal development, and have long-term consequences on cardiometabolic health of the offspring. It further suggests that metformin should be prescribed with caution to pregnant women.

Due to the great deal of guidance given, the project was far less daunting and the workload was more than manageable. I learnt that research is coordinated within a specific lab group, with individuals each conducting their own research projects, and feeding back to the team to provide a more holistic understanding. Also, numerous different departments liaise with each other, and I had the privilege of being able to attend these meetings along with conferences held within the hospital. This showed me how a research environment is very much interdisciplinary and relies on understanding how the work presented by others may impact your own research.

This studentship has given me the opportunity to experience what it means to be a part of a research group and the fundamental impact your work could have, and this is something that has very much resonated with me. It's allowed me to be challenged, but also to gain a greater insight and grow in confidence in my laboratory techniques. Because of this, I now realise that a research-intensive career is not beyond my reach and that it is far less intimidating than I perceived it to be. The experience gave me the confidence to pursue a laboratory project for my final year dissertation, which I am currently in the process of writing. 


\section{Membership}

\section{Obituaries}

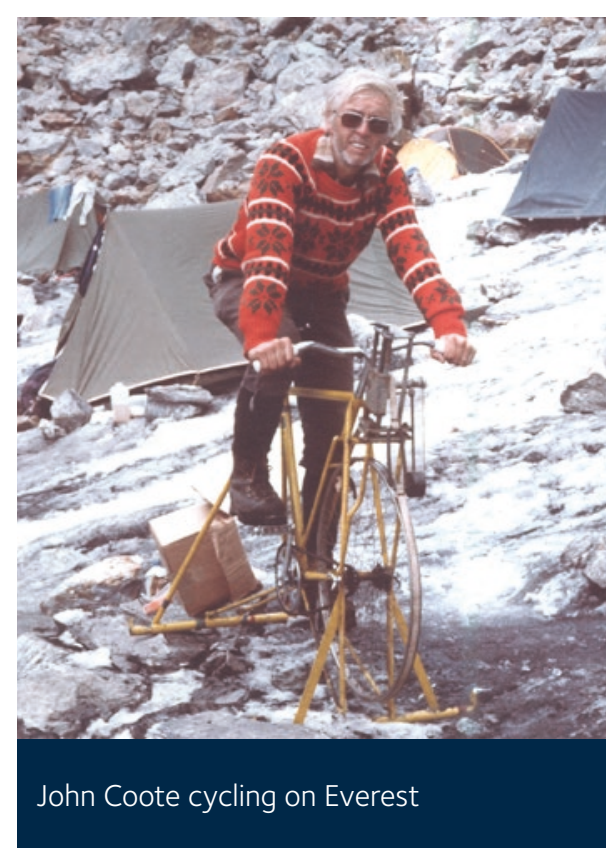

\section{John H Coote}

\section{$1936-2017$}

John Coote, who died suddenly and unexpectedly on 27 November 2017, had been there all my scientific life. Others have written about John's considerable scientific achievements as an autonomic physiologist. Here, I offer a personal perspective on John Coote, the man behind the physiology.

I first became aware of John in the 1970's when he was a young lecturer at the University of Birmingham. As a new PhD student, I was far too in awe of members of staff to venture to talk to him. But I did quite quickly learn two things about him: the first was his enthusiasm for the outdoors - there were stories about his prowess as a fell runner, climber and general action man. The second was his legendary ability as a dedicated, intensely practical, hands-on autonomic physiologist. This was a skillset he was to retain, develop and importantly to share, for the rest of his life.
John's love of the outdoors influenced Departmental life. It was usual for the Department to decamp - literally - to summer meetings of The Physiological Society in Oxford or Cambridge. As a student, it was some time before I realised that sleeping in a bed rather than a field, was an option when attending scientific meetings! John managed to marry his science with the outdoor life. His enduring interest in physiology at altitude lead to several expeditions to carry out experiments in places where the $\mathrm{pO} 2$ was suitably low. Some exploits were straight out of an action thriller movie - there are tales of chartering helicopters from shady characters encountered in a bar in Kathmandu, of being caught in crossfire between warring guerrilla factions in Peru, or being trapped on a mountain ledge with a climbing partner who tragically died. On another occasion, an expedition to the Alps was interrupted to rush a colleague with acute mountain sickness down the mountainside. Having instigated a life-saving diuresis, the copious urine output was carefully collected in lemonade bottles on the way down. I once asked whether a more controlled experimental environment, with fewer interruptions, might have been better achieved in an altitude chamber. He replied that altitude chambers weren't actually that comfortable to be in (but see the above) and anyway, compared to the mountains the view was terrible!

John served more than 20 years as Head of the Department of Physiology in Birmingham. Under his stewardship the Department grew considerably and attracted a stream of visitors from abroad, many to his own lab. He went out of his way to welcome them, and regularly invited visitors to share a traditional family Christmas at home with his wife Sue and their three children. He believed in fostering a collegiate environment. He saw the Departmental tea room as an important forum for exchange of news, views and ideas, but sadly he lost the battle to retain this facility. At one time, Departmental Christmas parties were quite a big production. In the days before Health and Safety got the upper hand and indeed for some years after it did, a suite of adjacent teaching labs would suddenly be transformed. Benches were turned into dining tables, hotplates were commandeered from labs to heat often quite elaborate dishes, music was organised, vast quantities of food and wine were drafted in and consumed. A late afternoon highlight was John's 'state of the nation' speech, delivered from atop a wobbly stool. Nobody ever remembered what he said, being far too agog at the prospect of him falling off before he got to the end. He never did.

John was a highly respected member of the international scientific community. He was interested in anything and everything physiological and was always a stimulating presence at scientific meetings. Wherever I went in the world, on learning that I was from Birmingham, people would ask after him. John valued, above all, Universities as bastions of scholarship. He was dismayed at the march of corporatisation, especially within his own institution, and fought hard to bring a voice of reason to the process, never failing to put his head above the parapet if he perceived an injustice.

Despite receiving many scientific honours and holding distinguished positions, John remained an unassuming man. On retiring from the administrative burden of Headship, he was generous with his time and on more than one occasion travelled across the world to help out former members of his lab. In the UK, his collaboration with Andre $\mathrm{Ng}$ and Kieran Brack at the University of Leicester on neural control of the heart was particularly fruitful. He showed absolutely no signs of slowing down and was always full of new ideas, opinions and future plans.

John Coote departed his life under full sail. Physiology has lost one of its finest, and many of us have lost a valued and much-respected mentor and friend.

Written by Thelma Lovick University of Bristol, UK 


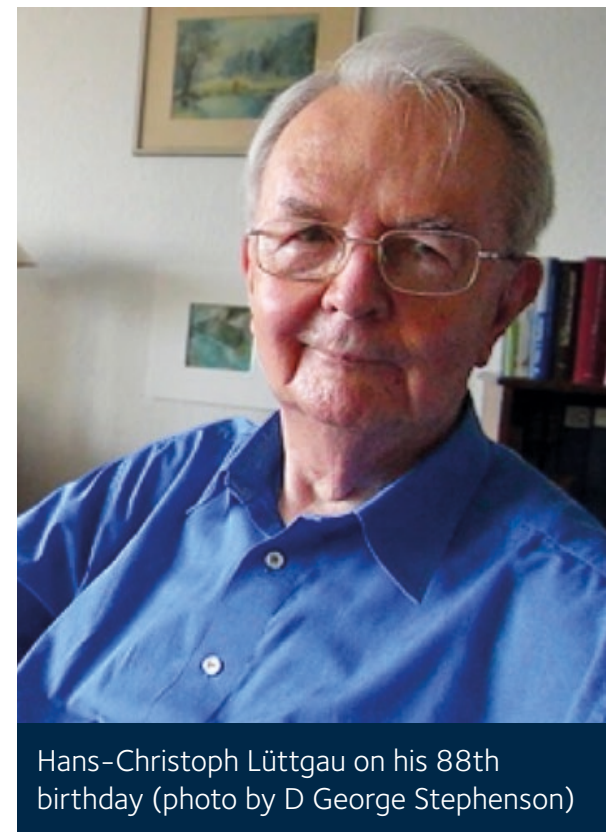

\section{Hans-Christoph Lüttgau}

\section{$1926-2017$}

Hans-Christoph Lüttgau was an eminent German physiologist, shaped by the British scientific tradition through interactions with the labs of Alan Hodgkin and Bernard Katz. He is best known for pioneering work on excitation-contraction coupling (ECC), the link between surface membrane electrical events and muscle contraction, and for his work on Na-Ca antagonism in cardiac muscle, a foundation for the discovery of the ubiquitous $\mathrm{Na}-\mathrm{Ca}$ exchanger (NCX) of plasma membranes.

\section{Lüttgau was born in Braunschweig}

(Brunswick). From 1937 to 1946 he attended the Gymnasium in Goslar. Though conscripted into the Wehrmacht (1944), he was not involved in active combat. He studied Physiology, Zoology, Botany, Physics and Chemistry in Göttingen, graduating in 1949. His doctoral studies there, supervised by Hansjochem Autrum, investigated the excitation threshold of myelinated axons.

In 1952, as the border between the British and Russian occupied zones was sealed, Lüttgau was already aware of better research opportunities outside Germany. Seeking a position in Bern, he wrote personally to Alexander von Muralt, whose group enjoyed links to the labs of both Hodgkin and Katz. He moved to Bern in 1954, holding posts there until 1967.

First, he continued research on myelinated axon excitation. Katz invited him in 1956 to University College London (UCL) for a year as an 'Honorary Research Assistant'. He was proud of the 'honorary' position before finding that it simply meant 'unpaid': fortunately, his Swiss salary was sustained.
He vividly described his 'paperless' arrival at Dover in an autobiographical essay in Physiology News (PN 32). At UCL, he joined Rolf Niedergerke to examine the influence of Ca-Na antagonism on frog cardiac contractile strength. Their work (1958) prompted the idea of a shared mechanism for inward movements of $\mathrm{Ca}$ and $\mathrm{Na}$. This was extended by Reuter and Seitz on guinea pig heart and Baker, Blaustein, Hodgkin and Steinhardt on squid axon, showing that inward movement of Ca is coupled to that of Na outward and vice versa. NCX is now established as a key mechanism keeping intracellular $\left[\mathrm{Ca}^{2+}\right]$ low, an essential feature of cellular regulation.

Back in Bern, Lüttgau showed that the generation of abnormal action potentials (APs) in Na-free, K-rich solutions, presented by others as evidence against Hodgkin and Huxley's ionic theory of excitation, does not contradict that concept but is indeed explained by it.

After 1961, he changed focus from nerve to skeletal muscle, becoming interested in the role of extracellular $\mathrm{Ca}\left(\mathrm{Ca}^{2+}{ }_{0}\right)$ in ECC, initially by studying high $\left[\mathrm{K}_{0}^{+}\right]$(i.e. depolarisationinduced) contractures in frog single skeletal fibres. This work continued in Cambridge, (where Lüttgau spent a year, 1962-1963, at Alan Hodgkin's invitation) and later at the Ruhr University, Bochum (from 1967, when he became the Founding Professor of Cell Physiology). This body of work settled a major controversy in skeletal muscle research, conclusively showing that - unlike cardiac muscle - a $\mathrm{Ca}^{2+}$-influx is not necessary to initiate contraction.

Lüttgau was much influenced by his time with Hodgkin. One anecdote is illuminating: he had given Hodgkin the first draft of a paper to review. On collecting it, he was disappointed by the many remarks on the text. Hodgkin recognised his anguish, saying 'Yes, we all are ready to be corrected, but we don't want to be criticised'. In Bochum, Lüttgau sought to fill 'the infinitely many rooms [in the Department] with scientific life'. Deploying the Cambridge model of small-group working, he remained directly involved in selecting the topic, designing experiments, collecting data, analysing results and manuscript preparation, only coauthoring publications when significantly involved. The Cell Physiology Department provided a happy and stimulating environment, and the two of us (DGS and DJM) relished Christoph's leadership and support whilst working there in the 1970s as young, UK-trained postdocs.

A major contribution was to introduce caffeine and tetracaine as valuable tools to study ECC. Lüttgau's paper with Hans Oetliker (1968) was the first systematic investigation of these agents on the voltage-dependence of contractile activation and inactivation. That work impelled intense study of the (then) poorly understood mechanism of skeletal muscle ECC. Caffeine remains a versatile tool in muscle research and in the clinical diagnosis of conditions such as malignant hyperthermia. He promoted perchlorate as an investigative tool and performed the first truly quantitative analyses of several $\mathrm{Ca}^{2+}$ antagonists (used to treat various cardiac disorders) as tools for understanding ECC. He made major contributions to the characterisation of muscle fatigue, including demonstrating (i) the associated diminution, then failure, of APs, (ii) greatly decreased membrane resistance, and (iii) that caffeine can restore force by facilitating sarcoplasmic reticulum $\mathrm{Ca}^{2+}$ release.

Lüttgau became Professor Emeritus in 1991. A highly cited review on the role of $\mathrm{Ca}^{2+}$ in skeletal muscle ECC (with Werner Melzer and Annegret Hermann-Frank) appeared in 1995 With Hermann-Frank and one of us (DGS), in 1999 he reviewed caffeine as a research tool. He also wrote insightful biographical memoirs (for Naturwissenschaftliche Rundschau) of Alan Hodgkin, Bernard Katz, Silvio Weidmann and (with Rolf Thieleczek) of Andrew Huxley. He collaborated with one of us (DJM) on Rolf Niedergerke's obituary for Physiology News (PN 87).

Hans-Christoph Lüttgau was always a reflective and thoughtful man. He was very close to his two sons and his four grandchildren. In later years, he addressed questions of philosophy and religion, notably in 2009 when preparing two lectures for a lay audience to mark the anniversaries of Darwin's birth and the publication of The Origin of Species. His mind stayed clear to the end as he followed the scientific literature that he enjoyed discussing regularly with several former students and colleagues, many of whom have gone on to leading academic positions.

Like many fellow-citizens of his generation, he was remorseful and critical of the atrocities perpetrated by Nazi Germany. He was humbled by the support he and other German scientists enjoyed after the war from people who had suffered at the hands of that regime.

Lüttgau was elected to The Society in 1965. He regularly presented at meetings and published in The Journal of Physiology. He edited The Journal (1988-1993) and became an Honorary Member in 1995, pleased that 'Honorary' then really did indicate an honour, rather than the unpaid position it had flagged some 40 years earlier!

\section{Written by D George Stephenson} LaTrobe University, Melbourne, Australia \& David Miller

University of Glasgow, Glasgow, UK 
investigate the TRPV4 channel as a source of calcium and a regulator of junctional remodelling. Using immunohistochemistry, calcium imaging, electrophysiology, impedance measurements and permeability assays, they show that the TRPV4 channel plays a major role in this process. It is involved in $\mathrm{Ca}^{2+} /$ cation signalling, cytoskeletal remodelling and barrier function. Human retinal MVE cells (HrMVECs) predominantly expressed Trpv1 and Trpv4 transcripts, and TRPV4 was broadly localised to the plasma membrane of cultured cells and intact blood vessels in the inner retina. Treatment with the selective TRPV4 agonist GSK1016790A (GSK101) activated a nonselective cation current, robustly elevated $\left[\mathrm{Ca}^{2+}\right]$ i and reversibly increased the permeability of MVEC monolayers. These and other findings indicate a major role for TRPV4 in $\mathrm{Ca}^{2+}$ homeostasis and barrier function in human retinal capillaries.

Andelain Erickson, Annemie Deiteren, Andrea M. Harrington, Sonia Garcia-Caraballo, Joel Castro, Ashlee Caldwell, Luke Grundy, Stuart M. Brierley. 596(5), 785-807 (6 February 2018)

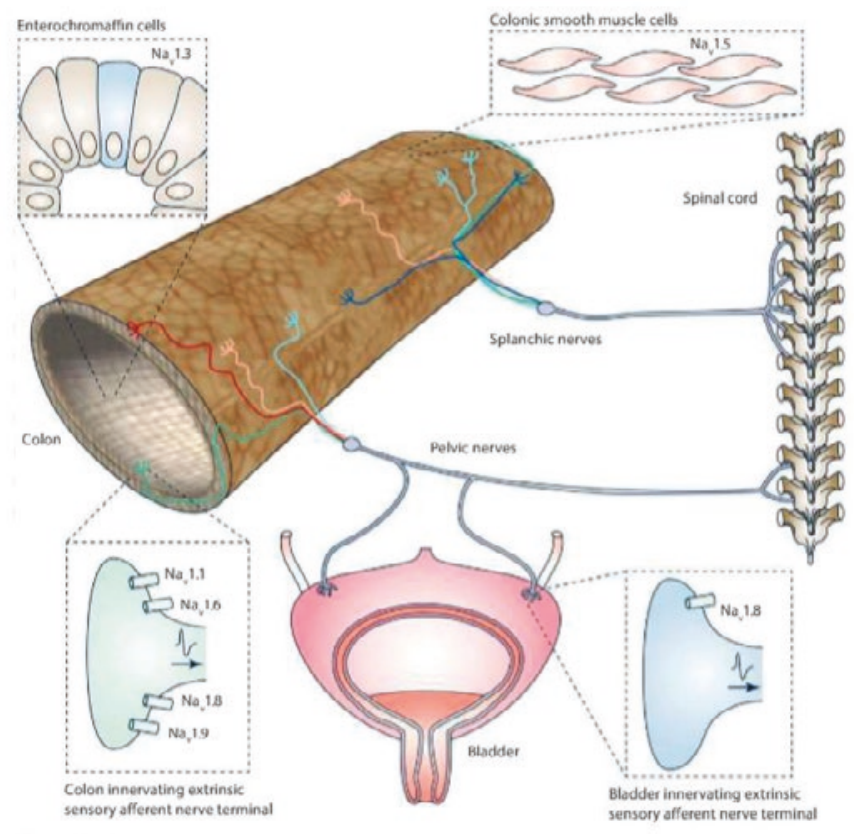

Current understanding of how specific voltage-gated sodium channels $\left(\mathrm{Na}_{\mathrm{v}}\right)$ contribute to the functioning of neurons and non-neuronal cells within visceral organs

Disorders of the gastrointestinal and urinary tracts with pain, motility problems and bladder dysfunction are common. These may be associated with defects in the classic voltage-gated sodium channel. The current evidence about the way the nine sodium channel families appear to contribute is reviewed here. New light is shed on the contribution of voltage-gated sodium channels to the operation of both neuronal and non-neuronal tissues within the gut and bladder.

DOI: $10.1113 / J P 273461$

\section{Calcium influx through TRPV4 channels modulates} the adherens contacts between retinal microvascular endothelial cells

Tam T. T. Phuong, Sarah N. Redmon, Oleg Yarishkin, Jacob M. Winter, Dean Y. Li, David Križaj.

595(22), 6869-6885 (25 October 2017)

In the mammalian retina, microvascular endothelial cells (MVECs) form the inner retinal blood-retina barrier. Here, the researchers

DOI: $10.1113 / J P 275052$

Non-invasive methods for the assessment of brown adipose tissue in humans

Maria Chondronikola, Scott C. Beeman, Richard L. Wahl. 596(3), 363-378 (15 January 2018)

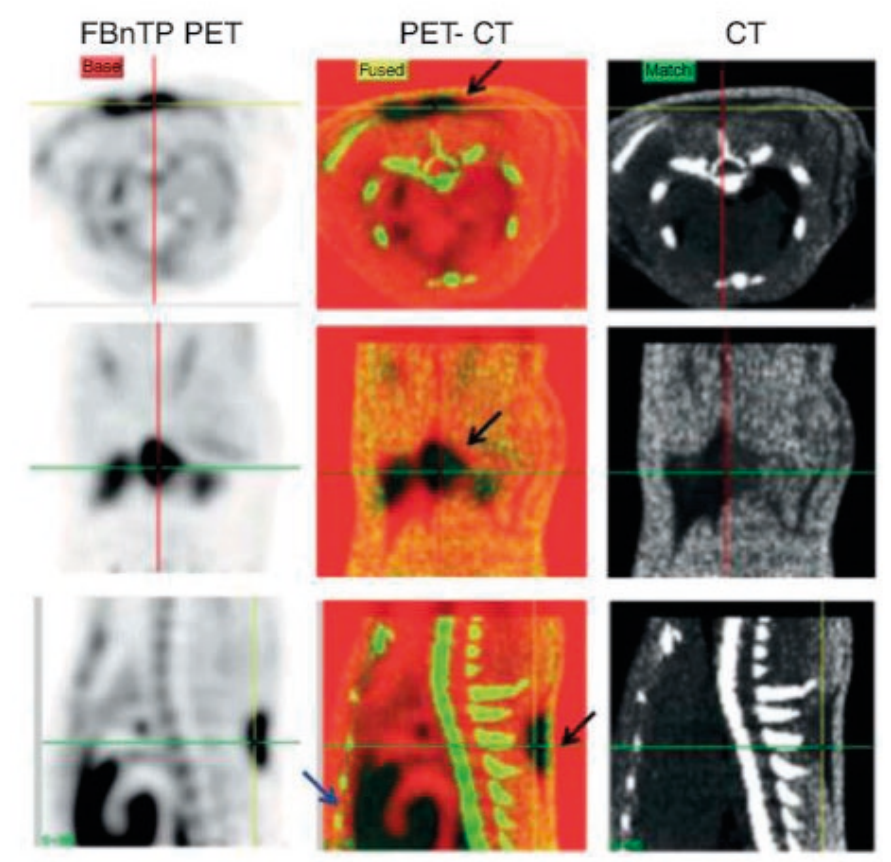

${ }^{18} \mathrm{~F}-$ Fluorobenzyl tryphenyl phosphonium $\left({ }^{18} \mathrm{~F}-\mathrm{FBnTP}\right)$ uptake in interscapular brown adipose tissue at room temperature

Adipose tissue is of two types, white and brown. The latter is full of mitochondria and can generate heat either to raise the body temperature or to lose weight. To allow its importance in metabolic control in humans to be evaluated we need reliable non-invasive assessment of its volume and activity. Positron emission tomography/computed tomography (PET/CT) in combination with 2-deoxy-2-[18 F]fluoroglucose administration is currently the most frequently used and most established method. However, it involves radiation exposure and can detect activated (e.g. after cold exposure), but not quiescent, brown adipose tissue. Several alternative methods that overcome some of these limitations have been developed and are here summarized and critically evaluated.

DOI: $10.1113 / J P 274255$ 


\section{EP Experimental Physiology}

Three-dimensional morphology and volume of the free Achilles tendon at rest and under load in people with unilateral mid-portion Achilles tendinopathy

Leila Nuri, Steven J. Obst, Richard Newsham-West, Rod S. Barrett 103(3), 358-369 (15 January 2018)
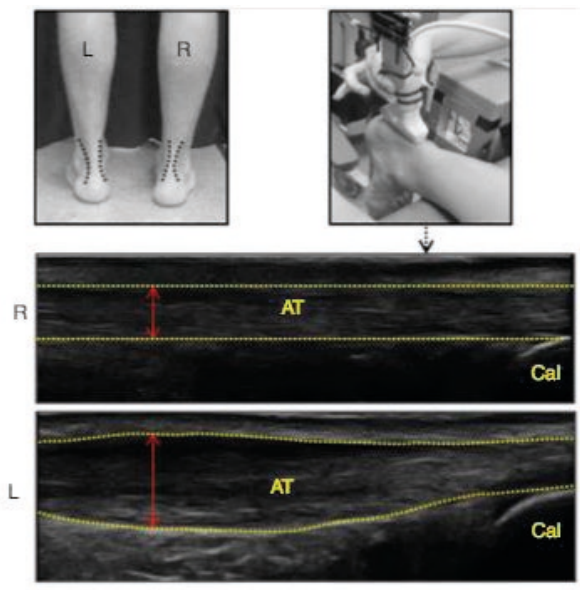

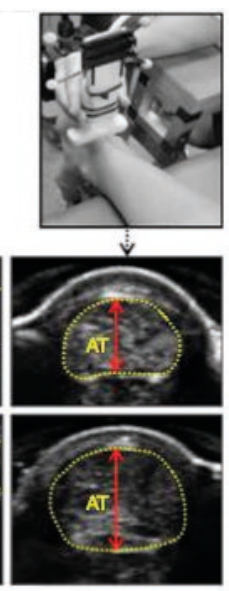

A common injury among runners and recreational athletes is here investigated using 3-D ultrasound to examine the injury's effects on free tendon 3-D morphology (length, cross-sectional area, anteroposterior diameter and mediolateral diameter) and volume at rest and during a submaximal (50\%) voluntary contraction bilaterally in 10 injured and 10 healthy individuals. The injured free tendon has a larger resting tendon cross-sectional area and anteroposterior diameter along the entire tendon length. Overall, the structural changes found suggest a fundamental reorganization of the tendon matrix and alterations in tendon fluid content and distribution under load in injured tendons.

DOI: $10.1113 /$ EP086673

Do male athletes with already high initial haemoglobin mass benefit from 'live high-train low' altitude training?

Anna Hauser, Severin Troesch, Thomas Steiner, Franck Brocherie, Olivier Girard, Jonas J. Saugy, Laurent Schmitt, Grégoire P. Millet, Jon P. Wehrlin. 103(1), 68-76 (5 November 2017)

A total of 58 well-trained endurance or team sport athletes were recruited to study the effects on blood haemoglobin of living at low altitude and training at simulated high altitude (LHTL). The results indicate that trivial (absolute values) to moderate (relative values) relationships occurred between initial haemoglobin levels and the increase observed following altitude training in endurance and teamsport athletes. This indicates that even athletes with higher initial haemoglobin can reasonably expect gains post altitude training. Furthermore, it seems that in the present study the moderate relationship between initial haemoglobin and percentage increase following LHTL could be attributed to changes in body weight and possibly to the statistical phenomenon 'regression to the mean', rather than to a pure physiological effect.

\section{Oxytocin mediates the beneficial effects of the exercise training on breast cancer}

Ali Mohammad Alizadeh, Zahra Heydari, Mostafa Rahimi,

Behzad Bazgir, Hossein Shirvani, Sadaf Alipour, Yassaman Heidarian, Solmaz Khalighfard, Amin Isanejad.

103(2), 222-235 (1 February 2018)

In a mouse model of breast cancer the researchers tested the role of oxytocin and an oxytocin antagonist in the effect of exercise training on tumour growth and tumour-related signalling pathways, including PI3K/AKt and ERK. They found that the volume and weight of tumours were decreased significantly after both exercise training and oxytocin administration. The expression of genes involved in tumour cell proliferation, such as PI3KR2, Akt and mTOR, was notably lower in the exercise-trained and oxytocin-treated groups.

DOI: $10.1113 /$ EP086463

\section{Physiological Reports}

\section{Drosophila tafazzin mutants have impaired exercise capacity}

Deena Damschroder, Christian Reynolds, Robert Wessells. 6(3), (12 February 2018)

Barth syndrome in humans is associated with exercise intolerance and muscle weakness. It appears to be caused by mutations in the TAZ gene which generate faulty Tafazzin, an enzyme needed to synthesise the mitochondrial protein cardiolipin. Drosophila with mutations of the TAZ gene are now shown to exhibit reduced endurance, climbing speed and failure to adapt to a program of chronic exercise. These results support the idea that Drosophila TAZ mutants experience weakened muscle function that is not improved with endurance exercise training, most likely due to impaired mitochondrial function.

DOI: $10.14814 /$ phy2.13604

Nominal carbonic anhydrase activity minimizes airway-surface liquid pH changes during breathing

Ian M. Thornell, Xiaopeng Li, Xiao Xiao Tang, Christian M. Brommel, Philip H. Karp, Michael J. Welsh, Joseph Zabner .

6(2), (January 25, 2018)

Working with cultured airway cells isolated from pig lungs, and measuring surface fluid $\mathrm{pH}$ with the fluorescent indicator SNARFdextran, the authors show that there is little change in $\mathrm{pH}$ during normal ventilation, when air carbon dioxide levels vary between $5 \%$ and close to zero. This seems to be due to the minimal carbonic anhydrase activity in the fluid. This low activity may have evolved to reduce dynamic changes in airway surface $\mathrm{pH}$.

DOI: 10.14814/phy2.13569 
Physiology 2019 The Society's Annual Conference Aberdeen Exhibition and Conference Centre, UK
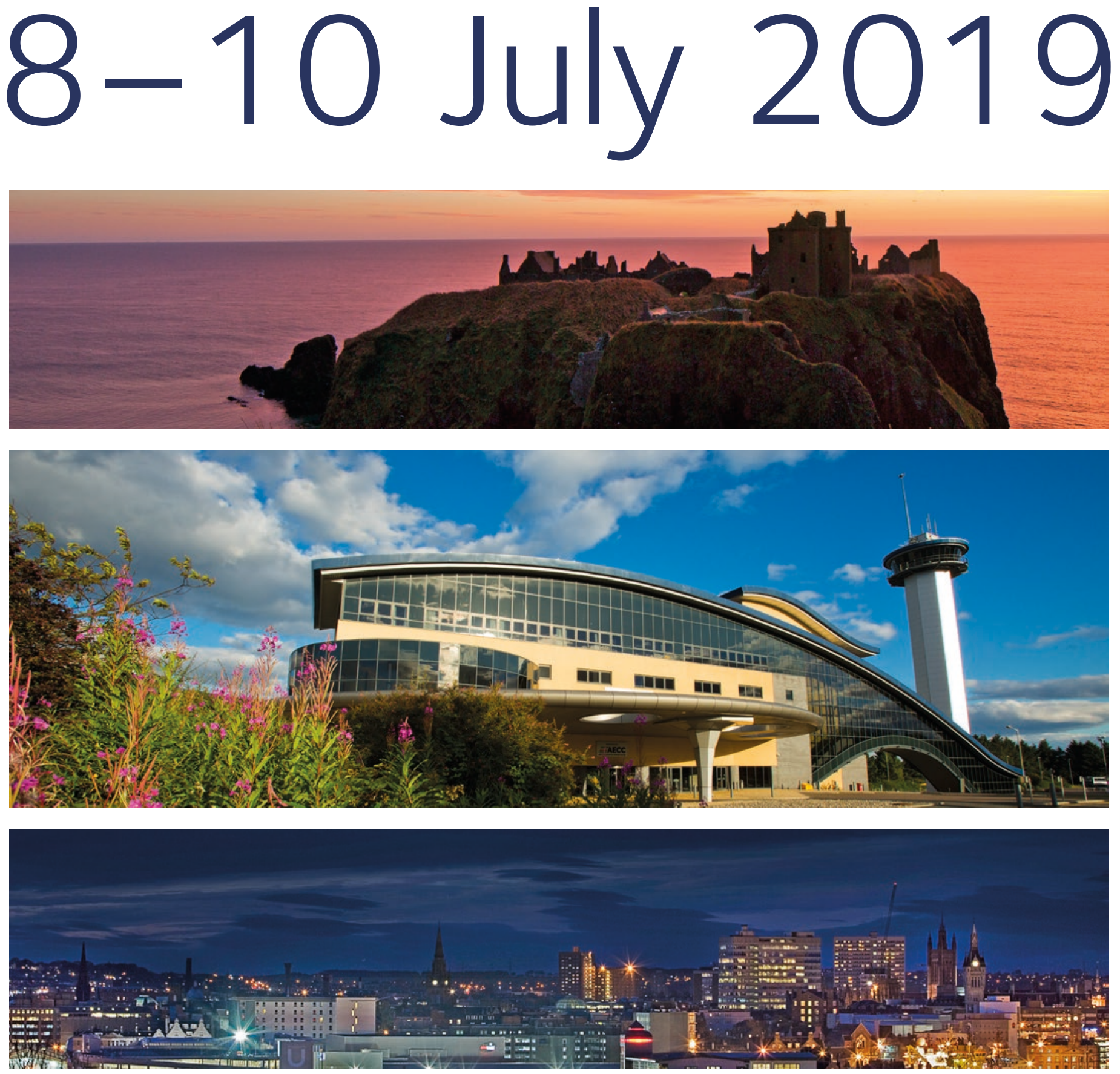

www.physoc.org/physiology2019 $2 \begin{aligned} & \text { The } \\ & \text { Physiological }\end{aligned}$ 